$$
\begin{array}{ll}
\text { Recoivent. IS } & \\
\text { OCT O } 1990 & \text { DE91 } 000611
\end{array}
$$

Electrocatalysis of Anodic and cathodic oxygen-Transfer Reactions

by

Wels, Brian

PHD Thesis submitted to Iowa State University

Ames Laboratory, U.S. DOE

Iowa State University

Ames, Iowa 50011

Date Transmitted: September 21, 1990

PREPARED FOR THE U.S. DEPARTMENT OF ENERGY

UNDER CONTRACT NO. W-7405-Eng-82. 


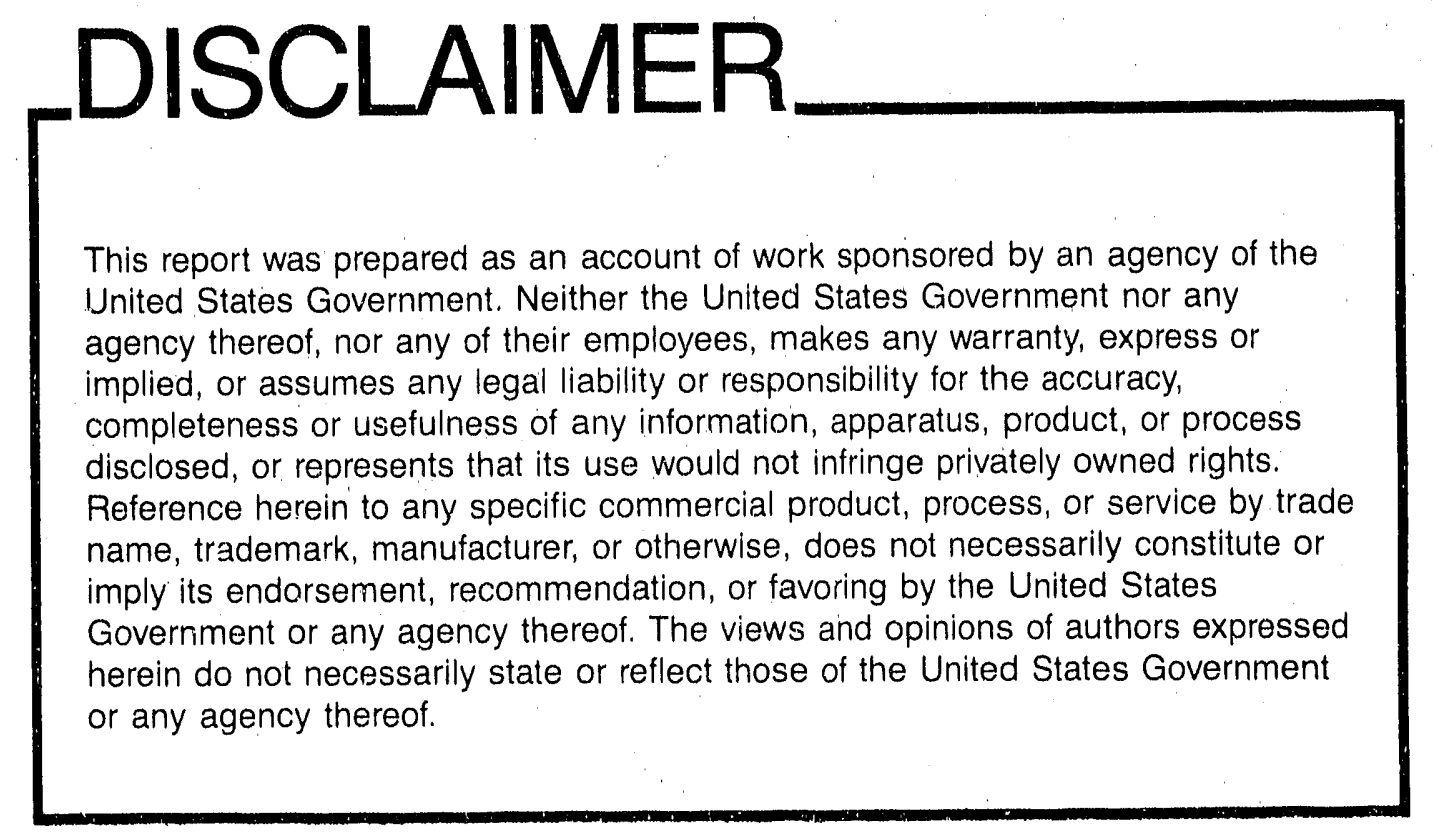




\begin{abstract}
Electrocatalysis of anodic and cathodic oxygen-transfer reactions ${ }^{l}$
\end{abstract}

Brian Reid Wels
Under the supervision of Dennis C. Johnson From the Department of Chemistry Iowa state University

The electrocatalysis of oxygen-transfer reactions is discussed in two parts. In part $I$, the reduction of iodate $\left(\mathrm{IO}_{3}^{-}\right)$is examined as an example of cathodic oxygen transfer. on oxide-covered Pt electrodes (PtO), a large cathodic current is observed in the presence of $\mathrm{IO}_{3}^{-}$to coincide with the reduction of Pto. The total cathodic charge exceeds the amount required for reduction of $\mathrm{PtO}$ and $\mathrm{IO}_{3}^{-}$to produce an adsorbed product. An electrocatalytic link between reduction of $\mathrm{IO}_{3}^{-}$and reduction of Pto is indicated.

In addition, on oxide-free pt electrcdes, the reduction of $\mathrm{IO}_{3}^{-}$is determined to be sensitive to surface treatment. The results are consistent with a mechanism involving the adsorption of $\mathrm{IO}_{3}^{-}$onto $\mathrm{I}^{\circ}$-covered Pt sites (Pt ( Iåds)). previous researchers have relied on chemical steps in the mechanism of $\mathrm{IO}_{3}^{-}$reduction to account for their results.

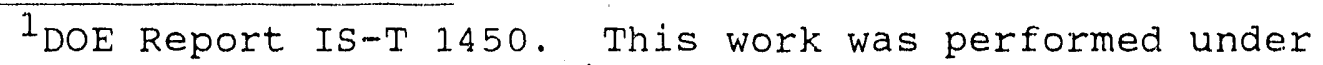
contract No. W-7405-eng-82 with the U.S. Department of Energy. 
The electrocatalytic oxidation of $\mathrm{CN}^{-}$is presented as an example of anodic oxygen transfer in Part II. The electrocatalytic oxidation of $\mathrm{CN}^{-}$is considered to be an important process for the treatment of industrial and laboratory wastes. Present electrode materials are unsuitable for $\mathrm{CN}^{-}$ oxidation for reasons of low current efficiency and high attrition rates. The voltammetric response of $\mathrm{CN}^{-}$is virtually nonexistent at $\mathrm{PbO}_{2}$ electrodes. Whereas the response is not improved by doping $\mathrm{PbO}_{2}$ with $\mathrm{Bi}$, the response is significantly improved by doping $\mathrm{PbO}_{2}$ with $\mathrm{Cu}$. Cyanide is also oxidized effectively at cuo-film electrodes. Copper is concluded to serve as an adsorption site for $\mathrm{CN}^{-}$. It is proposed that an oxygen tunneling mechanism comparable to electron tunneling does not occur at the electrode-solution interface. The adsorption of $\mathrm{CN}^{-}$is therefore considered to be a necessary prerequisite for oxygen transfer. 


\section{Electrocatalysis of anodic and cathodic oxygen-transfer reactions}

\section{by}

Brian Reid Wels

A Dissertation submitted to the Graduate Faculty in Partial Fulfillment of the Requirements for the Degree of DOCTOR OF PHILOSOPHY

Department: Chemistry

Major: Analytical Chemistry

Approved:

In. Charge of Major Work

For the Major Department

For the Graduate college

Iowa State University
Ames, Iowa 
TABLE OF CONTENTS

LIST OF SYMBOLS AND ABBREVIATIONS

Page

INTRODUCTION

vi

1

REFERENCES

5

LITERATURE REVIEW

REFERENCES

PART I. ELECTROCATALYTIC REDUCTION OF IODATE

INTRODUCTION

EXPERIMENTAL

RESULTS AND DISCUSSION

CONCLUSIONS

REFERENCES

PART II. ELECTROCATALYTIC OXIDATION OF CYANIDE

INTRODUCTION

EXPERIMENTAL

RESULTS AND DISCUSSION 70

CONCLUSIONS 95

SUMMARY

100

SUGGESTIONS FOR FUTURE RESEARCH

REFERENCES 103

ACKNOWLEDGMENTS 105 APPENDIX 
Figure I-1. Current-potential curves for $\mathrm{IO}_{3}{ }^{-}$at

a Pt RDE by cyclic voltammetry in

$0.50 \mathrm{M} \mathrm{H}_{2} \mathrm{SO}_{4}$

Figure I-2. Current-potential curves for $0.50 \mathrm{mM}$

$\mathrm{IO}_{3}{ }^{-}$at a Pt RRDE by cyclic voltammetry in $0.50 \mathrm{M} \mathrm{H}_{2} \mathrm{SO}_{4}$

Figure I-3. Current-potential curves for $\mathrm{IO}_{3}^{-}$at a Pt RDE by cyclic voltammetry in $0.50 \mathrm{M}$ $\mathrm{H}_{2} \mathrm{SO}_{4}$

Figure I-4. current vs. $w^{1 / 2}$ data obtained from $i-E$ curves recorded at $6.0 \mathrm{~V} \mathrm{~min}-1$ scan rate

Figure I-5. Effect on $i-E$ curves of changing the cathodic sca: limit ( $\left.E_{-}\right)$for $0.50 \mathrm{mM}$ $\mathrm{IO}_{3}{ }^{-}$at a Pt RDE in $0 . \overline{5} 0 \mathrm{M} \mathrm{H}_{2} \mathrm{SO}_{4}$

Figure I-6. Effect of changing anodic scan limit on current-potential curves for $0.50 \mathrm{mM}$ $\mathrm{IO}_{3}$ at a Pt RDE in $0.50 \mathrm{M} \mathrm{H}_{2} \mathrm{SO}_{4}$

Figure I-7A. Effect of surface treatment on currentpotential curves for $0.50 \mathrm{mM} \mathrm{IO}_{3}$ at a Pt $\mathrm{RDE}$ in $0.50 \mathrm{M} \mathrm{H}_{2} \mathrm{SO}_{4}$. Electrode was polished with $0.50-\mathrm{um}$ alumina prior to treatment with $\mathrm{H}_{2} \mathrm{O}$ and a cotton swab. Arrows indicate scan direction

Figure I-7B. Effect of surface treatment on currentpotential curves for $0.50 \mathrm{mM} \mathrm{IO}_{3}^{-}$at a Pt RDE in $0.50 \mathrm{M} \mathrm{H}_{2} \mathrm{SO}_{4}$. Electrode was polished with $0.50-\mathrm{mm}$ alumina prior to treatment with $\mathrm{H}_{2} \mathrm{O}$ and a Kimwipe. Arrows indicate scan direction

Figure I-7C. Effect of surface treatment on currentpotential curves for $0.50 \mathrm{mM} \mathrm{IO}_{3}$ at a Pt $\mathrm{RDE}$ in $0.50 \mathrm{M} \mathrm{H}_{2} \mathrm{SO}_{4}$. Electrode was polished with $0.50-\mathrm{um}$ alumina prior to treatment with $\mathrm{H}_{2} \mathrm{O}$ and a microcloth

Figure I-7D. Effect of surface treatment on currentpotential curves for $0.50 \mathrm{mM} \mathrm{IO}_{3}^{-}$at a Pt RDE in $0.50 \mathrm{M} \mathrm{H}_{2} \mathrm{SO}_{4}$. Electrode was polished with $0.50-\mathrm{Lm}$ alumina prior to rinsing with $\mathrm{H}_{2} \mathrm{O}$ 
Figure II-1. Current-potential curves for $\mathrm{CN}^{-}$at a $\mathrm{B}-\mathrm{PbO}_{2} \mathrm{RDE}$ in $0.1 \mathrm{M} \mathrm{NaClO}_{4}, 10 \mathrm{mM} \mathrm{NaOH}$

Figure II-2. Current-potential curves for $\mathrm{CN}^{-}$at a $\mathrm{Bi}$-doped ( 30 mole $8 \mathrm{Bi}$ ) $\mathrm{PbO}_{2} \mathrm{RDE}$ in $0.1 \mathrm{M} \mathrm{NaClO}_{4}, 10 \mathrm{mM} \mathrm{NaOH}$

Figure II-3. Current-potential curves for $\mathrm{CN}^{-}$at an a- $-\mathrm{PbO}_{2} \mathrm{RDE}$ in $0.1 \mathrm{M} \mathrm{NaClO}_{4}, 10 \mathrm{mM} \mathrm{NaOH}$

Figure II-4. Current-potential curves for $\mathrm{CN}^{-}$at a Cu-doped $\mathrm{PbO}_{2} \mathrm{RDE}$ in $0.1 \mathrm{M} \mathrm{NaClO}_{4}$, $10 \mathrm{mM} \mathrm{NaOH}$

Figure II-5. X-ray diffraction spectra of Cu-doped $\mathrm{PbO}_{2}$

Figure II-6. Scanning electron micrograph of copper oxide films

Figure II-7. X-ray diffraction spectra of copper oxide films from Figure II- 6 a

Figure II-8. Voltammetric response of $\mathrm{NaCN}$ at a rotated, Cuo-film, disk electrode as a function of concentration in $0.10 \mathrm{M}$ $\mathrm{Na}_{2} \mathrm{SO}_{4}$ with $0.010 \mathrm{M} \mathrm{NaOH}$

Figure II-9. Amperometric response for $\mathrm{NaCN}$ at a rotated, cuo-film, disk electrode as a function of concentration in $0.1 .0 \mathrm{M}$ $\mathrm{Dia}_{2} \mathrm{SO}_{4}$ with $0.010 \mathrm{M} \mathrm{NaOH}$

Figure II-10. Voltammetric response of a rotated, cuo-film, disk electrode as a function of film thickness in $0.10 \mathrm{M} \mathrm{Na}_{2} \mathrm{SO}_{4}$ with $0.010 \mathrm{M} \mathrm{NaOH}$

Figure II-11. Residual voltammeric response of a rotated, cuo-film, disk electrode in $0.10 \mathrm{M} \mathrm{Na}_{2} \mathrm{SO}_{4}$ with $0.010 \mathrm{M} \mathrm{NaOH}$

Figure II-12. Effect of $\mathrm{pH}$ on the voltammetric response for 1.0 $\mathrm{mM} \mathrm{NaCN}$ at a rotated, cuo-film electrode at constant ionic strength

Figure II-13. Koutecky-Levich plot for $1.0 \mathrm{mM} \mathrm{NaCN}$ at a rotated, CuO-film, disk electrode in $0.10 \mathrm{M} \mathrm{Na}_{2} \mathrm{SO}_{4}$ with $0.010 \mathrm{M} \mathrm{NaOH}$ 


\section{$\mathrm{v}$ \\ LIST OF TABLES}

Page

Table I-1. Examples of electrochemical oxygen-

Table II-1. Kinetic data for oxidation of $1.0 \mathrm{mM}$ $\mathrm{NaCN}$ at the rotated, Cuo-film, disk electrode 


\section{LIST OF SYMBOLS AND ABBREVIATIONS}

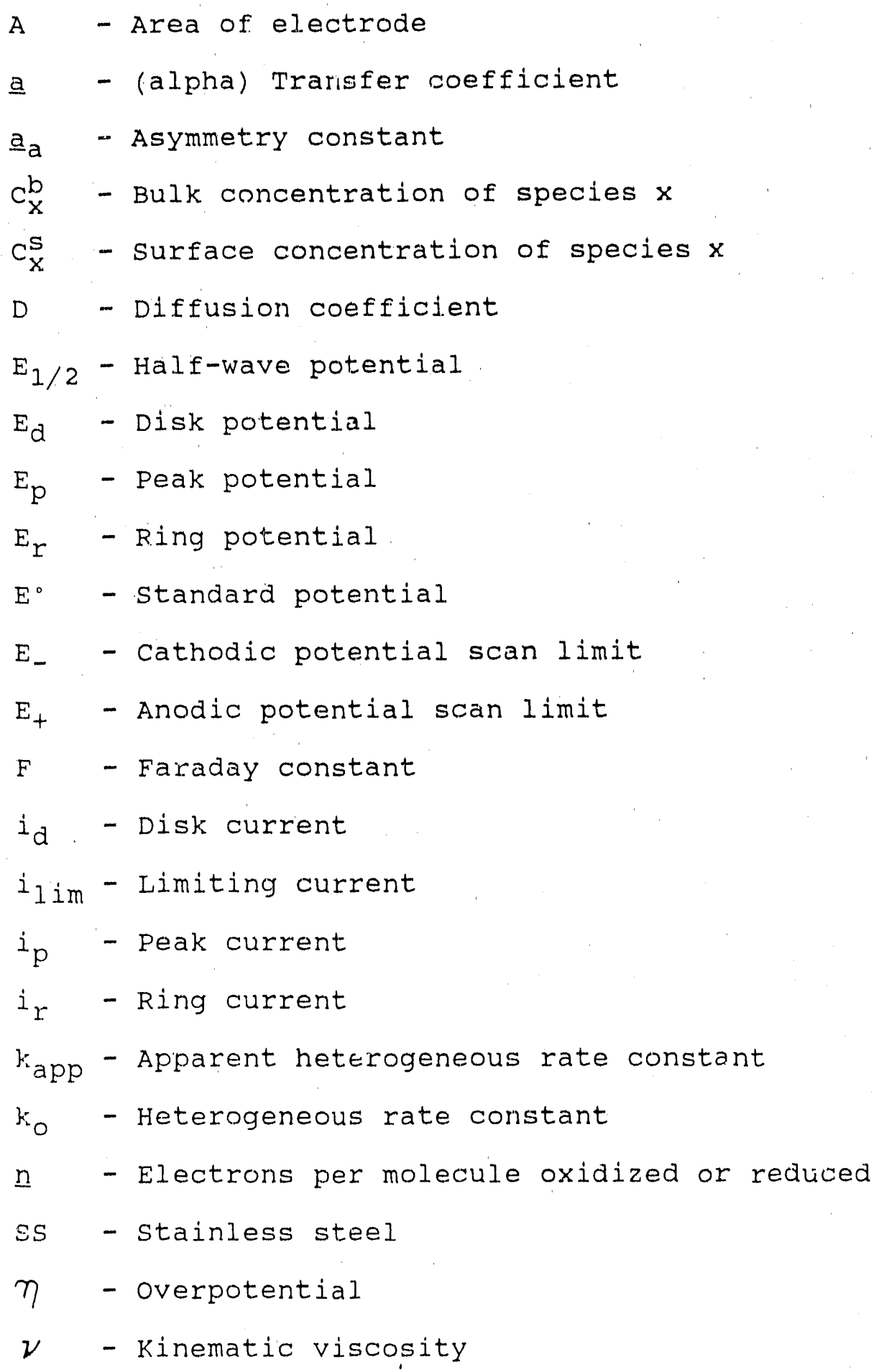


vii

$$
\begin{aligned}
& \sigma^{*} \quad \text { - Antibonding orbital } \\
& \varnothing \quad \text { - Scan rate } \\
& \text { w - Rotational velocity }
\end{aligned}
$$


INTRODUCTION

Many electrochemical reactions occur only at very high overpotentials because of slow heterogeneous kinetics. The rate of electrochemical reactions can be altered by modification of such parameters as electrode material, surface morphology, and chemical composition of the double layer at the electrode/solution interface. The objective of electrocatalysis research is to find reaction pathways of lover activation energy in order to permit such reactions to occur at high current densities near the equilibrium potential. Therefore, the term "electrocatalysis" can apply to the acceleration of the rate of the electrochemical reaction by manipulation of one or all of these parameters. Bard and Faulkner (1) described electrocatalysis using the general example of dissociative adsorption of chemical species to produce reactive fragments. The search for electrocatalytic conditions for a specific reaction is still largely an empirical process. As recently as 1985 , catalyst design was described as a goal for the future (2).

The study of electrocatalysis is of great importance in applied electrochemistry. The energy efficiency of any electrochemical cell is established in part by the overpotentials required at the electrodes. Suitable electrocatalysts for the oxidation of primary fuels (e.g., hydrocarbons, alcohols, and carbon monoxide) and for the 
reduction of oxygen need to be found for the development of economical fuel cells (3). The development of new electrocatalysts has been partly responsible for recent significant advances in organic electrosynthesis (4). The use of electrochemical techniques for the detoxification of hazardous chemical wastes is a promising new area of research in electrocatalysis $(5-7)$.

certain oxidation-reduction reactions can be characterized by a change in the oxygen content of the reacting species ( 8 ). The oxidizing agent loses oxygen, in the process of being reduced, whereas the reducing agent gains oxygen in the process of being oxidized. For these types of reactions occurring in alueous solution, it is possible that the oxygen appearing on the reducing agent is derived from water as in the oxidation of sulfite by nitrite (9).

Electrcchemical oxygen-transfer reactions necessarily occur at electrode surfaces. Examples of electrochemical oxygen-transfer reactions are given in Table I. Anodic oxygen-transfer reactions: can be schematically represented by the generic mechanism given in Equations $1-3$.

$$
\begin{aligned}
& \mathrm{S}[\mathrm{O}]+\mathrm{R} \longrightarrow \mathrm{RO}+\mathrm{S}[] \\
& \mathrm{net}: \longrightarrow \mathrm{S}\left[\mathrm{O}[\mathrm{O}]+2 \mathrm{H}_{2} \mathrm{O} \longrightarrow 2 \mathrm{H}\right. \\
& \mathrm{R}+\mathrm{H}_{2} \mathrm{O} \longrightarrow \mathrm{RO}+2 \mathrm{H}^{+}+2 e
\end{aligned}
$$


Table I-1. Examples of electrochemical oxygen-transfer reactions

\section{Reactant}

Anodic processes:

$\mathrm{H}_{2} \mathrm{O}$

$I^{-}$

$\mathrm{AsO}_{3}^{-}$

(O)

$\mathrm{Me}_{2} \mathrm{SO}$

$\mathrm{Mn}^{+2}$

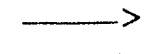

$\longrightarrow$
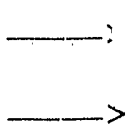

$\longrightarrow$

$\longrightarrow$

Product

Cathodic processes:
$\mathrm{O}_{2}$
$\longrightarrow$
$\mathrm{H}_{2} \mathrm{O}$
$\mathrm{IO}_{3}^{-}$
$\longrightarrow$

$\mathrm{O}_{2}$

$\mathrm{IO}_{3}^{-}$

$\mathrm{AsO}_{4}^{-}$

$0=0$

$\mathrm{Me}_{2} \mathrm{SO}_{2}$

$\mathrm{MnO}_{4}^{-}$ 
In the equations above, $s[0]$ represents labile surface-bound oxygen and $S[$ ] represents a vacant adsorption site. Similarly, cathodic oxygen-transfer reactions can be represented by the reaction sequence shown below.

$$
\begin{aligned}
\mathrm{S}[\mathrm{H}+\mathrm{RO} & \longrightarrow \mathrm{R}+\mathrm{S}[\mathrm{O}] \\
\frac{\mathrm{S}[\mathrm{O}]+2 \mathrm{H}^{+}+2 \mathrm{e}}{\operatorname{net}:} \longrightarrow \mathrm{RO}+2 \mathrm{H}^{+}+2 \mathrm{e} & \longrightarrow \frac{\mathrm{S}[]+\mathrm{H}_{2} \mathrm{O}}{\mathrm{R}+\mathrm{H}_{2} \mathrm{O}}
\end{aligned}
$$

According to these reaction schemes, the electrode surface can act as a catalyst (or electrocatalyst) for the or:'gentransfer reaction. It should be noted that, although these schemes imply the possibility of electrochemical reversibility, that property is rarely observed. The research described in this dissertation has been divided into two parts:

Part I. Electrocatalytic reduction of $\mathrm{IO}_{3}^{-}$ Part II. Electrocatalytic oxidation of $\mathrm{CN}^{-}$ Part I is concerned with the discovery of a cathodic oxygen-transfer pathway analogous to Equations 4-6. Iodate was investigated because of previous reports of catalytic reduction on Pt electrodes. Part II is concerned with the search for a suitable electrode material which will exhibit high current densities for the anodic oxidation of cyanide $\left(\mathrm{CN}^{-}\right)$. 


\section{REFERENCES}

1. Bard, A. J.; Faulkner, L. R. Electrochemical Methods; John Wiley: New York, 1980; p 515.

2. Instrumental Methods in Electrochemistry; Kemp, T. J., Ed.; John Wiley: New York, 1985; Chapter 7.

3. Kordesch, K.; Reindl, M. in Electrochemical Reactors; Ismail, M. I., Ed.; Elsevier: New York, 1989; Chapter 15.

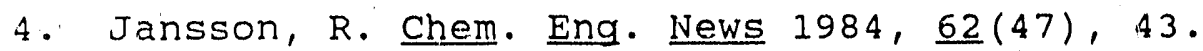

5. Feng, J.; Johnson, D. C. I. Electrochem. Soc. 1990, 137,507 .

6. Wels, B.; Johnson, D. C. I. Electrochem. Soc. 1990, 137,2785 .

7. Kaba, L.; Hitchens, G. D. ; Bockris, J. O'M. J. Electrochern. SOC. 1990, 137, 1341.

8. Halperin, J.; Taube, H. I. Am. Chem. Soc. 1950, 72, 3319.

9. Rutenberg, A. C.; Halperin, J.; Taube, H. I. Am. Chem. SOC. 1951, 73, 4487 . 


\section{Nature of the surface-bound oxygen intermediate}

The postulated mechanism of electrochemical oxygen transfer involves a surface-bound oxygen intermediate (i.e. , $S[0]$ in Equations $1,2,4,5)$. The identity of the oxygen species is speculative. A brief review of the literature is included here to summarize present knowledge surrounding the ldentity of surface oxygen species involved in anodic processes.

one of the most intensely investigated reactions listed in Table I-1 is the oxidation of water to produce dioxygen. The electrolysis of water plays a key role in energy storage systems based on hydrogen (1). The evolution of oxygen is also a side reaction in many anodic processes as well as the counter electrode reaction in such cathodic processes as electroplating, organic synthesis, and metal electrowinning. The activation overpotential of the oxygen evolution reaction at the anode is the primary source of lost energy efficiency in water electrolysis. Under conditions of oxygen evolution, metal surfaces always contain an oxicle film. Therefore, much of the recent work in the electrocatalysis of oxygen evolution has focused on a variety of single and mixed oxides (2-13). The mechanism for oxygen evolution is difficult to determine because of the large number of possible pathways. Differences in 
electrode preparation and variable or unknown intrinsic surface areas make comparisons of results difficult. $\mathrm{RuO}_{2}$ exhibits the highest catalytic activity (i.e., lowest activation barrier) for oxygen evolution in short term tests $(2-7)$. Burke et al. (2) correlated the anodic and cathodic charge passed during cyclic potential scans with true electrode surface areas. The evidence strongly suggested that redox processes occurring at the hydrated oxide surface could account for the observed voltammetric charging. The redox couples $\mathrm{OH}_{a d s} / \mathrm{H}_{2} \mathrm{O}$ and $\mathrm{O}_{\text {ads }} / \mathrm{OH}_{\mathrm{ads}}$ among others were proposed. Decomposition of electrogenerated $\mathrm{RuO}_{3}$ in acid was proposed according to Equation 7. The final step could occur by several paths. Equations 8 a and $8 \mathrm{~b}$ were suggested possibilities. Notice that the process

$$
\begin{aligned}
& \mathrm{RuO}_{3} \longrightarrow \mathrm{RuO}_{2}+\mathrm{O}_{\text {ads }} \\
& 2 \mathrm{O}_{\mathrm{ads}} \longrightarrow \mathrm{O}_{2} \\
& \mathrm{O}_{\mathrm{ads}}+\mathrm{OH}_{\mathrm{ads}} \longrightarrow \mathrm{O}_{2}+\mathrm{H}^{+}+\mathrm{e}
\end{aligned}
$$

in Equation 8 a does not contribute to the faradaic current. Under alkaline conditions, oxygen evolution was proposed to occur via decomposition of an electrogenerated peroxide species according to Equations 9 and 10. This scheme was supported by the conclusion of carrington and symons (14) that coordination of hydroxide to $\mathrm{RuO}_{4}{ }^{-}$was an important factor in the homogeneous decomposition of $\mathrm{RuO}_{4}{ }^{-}$. 


$$
\begin{aligned}
\mathrm{RuO}_{4}^{-}+2 \mathrm{OH}^{-} & \longrightarrow \mathrm{RuO}_{4}(\mathrm{OH})_{2}^{-}+2 \mathrm{e} \\
\mathrm{RuO}_{4}(\mathrm{OH})_{2}^{-} & \longrightarrow \mathrm{RuO}_{4}^{-}+2 \mathrm{H}^{+}+2 \mathrm{e}+\mathrm{O}_{2}
\end{aligned}
$$

Perovskite oxides have received considerable attention as catalysts for oxygen electrode reactions (8-13). The general formula for these oxides is $\mathrm{ABO}_{3}$ where $\mathrm{A}$ is typicaliy a lanthanide and $B$ is a transition metal. Mixed oxides with dissimilar lanthanides or transition metals (i.e., $\mathrm{A}_{1-x} \mathrm{~A}_{x}^{\prime} \mathrm{BO}_{3}$ or $\mathrm{AB}_{1-x} \mathrm{~B}_{x}^{\prime} \mathrm{O}_{3}$ ) can be propared which may affect their catalytic activity. Matsumoto et al. (8-11) investigated the catalytic properties of several perovskite oxides: $\operatorname{SrFeO}_{3}(8), \mathrm{La}_{1-x} \mathrm{Sr}_{x} \mathrm{MnO}_{3}(9), \mathrm{La}_{1-\mathrm{x}} \mathrm{Sr}_{\mathrm{x}} \mathrm{COO}_{3}$ and $\mathrm{La}_{1-x} \mathrm{Sr}_{x} \mathrm{Fe}_{1-y} \mathrm{CO}_{y} \mathrm{O}_{3}$ (11). The general mechanism given by Equations 11-14 was proposed, where $S$ represents the

$$
\begin{aligned}
\mathrm{S}+\mathrm{OH}^{-} & \longrightarrow \mathrm{SOH}+\mathrm{e} \\
\mathrm{SOH}+\mathrm{OH}^{-} & \longrightarrow \mathrm{SO}^{-}+\mathrm{H}_{2} \mathrm{O} \\
\mathrm{SO}^{-} & \longrightarrow \mathrm{SO}+\mathrm{e} \\
2 \mathrm{SO} & \longrightarrow \mathrm{O}_{2}+2 \mathrm{~S}
\end{aligned}
$$

transition metal ion on the electrode surface. The catalytic activity of these oxides was correlated with $\sigma^{*}$ band formation in the oxide. Overlap between an $e_{g}$ orbital of the transition metal with an sp orbital of oxygon is responsible for $\sigma^{*}$ band formation. As $x$ was increased in $\mathrm{La}_{1-\mathrm{x}} \mathrm{Sr}_{\mathrm{x}} \mathrm{MnO}_{3}$ (9), for example, the degree of overlap between $e_{g}$ and $s p$ orbitals in the oxide was concluded to 
increase. Hence, the rate of electron transfer in the primary discharge step (Equation 11) would be enhanced. Increased substitution (i..e., $\mathrm{x}$ in $\mathrm{La}_{1-\mathrm{x}} \mathrm{Sr}_{\mathrm{x}} \mathrm{COO}_{3}$ ) enhanced the rate of Equation 12 by increasing the positive charge density on the transition metal cation (10).

A systematic study of the catalytic activity of perovskite oxides for oxygen evolution was conducted by Bockris and otagawa (13). The proposed mechanism is given by Equations $15-18$ and involves $\mathrm{H}_{2} \mathrm{O}_{2}$ as an intermediate. A reasonably linear correlation was obtained for current

$$
\begin{aligned}
\mathrm{M}^{2}+\mathrm{OH}^{-} & \stackrel{\mathrm{rds}}{\longrightarrow} \mathrm{M}^{2}-\mathrm{OH}+\mathrm{M} \\
\mathrm{M}^{2}-\mathrm{OH}+\mathrm{OH}^{2}-\mathrm{H}_{2} \mathrm{O}_{2}+\mathrm{e} & \stackrel{\mathrm{CH}}{\longrightarrow} \mathrm{M}^{2}--\mathrm{HO}_{2}^{-}+\mathrm{H}_{2} \mathrm{O} \\
\mathrm{M}^{2}--\mathrm{H}_{2} \mathrm{O}_{2}+\mathrm{OH}^{-} & \longleftrightarrow \longrightarrow \mathrm{M}^{2}+\mathrm{H}_{2} \mathrm{O}+\mathrm{OH}^{-}+\mathrm{O}_{2}
\end{aligned}
$$

density vs. $\mathrm{M}-\mathrm{OH}$ bond strengths for $\mathrm{M}$ (III) (OH) 3 hydroxides. The electrocatalytic activity for oxygen evolution was observed to decrease as $\mathrm{M}-\mathrm{OH}$ bond strength increased. Thus, breaking the $\mathrm{M}-\mathrm{OH}$ bond (Equation 16) was concluded to be the rate determining step.

oxygen evolution on Pt has been studied in conjunction with the growth of oxide films (15-18). The production of $\mathrm{OH}$ radicals was postulated as the first step of oxide formation on Pt (19-21). The participation of the oxide film in oxygen evolution has been suggested by Damjanovic and Jovanovic (15). These authors suggested that oxygen 
evolution on Pto involves adsorption of $\mathrm{OH}$ following discharge of water according to Equations 19-21.

$$
\begin{aligned}
\text { PtO }+\mathrm{H}_{2} \mathrm{O} & \longrightarrow \mathrm{Pt}---\mathrm{O}-\mathrm{OH}+\mathrm{H}^{+}+\mathrm{e} \\
\mathrm{Pt}-\mathrm{O}-\mathrm{OH} & \longrightarrow \mathrm{Pt}--\mathrm{O}-\mathrm{O}^{-}+\mathrm{H}^{+} \\
\mathrm{Pt}--\mathrm{O}-\mathrm{O}^{-} & \longrightarrow \mathrm{Pt}+\mathrm{O}_{2}+\mathrm{e}
\end{aligned}
$$

The oxide is reformed via discharge of water on Pt and also involves adsorbed $\mathrm{OH}$ intermediates (Equations 22-23).

$$
\begin{aligned}
\mathrm{Pt}+\mathrm{H}_{2} \mathrm{O} & \longrightarrow \mathrm{Pt}---\mathrm{OH}+\mathrm{H}^{+}+e \\
\mathrm{Pt}--\mathrm{OH} & \longrightarrow \mathrm{PtO}+\mathrm{H}^{+}+e
\end{aligned}
$$

Results of oxygen-18 tracer experiments $(22,23)$ support this mechanism. The presence of adsorbed $\mathrm{OH}$ on Pt has been used to account for the observed electrocatalytic oxidation of $\mathrm{I}^{-}$ $(24,25)$ and $\mathrm{AsO}_{3}^{-3}(26)$.

oxygen evolution on $\mathrm{FbO}_{2}$ electrodes in $\mathrm{H}_{2} \mathrm{SO}_{4}$ has been extensively investigated (27-30). A mechanism proposed by Krasil'shchikov (27) involves decomposition of a higher oxide (28). It has been established, however, that an oxide of lead having stoichiometry higher than that of $\mathrm{PbO}_{2}$ does not exist (29). Therefore, $\mathrm{PbO}_{2}$ is concluded to behave as an inert electrode and mechanisms proposed for oxygen evolution on $\mathrm{PbO}_{2}$ are analogous to those proposed for noble metals (Equations 24-26).

The presence of $\mathrm{OH}_{a d s}$ on $\mathrm{PbO}_{2}$ during oxygen evolution has been confirmed (30). 


$$
\begin{aligned}
\mathrm{H}_{2} \mathrm{O} & \longrightarrow \mathrm{OH}_{\mathrm{ads}}+\mathrm{H}^{+}+\mathrm{e} \\
2 \mathrm{OH}_{\mathrm{ads}} & \longrightarrow \mathrm{O}_{\mathrm{ads}}+\mathrm{H}_{2} \mathrm{O} \\
2 \mathrm{O}_{\mathrm{ads}} & \longrightarrow \mathrm{O}_{2}
\end{aligned}
$$

In atom of oxygen adsorber on an oxide surface $(\mathrm{MO} X)$ is expected to simulate the formation of the higher oxide $\left(\mathrm{MO}_{\mathrm{x}+1}\right)$. The strength of the oxide-oxygen interaction is generaliy regarded as the primary factor governing catalytic activity. Trasatti (31) correlated the enthalpy of ransition $\left(\Delta \mathrm{H}_{t}\right)$ of metal oxides from a lower to a higher oxidation state with electrochemical activity (i.e., overpotential) for oxygen evolution. The overpotential for oxygen evolution changed with $\Delta H_{t}^{0}$ of the oxide according to a volcano-shaped curve. Thus, oxides characterized by strong oxide-oxygen interaction ( $\underline{i} . \underline{e} .$, large $\Delta H_{t}^{0}$ ) were concluded to be poor catalysts; desorption of reaction products was considered to be the rate limiting step. Similarly, oxides characterized by weak oxide-oxygen interaction ( 1 .e., $\operatorname{small} \Delta H_{t}^{o}$ ) were concluded to be poor catalysts; water discharge was considered to be the rate limiting step. Highest activity was associated with oxides characterized by moderate oxide-oxygen interactions.

\section{Reduction of iodate}

Anson (32) attributed the cathodic reduction of $\mathrm{IO}_{3}{ }^{-}$to $I_{2, a q}$ at a pre-oxidized pt surface to an electrocatalytic 
mechanism coupled to the oxide-reduction process. A rapid decreasa in cathodic current for IO.j reduction was observed as the surface oxlde was cathodically removed from the electrode surface. When oxide removal was complete, no current was observed for $\mathrm{IO}_{3}^{-}$until the overpotential was sufficiently large to cause direct reduction of $\mathrm{IO}_{3}{ }^{-}$to $\mathrm{I}^{-}$ at the reduced Pt surface. When the potential of a preoxidized pt electrode was stepped to a constant value in the region of $\mathrm{IO}_{3}{ }^{-}$reduction, the rate of current decay below the transport-limited value increased with increasingly negative potential values. In contrast, no decrease in current with time was observed for reactions such as the reductions of $\mathrm{Fe}(\mathrm{III})$ and $\mathrm{I}_{2}$, aq which do not involve mechanisms coupled to reduction of surface oxlde. Anson (32) also observed that the voltammetric peak for $\mathrm{IO}_{3}{ }^{-}$ reduction shifted to more negative values with increased $\mathrm{pH}$ in the range 1 to 6 in accord with the shift observed for reduction of the oxide film in the absence of $\mathrm{IO}_{3}{ }^{-}$. Based on these observations, Anson concluded that reduction of the oxide layer is essential for tire $\mathrm{IO}_{3}{ }^{-}$reduction at values of overpotential $(\eta)$ below $750 \mathrm{mV}(32)$.

Davis (33) also concluded that $\mathrm{IO}_{3}{ }^{-}$reduction at $\mathrm{Pt}$ electrodes is facilitated by the simultaneous reduction of surface oxide (33). current densities measured at $0.45 \mathrm{~V}$ vS. SCE were observed to increase as the potential for prior. anodic polarization was increased. Furthermore, Davis (33) 
observed an abrupt decrease in the kinetic term na when the electrode had been reduced at $E<0.25 \mathrm{~V}$; a is the transfer coefficient characteristic of the symmetry of the activation barrier. Therefore, Davis (33) concluded that reduction of $\mathrm{IO}_{3}{ }^{-}$orcurs via a different mechanism on a reduced $\mathrm{Pt}$ surface than on a pre-oxidized surface. No mechanisms were proposed, however.

Muller (34) proposed the mechanism given by Equations 27-30 for reduction of $\mathrm{IO}_{3}{ }^{-}$. This mechanism involves

$$
\begin{aligned}
\mathrm{IO}_{3}^{-}+\mathrm{H}^{+} & \longleftrightarrow \mathrm{IO}_{2}, \mathrm{ads}+\mathrm{OH}_{\mathrm{ads}} \\
\mathrm{IO}_{2}, \mathrm{ads}+\mathrm{H}_{2} \mathrm{O} & \longleftrightarrow \mathrm{IO}_{2}^{-}+\mathrm{H}^{+}+\mathrm{OH}_{\mathrm{ads}} \\
2 \mathrm{OH}_{\mathrm{ads}}+2 \mathrm{H}^{+}+2 \mathrm{e} & \longrightarrow 2 \mathrm{H}_{2} \mathrm{O}
\end{aligned}
$$

net: $\mathrm{IO}_{3}^{-}+2 \mathrm{H}^{+}+2 \mathrm{e} \longrightarrow \mathrm{IO}_{2}^{-}+\mathrm{H}_{2} \mathrm{O}$

dissociative adsorption as the initial step (Equation 27) to produce adsorbed hydroxyl radicals $\left(\mathrm{OH}_{\mathrm{ads}}\right)$ that are subsequently, reduced to $\mathrm{H}_{2} \mathrm{O}$ (Equation 29). The adsorbed iodite reacts further with $\mathrm{H}_{2} \mathrm{O}$ to produce $\mathrm{IO}_{2}{ }^{-}$and another $\mathrm{OH}_{\text {ads }}$ (Equation 28) to be reduced to $\mathrm{H}_{2} \mathrm{O}$ (Equation 29). The $\mathrm{IO}_{2}{ }^{-}$produced in Equation 28 disproportionates rapidiy to give $\mathrm{IO}_{3}^{-}$and $\mathrm{I}^{-}$as shown by Equation 31 .

$$
3 \mathrm{IO}_{2}{ }^{-} \longrightarrow 2 \mathrm{IO}_{3}^{-}+\mathrm{I}^{-}
$$

According to this mechanism, faradaic current originates solely from reduction of $\mathrm{OH}_{\text {ads }}$ (Equation 29). Muller 
concluded that the adsorption step (Equation 27) is accelerated on the oxide film.

Desideri (35) discussed two mechanisms for reduction of $\mathrm{IO}_{3}{ }^{-}$at oxide-free Pt electrodes, as described by Equations 32-36. The direct reduct: on of $\mathrm{HIO}_{3}$ to $\mathrm{I}^{-}$(Equation 32) is very slow, according to this mechanism. However, the $I^{-}$ produced diffuses from the Pt surface and reacts rapidly with $\mathrm{IO}_{3}{ }^{-}$in the diffusion layer to give $I_{2}$, aq (Equation 33 ).

$$
\begin{aligned}
\mathrm{HIO}_{3}+5 \mathrm{H}^{+}+6 \mathrm{e} & \longrightarrow \mathrm{I}^{-}+3 \mathrm{H}_{2} \mathrm{O} \\
1 / 5 \mathrm{HIO}_{3}+\mathrm{I}^{-}+\mathrm{H}^{+} & \longrightarrow 3 / 5 \mathrm{I}_{2, \mathrm{aq}}+3 / 5 \mathrm{H}_{2} \mathrm{O}
\end{aligned}
$$

net: $6 / 5 \mathrm{HIO}_{3}+6 \mathrm{H}^{+}+6 \mathrm{e} \longrightarrow 3 / 5 \mathrm{I}_{2}+18 / 5 \mathrm{H}_{2} \mathrm{O}$

The $I_{2}$, aq, in turn, can then be rapidly reduced to $I^{-}$at the electrode (Equation 35) with the net result of 6 equivalents of charge per mole of $\mathrm{IO}_{3}^{-}$(Equation 36).

$$
3 / 5 I_{2}+6 / 5 e \longrightarrow 6 / 5 I^{-}
$$

overall: $\mathrm{HIO}_{3}+5 \mathrm{H}^{+}+6 \mathrm{e} \longrightarrow \mathrm{I}^{-}+3 \mathrm{H}_{2} \mathrm{O}$

This mechanism was supported by observations that $\mathrm{IO}_{3}{ }^{-}$ reduction at oxide-free Pt appeared to be catalyzed by addition of traces of $I_{2}$, aq $(35-39)$.

Beran and Bruckenstein (37) examined the chronoamperometric response for $\mathrm{IO}_{3}{ }^{-}$reduction following a potential step from $0.8 \mathrm{~V}$ to $0.2 \mathrm{~V} \underline{\mathrm{Vs}}$. SCE in the absence and presence of added $I_{2}, a q$. In the absence of $I_{2}$, aq, a steady-state current was not attained until ca. $5 \mathrm{sec}$ 
elapsed following the potential step. The delay was only 2 sec after addition of $10^{-5} \mathrm{M} \mathrm{I}_{2}$, aq and virtually zero for $5 \times 10^{-5} \mathrm{M} \mathrm{I}_{2}, \mathrm{aq}$.

\section{Oxication of cyanide}

Cyanide is a metabolic poison. Its lethality is derived from its inhibition of cytochrome oxidase in the mitochondrial respiratory chain (40). In order to place cyanide in a proper biochemical perspective, it should be noted that cyanide is a microconstituent of our "unpoliuted" environment and a metabolic product of many species (41). Complete books dating back to the early 1900 s have been written about cyanide and cyanide compounds, their manufacture, properties, and determination (42-44). Cyanide is known to form complexes with nearly all of the transition metals. The hydrolysis of $\mathrm{HCN}$ according to Equations 37 and 38 is catalyzed by the presence of mineral acids $(45,46)$. Interestingly, in the case of $\mathrm{HCl}$, the rate increases in the

$$
\begin{array}{r}
\mathrm{HCN}+\mathrm{H}_{2} \mathrm{O} \longrightarrow \mathrm{HCONH}_{2} \\
\mathrm{HCONH}_{2}+\mathrm{H}_{2} \mathrm{O} \longrightarrow \mathrm{HCOONH}_{4}
\end{array}
$$

same order as the activity of molecular $\mathrm{HCl}$. Krieble et al. (47) noted a 600-fold increase in the rate of hydrolysis of $\mathrm{HCN}$ in $75 \%$ acetic acid containing $\mathrm{HCl}$. The chemistry of cyanide as a ligand has been reviewed $(48,49)$. In the early 1900s, catalysts were sought for the 
oxidation of gaseous $\mathrm{HCN}$ to $N O(50,51)$. Initial efforts were directed at Pt (50), but later other oxides and mixtures of oxides were investigated (51). The oxide catalysts were heated $\left(300-900^{\circ} \mathrm{C}\right)$ in a stream of $\mathrm{HCN}$ in air. The effect of temperature on the extent of $\mathrm{HCN}$ oxidation was determined by analyzing the reactor effluent. Cyanic acid (HCNO) was identified as an intermediate product in the oxidation of $\mathrm{HCN}$ to $\mathrm{NO}$ and $\mathrm{CO}$ or $\mathrm{CO}_{2}$. Of the oxides studied, $\mathrm{Fe}_{2} \mathrm{O}_{3}$ mixed with $\mathrm{Bi}_{2} \mathrm{O}_{3}, \mathrm{CO}_{2} \mathrm{O}_{3}, \mathrm{CO}_{2} \mathrm{O}_{3}$ mixed with $\mathrm{Bi}_{2} \mathrm{O}_{3}$, and $\mathrm{MnO}_{2}$ mixed with Cuo were found to be almost as effective as Pt.

Reports of environmental concern over cyanide began to appear in the literature in the 1930 s (52-54). Early methods of treating cyanide wastes included the lagooning of acidified waste (55), reaction with $\mathrm{FeSO}_{4}$ to produce Prussian blue :56), and air scouring of acidified wastes (57). The use of sodium hypochlorite (NaClO) for eliminating cyanide from industrial wastes was first reported in 1941 (58). The process of alkaline chlorination of cyanide-bearing wastes has been described by Dobson (59) . Metals present in waste are usually precipitated as hydroxides under these alkaline conditions. Chlorine demand can be increased substantially by other components of the waste stream (e..g., sulfites, degreasers).

The Kastone process (60) was developed by Du Pont as an alternative to alkaline chlorination. Kastone is a 
proprietary $\mathrm{H}_{2} \mathrm{O}_{2}$ formulation which oxidizes $\mathrm{CN}^{-}$to $\mathrm{CNO}^{-}$and favors the formation of metal oxides over hydroxides making filtration easier.

Carbonaceous mater:als have been demonitrated to catalyze the oxidation of $\mathrm{CN}^{-}$to $\mathrm{CNO}^{-}$by dissolved oxygen $(61,62)$. According to Bernardin (63), the catalytic oxidation of $\mathrm{CN}^{-}$on granular activated carbon is accelerated by the presence of $\mathrm{Cu}^{+2}$. It was possible to impregnate the copper onto the activated carbon or feed it continuously into the flowing stream. The latter approach was observed. to increase hydrolysis of cyanate, as well. Other metals ( $\mathrm{Cd}, \mathrm{Fe}, \mathrm{Zn}, \mathrm{Ni}$ ) were found to be ineffective and, in fact, interfered with the function of $\mathrm{Cu}$ when present in the waste stream. Proper pre-treatment of the waste included removal of oils and tars which would foul the carbon surface. A similar approach was used to treat a CuCN effluent (64). Electrolytic methods $(65-67)$ of treating cyaride wastes have been investigated since the late 1940s. Sperry and Caldwell (65) used electrolysis at elevated temperatures $\left(>120^{\circ} \mathrm{F}\right)$ to treat copper cyanide solutions. While zero total cyanide was achieved after 35 hours in a 700 gallon plant trial, the carbon-steel anodes were rapidly attacked toward the end of the experiment. Dart et al. (66) described a method for electrolytic destruction of solid $\mathrm{NaCN}$ on a laboratory scale. Solid $\mathrm{Na}_{2} \mathrm{CO}_{3}$ was recovered by crystallization from the product mixture. Other products 
included $\mathrm{NH}_{3}, \mathrm{CO}_{2}$, and $\mathrm{H}_{2}$. The anodic reactions were formulated as given by Equations 39-41.

$$
\begin{aligned}
\mathrm{OH}^{-} & \longrightarrow \mathrm{OH}^{-}+\mathrm{e} \\
2 \mathrm{H}^{-} & \longrightarrow \mathrm{H}_{2} \mathrm{O}+\mathrm{O}^{\circ} \\
\mathrm{CN}^{-}+\mathrm{O}^{-} & \longrightarrow \mathrm{CNO}^{-}
\end{aligned}
$$

The advocates of electrolytic treatment generally agree on the advantages of the method:

1. Cyanide is destroyed without formation of other toxic compounds:

2. Metals can be reclaimed easily;

3. No sludge disposal problem is created.

However, according to Easton (67), electrolytic decomposition is not practical for the treatment of dilute cyanide wastes.

The electrochemical oxidation of cyanide has been studied on Pt (68-72), graphite (73), and $\mathrm{PbO}_{2}$ (74). Sawyer and Day (68) determined that only free $\mathrm{CN}^{-}$was oxidized at Pt and they concluded from chronopotentiometric experiments that oxidation occurred via a one-electron step as shown by Equation 42. Tamura et al. (69) proposed instead the

$$
\mathrm{CN}^{-} \longrightarrow \mathrm{CN}^{\cdot}+\mathrm{e}
$$

reaction in Equation 43 based on a reported value of $\underline{n}=2$

$$
\mathrm{CN}^{-}+2 \mathrm{OH}^{-} \longrightarrow \mathrm{CNO}^{-}+\mathrm{H}_{2} \mathrm{O}+2 \mathrm{e}
$$

determined by controlled-potential coulometry. Equation 43 was supported by the work of Kitamura et al. $(70,71)$ who 
determined the presence of $\mathrm{CNO}^{-}$on the Pt surface using Polarization Modulated Infrared Reflection Absorption spectroscopy (PM IRRAS). Cyanogen was not detected as had been propused by Sawyer and Day (68). Oxidation of cyanide in methanol failed to produce cyanate. Further oxidation of $\mathrm{CNO}^{-}$above $0.8 \mathrm{~V}$ vs. Ag/AgCl was indicated by spectroscopic measurements (71).

Hine et al. (74) also proposed Equation 43 as the overall reaction of $\mathrm{CN}^{-}$on $\mathrm{PbO}_{2}$ electrodes. Discharge of $\mathrm{CN}^{-}$by Equation 42 was concluded to be the rate determining step. Cyanogen was determined to be an intermediate product at low $\mathrm{C}_{\mathrm{OH}^{-}}{ }^{-}$. The effect of coexistent metal ions ( $\mathrm{Cu}, \mathrm{Cd}$, $\mathrm{Zn}, \mathrm{Fe}$ ) on the oxidation of cyanide was also determined by Hine et al. (74). Generally, these ions lowered current efficiency as a result of complex formation; however, cuprous ion was observed to promote cyanide oxidation. The Tafel slope for the oxidation of $\mathrm{CN}^{-}$on $\mathrm{PbO}_{2}$ was reported to be 300-350 mV decade ${ }^{-1}$ in the absence of $\mathrm{Cu}^{+}$and $70-110 \mathrm{mV}$ decade ${ }^{-1}$ in the presence of $\mathrm{Cu}^{+}$. Katagiri et al. (72) considered the possibility that copper functioned as a mediator for $\mathrm{CN}^{-}$oxidation according to Equations 44-48.

The anodic oxidation of cyanide on graphite ejectrodes was studied by Arikado et al. (73). The reaction was found to be first order in cyanide concentration and zero order in hydroxide. Controlled-potential coulometry indicated $\underline{\underline{n}}=2$ at high $\mathrm{OH}^{-}$concentration $\left(\mathrm{C}_{\mathrm{OH}^{-}}{ }^{-}\right)$but $\underline{\mathrm{n}}$ approached one at low 


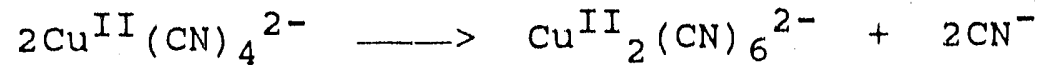

$$
\begin{aligned}
& \mathrm{CN}_{2} \mathrm{II}_{2} 6^{2-} \longrightarrow 2 \mathrm{Cu}^{\mathrm{I}}(\mathrm{CN})_{2}{ }^{-}+(\mathrm{CN})_{2} \\
& 2\left[\mathrm{Cu}^{I}(\mathrm{CIN})_{2}^{-}+2 \mathrm{CN}^{-} \longrightarrow \mathrm{Cu}^{\mathrm{I}}(\mathrm{CN})_{4}^{3-}\right] \\
& 2 \mathrm{Cu}^{I}(\mathrm{CN})_{4}^{3-} \longrightarrow 2 \mathrm{Cu}^{\mathrm{II}}(\mathrm{CN})_{4}^{2-}+2 \mathrm{e}
\end{aligned}
$$

$\mathrm{C}_{\mathrm{OH}^{-}}{ }^{-}$. Whereas $\mathrm{CNO}^{-}$was detected in the product mixture at high and low $\mathrm{C}_{\mathrm{OH}^{-}}$, Arikado et al. (73) concluded that oxidation of $\mathrm{CN}^{-}$proceeded through a $\mathrm{CN}^{\circ}$ intermediate state on graphite.

Reports of cyanide waste treatment in the recent literature include electrolytic oxidation $(75,76)$, biodegradation (77), photooxidation (78), and ozonation (79). In addition to treatment, waste minimization (80) and cyanide recycling techniques (81-85) have been investigated. Recent patent applications for cyanide waste treatment techniques include precipitation $(86,87)$, biodegradation $(88,89)$, hydrolysis $(90-93)$ and a modification of alkaline chlorination (94). An overview of cyanide treatment technology prior to 1975 has been published by Patterson (95). 


\section{REFERENCES}

1. Bockris, J. O'M.; Nagy, Z. Electrnchemistry for Ecologists; Plenum: New York, 1974; Chapter 11.

2. Burke, L. D.; Murphy, O. J.; O'Neil1, J. F.; Venkatesan, S. I. Chem. Soc. Faraday Trans. 1 1977, 73, 1659.

3. Kotz, R.; Lewerenz, H. J.: Bruesch, P.; Stucki, S. I. Electroanal. Chem, 1983, 150, 209.

4. Kotz, R.; Lewerenz, H. J.; Stucki, S. I. Electrochem. SOC. $1983,130,825$.

5. Kotz, R.; Stucki, S.; Scherson, D. ; Kolb, D. M. I. Electroanal. Chem. 1984, 172, 211.

6. Burke, L. D.; McCarthy, M. Electrochim. Acta 1984, 29, 211 .

7. Doblhofer, K.; Metikos, M.; Ogumi, Z.; Gerischer, H. Ber. Bunsenges. Phys. Chem. 1978, 82, 1046.

8. Matsumoto, Y.; Kurimoto, J.; Sato, E. J. Electroanal. Chem. 1979, 102, 77.

9. Matsumoto, Y.; Sato, E. Electrochim. Acta 1979, 24, 421 .

10. Matsumoto, Y.; Manaive, H.; Sato, E. I. Electrochem. Soc. 1980, 127, 811 .

11. Matsumoto, Y.; Yamada, S.; Nishida, T.; Sato, E. I. Electrochem. Soc. 1980, 127, 2360.

12. Kobussen, A. B. C.; Willems, H.; Broers, G. H. J. I. Electroanal. Chem. 1982, 142, 67 .

13. Bockris, J. O'M.; Otagawa, T. J. Electrochem. Soc. $1984,131,290$.

14. Carrington, A.; Symons, M. C. R. I. Chem. SoC. 1960, 284 .

15. Damjanovic, A.; Jovanovic, B. I. Electrochem. Soc. $1976,123,374$. 
16. Birss, V. I.; Damjanovic, A. I. Electrochem. Soc. $1983,130,1688$.

17. Birss, V. I.; Damjanovic, A. I. Electrochem. Soc. $1983,130,1694$.

18. Birss, V. I.; Damfanovic, A.; Hudson, P. G. I. Electrochem. Soc. 1986, 133, 1621 .

19. Angerstein-Kozlowska, H.; Conway, B. E.; Sharp, W. B. A. I. Electroanal. Chem. 1973, 43, 9.

20. Conway, B. E.; Gottesfeld, S. I. Chem. Soc. Faraday Trans. 1 1973, 69, 1090.

21. Tilak, B. V.; Conway, B. E. ; Angerstein-Kozlowska, H. I. Electroanal. Chem. 1973, 48, 1 .

22. Rozenthal, K. I.; Veselovski, V. I. Dokl. Akad. Nauk USSR 1956, 111, 637; Chem. Abstr. 1957, 51, $12699 \mathrm{~b}$.

23. Churchill, C. R.; Hibbert, D. B. I. Chem. Soc. Faraday Trans. 11982, 78, 2937 .

24. Austin, D. S.; Johnson, D. C.; Hines, T. G.; Berti, E. T. Anal. Chem. 1983, 55, 2222.

25. Austin, D. S. Ph.D. Dissertation, Iowa state University, 1984.

26. Cabelka, T. D. i Austin, D. S.; Johnson, D. C. I. Electrochem. Soc. 1984, 131, 1595.

27. Krasil'shchikov, A. J. Zh. Fiz. Khim. 1963, 37, 531; Chem. Abstr. 1963, 59, 1279g.

28. Glasstone, S. I. Chem. SOC. 1922, 121, 2091.

29. Amlie, R. G.; Ockerman, J. B.; Ruetschi, P. J. Electrochem. Soc. 1961, 108, 377.

30. Kokarev, G. A.; Bakhchisaraits'yan, N. G.; Medvedev, G. J. Katal. Reakts. Zhidk. Faze, Tr. Vses. Konf., 2nd, $1966,1967,405 ;$ Chem. Abstr. $1968, \underline{68}, 74586 \mathrm{w}$.

31. Trasatti, S. I. Electroanal. Chem. 1980, 111, 125.

32. Anson, F. C. I. Am. Chem. SoC. 1959, 81, 1554.

33. Davis, D. G. Talanta 1960, 3, 335. 
34. Muller, I. I. Electroana1. Chem. 1968, 16, 67.

35. Destderi, P. G. I. Electroanal. Chem. 1965, 9, 218.

36. Desideri, P. G. I. Electroanal. Chem. 1965, 9, 229.

37. Beran, P.; Bruckenstein, S. Anal. Chem. 1968, 40, 1044 .

38. Beran, P.; Bruckenstein, S. I. Phys. Chem. 1968, 72, 3630 .

39. Vallat, A.; Person, M.; Laviron, E. Electrochim. Acta $1982, \underline{27}, 657$.

40. Solomonson, L. P. In Cyanide in Blology; Vennesland, B.; Conn, E. E.; Knowles, C. I.; Westley, J.; Wissing, F. ; Eds.; Academic Press: New York, 1981; pp. 11-29.

41. Cyanide in Biology; Vennesland, B.; Conn, E. E.; Knowles, C. J.; Westley, J.; Wissing, F., Eds.; Academic Press: New York, 1981; pp. 11-29.

42. Robine, R.; Lenglen, M. The Cyanide Industry; John Wiley: New York, 1906.

43. Migrdichian, V. The Chemistry of organic Cyanogen Compounds; Reinhold Publishing: New York, 1947.

44. Williams, H. E. Cyanogen Compounds; Edward Arnold: London, 1948.

45. Krieble, V. K.; McNally, J. G. I. Am. Chem. Soc. 1929, 51, 3368 .

46. Krieble, V. K.; Peilier, A. L. I. Am. Chem. Soc. 1933, 55, 2326 .

47. Krieble, V. K.; Duennebier, F. C.; Colton, E. I. Am. Chem. Soc. 1943: 65, 1479.

48. Griffith, W. P. Quarterly Rev. 1962, 16, 188.

49. Sharpe, A. G. The Chemistry of Cyano Complexes of the Transition Metals; Academic Press: New York, 1976.

50. Hara, R.; Sinozaki, H. Technology Reports of the Tohoku University 1925, $5,71$.

51. Hara, R.; Sinozaki, H. Technology Reports of the Tohoku University $1926, \underline{6}, 95$. 
52. Schout, C. I. Am. Water Works Assoc. 1939, 31, 771.

53. Harsten, A. Black H111 Eng. 1934, 22, 145.

54. Smith, R. T. Sclence 1938, 87, 552 .

55. Clevenger, G. H.; Morgan, H. Mining Science Press $1916,113,413$.

56. Mo1r, J.; Gray, J. I. Chem. Metal1. Soc. South Africa $1909,10,433$.

57. KJempt, W. U.S, Patent 2008 253, 1935; Chem. Abstr. $1935,29,6000^{2}$.

58. Bezzubets; M. K. ; Vozhdayera, U. N. I. Gen. Chem. Ind. USSR 1941, 18(14), 17; Chem. Abstr. $1944, \underline{38}, 2777^{\frac{1}{2}}$.

59. Dobson, J.G. Metal Finishing 1947, 45(2), 78.

60. "New Process Detoxifies Cyanide Wastes," Environ. Sc1. Technol. 1971, $5,496$.

61. Honda, S.; Kondo, G. Osaka Kogyo Gijutsu Shikensho Koho 196, 18, 367; Chem. Abstr. 1968, 69, 45870z.

62. Buckste 29, W. ; Thiele, H. German Patent 1 140 963, 1969; Chem. Abstr. 1969, 70, 80720t.

63. Bernardin, F. E. I. Water Pol1. Control Fed. 1973, 45, 221 .

64: Zhang, S.; Tian, B.; Li, M.; Li, X. Zhejiang Gongxueyuan xuebao 1989, 44, 27; Chem. Abstr. 1990, 112, $222696 \mathrm{~b}$.

65. Sperry, L. B.; Caldwell, M. R. Plating 1949, 36, 343.

66. Dart, M. C.; Gentles, J. D. ; Renton, D. G. J. Appl. Chem. 1963, 13, 55 .

67. Easton, J. K. J. Water Pol1. Cuntrol Fed. 1967, 39, 1621 .

68. Sawyer, D. T.; Day, R. J. I. Electroanal. Chem. 1963, 5, 195 .

69. Tamura, H.; Arikado, T.; Yoneyama, H.; Matsuda, Y. Electrochim. Acta 1974, 19, 273. 
70. Kitamura, F.; Takahasht, M.; Ito, M. Chem. Phys. Lett. $1986,130,181$.

71. K1tamura, F.; Takahash1, M.; Ito, M. Chem. Phys. Lett. $1987,136,62$.

72. Katagiri, A.; Yoshimura, S.; Deguchi, Y.; Yoshizawa, S. proceedings of the symposium on Electrocatalysis;

O'Grady, W. E.; Ross, P. N.; Wil1, F. G., Eds.; The Electrochemical Society: Pennington, NJ, 1982; pp 336346 .

73. Arikado, T.; I.wakura, C.; Yoneyama, H.; Tamura, H. Electrochim. Acta 1976, 2.1, 1021.

74. Hine, F.; Yasuda, M.; Ilda, T.; Ogata, Y. Electrochim. Acta 1986, 31, 1389 .

75. Wiaux, J. P.; Nguyen, T. Oberflaeche-Surf. 1990, 31, 20 ; Chem. Abstr. 1990, 112, 187736r.

76. Ochmann, R.; Kastening, B. Chem.-Ing.-Tech. 1989, 61, 830 ; Chem. Abstr. 1990, 112, 11430x.

77. Whitlock, J. Journal of occupational Medicine 1989, 41(12), 36; Chem. Abstr. 1990, 112, 222630 a.

78. Yazawa, T.; Nakamichi, H.; Eguchi, K.; Tanaká, H. Japan Patent 63248443,1987 ; Chem. Abstr. 1989, 110, 102632.

79. Veresinina, E. E.; Freis, S.; Silrde, E. Khim. Tekhnol. Vody 1989, 11, 979; Chem. Abstr. 1990, 112, 185189 .

80. Hanlon, D. ; Callahan, M.; Le Thuy Land Disposal, Rem. Action, Incineration Treat. Hazard., Waste; U.S. Environmental Protection Agency, U.S. Government Printing office: Washington, DC, 1988; EPA-600/9$88 / 021$.

81. Semmens, M. J.; Chang, Y. Y. Proc. 43rd Ind. Waste Conf. 1988, 1989, 711 .

82. Semmens, M. J.; Chang, Y. Y. Int. Conf. Physiochemical Biol. Detoxif. Hazard. Wastes 1988, 1989, 212.

83. Slawski, K.; Mrornlinska, Z.; Wedzicha, L.; Waligora, A. Metalloberflaeche 1990, 44, 13; Chem. Abstr. 1990, $112,167859 \mathrm{e}$. 
84. Huang, P.; Zhang, X. Huanan Itgong Daxue Xuebao, Zitran Kewueban 1988, 16, 55; Chem. Abstr. 1990, 112, 185199.

85. Qtan, X.; Ma, X.; Sh1, Y. Water Treatment 1989, 4, 99.

86. Odaka, T.; Toyoshima, T. Japan Patent 01224 091, 1988 ; Chem. Abstr. 1990, 112, 83505y.

87. Schmidt, t. i Bamberg W. East German Patent 270322 , 1983 ; Chem. Abstr. 1990, 112, 81489x.

88. Winkler, M.; Dietel, S.; Patecki, H.; Richter, M.; Kranz, R.; Scheil, H. D. East German Patent 269376 , 1988 ; Chem. Atstr. 1990, 112, 83463h.

89. Kubota, T. Japan Patent 01293 195, 1988 ; Chem. Abstr. $1990,112,164433$ a.

90. Faith, I. E. ; Turner, L. H. i Martin, G. Q. European Patent 349035,1990 ; Chem. Abstr. 1990, 112, $102004 \mathrm{c}$.

91. Yoshikawa, M.; Tonomoto, M.; Higuchi, S. Japan Patent 01115490,1987 ; Chem. Abstr. 1990, 112, 164469s.

92. Yoshikawa: M.; Tonomoto, M.; Higuchi, is. Japan Patent 01123686,1987 ; Chem. Abstr. 1990, 112, 164440a.

93. Yoshlkawa, M.; Tonomoto, M.; Higuchl, S. Japan Patent 01123687,1987 ; Chem. Abstr. 1990, 112, 164441b.

94. Tanno, F.; Edo, N.; Jchikawa, Y. Japan Patent 01215 393,1989 ; Chem. Abstr. 1990, 112, 83484r.

95. Patterson, J. W. Wastewater Treatment Technology; Ann Arbor Science: Ann Arbor, 1975; Chapter 9. 
$27 a$

PART I. ELECTROCATALYTIC REDUCTION OF IODATE 


\section{INTRODUCTION}

The anodic and cathodic behavior of pt surfaces in aqueous media has been studied extensively over a large pH range. The following general conclusions have been drawn: 1) Adsorbed hydroxyl radicals on Pt (PtOH) are formed as the initial product in the anodic generation of surface oxide. 11) The PtoH can readily participate in anodic o-transfer reautions. 111) Place exchange of $\mathrm{OH}$ and $\mathrm{Pt}$ can occur to produce a species depicted as oHPt (1.). Iv) The anodic conversion of $\mathrm{PtOH}$ and OHPt to a more stable oxide (PtO) inhibits anodic o-transfer processes (2). v) The electrochemical evolution of $\mathrm{O}_{2}$ involves generation of adsorbed $\mathrm{OH}$ on the surface oxide (3) and, thereby, can have a catalytic effect on simultaneous anodic o-transfer reactions $(4,5)$.

The electrocatalytic behavior exhibited by noble metal electrodes for anodic transfer of oxygen from $\mathrm{H}_{2} \mathrm{O}$ to oxidation products has been attributed to hydroxyl radicals adsorbed on the electrode (4-13). Examples include the oxidations of $\mathrm{As}(\mathrm{OH})_{3}$ to $\mathrm{OAs}(\mathrm{OH})_{3}(4,6,7)$ and $\mathrm{I}^{-}$to $\mathrm{IO}_{3}{ }^{-}$ $(5,8,9)$ on Pt; $\mathrm{As}(\mathrm{OH})_{3}$ to $\mathrm{OAs}(\mathrm{OH})_{3}(10)$ and $\mathrm{NO}_{2}{ }^{-}$to $\mathrm{NO}_{3}{ }^{-}$ $(11,12)$ on $\mathrm{Au}$; and oxidation of methanol on Ru-doped Pt electrodes (13).

studies of the cathodic behavior of previously anodized pt electrodes indicate that the reduction of the oxides pto 
and oHPt also occurs with PtoH as an intermediate state (14) (Equations 1 and 2 ) followed by rapid reduction of $\mathrm{PtOH}$ to Pt (Equation 3).

$$
\begin{aligned}
& \text { OHPt } \longrightarrow \text { PtOH (slow) } \\
& \mathrm{PtO}+\mathrm{H}^{+}+\mathrm{e} \longrightarrow \mathrm{PtOH} \text { (slow) } \\
& \mathrm{PtOH}+\mathrm{H}^{+}+\mathrm{e} \longrightarrow \mathrm{Pt}+\mathrm{H}_{2} \mathrm{O} \text { (fast) }
\end{aligned}
$$

previous workers have noted that the reductions of $\mathrm{O}_{2}$ (15), $\mathrm{H}_{2} \mathrm{O}_{2}(16)$, and $\mathrm{IO}_{3}^{-}(17-23)$ can occur more readily on preoxidized pt surfaces simultaneously with reduction of the surface oxide.

A discussion of previous research surrounding the cathodic reduction of iodate was presented in the Literature Review section, earlier. Cyclic voltammetry at rotated disk electrodes was applied to a study of the electrocatalytic reduction of $\mathrm{IO}_{3}{ }^{-}$at $\mathrm{Pt}$ electrodes in $0.5 \mathrm{M} \mathrm{H}_{2} \mathrm{SO}_{4}$. Results reported here support prior conclusions that a transient mechanism for electrocatalytic reduction of $\mathrm{IO}_{3}{ }^{-}$is coupled to reduction of oHPt and Pto. However, results for an oxide-free $\mathrm{Pt}$ surface indicate that $\mathrm{IO}_{3}{ }^{-}$reduction requires a more intimate involvement of $\mathrm{IO}_{3}{ }^{-}$with the surface than previously thought. 


\section{EXPERIMENTAL}

\section{Reagents}

All solutions were prepared from reagent grade chemicals. Sulfuric acid was Ultrex grade (J. T. Baker). Water was distilled, demineralized and passed through a Nanopure II purification system (Barnstead). The supporting electrolyte was $0.50 \mathrm{M} \mathrm{H}_{2} \mathrm{SO}_{4}$. Dissolved $\mathrm{O}_{2}$ was removed from all solutions by saturation with dispersed $\mathrm{N}_{2}$. Nitrogen was filtered through active carbon.

\section{Apparatus}

All data were obtained at a Ft, Model AFMD19, rotated disk electrode (RDE, $\left.0.196 \mathrm{~cm}^{2}\right)$ or a Pt-Pt, Model AFMT28 rotated ring-disk electrode (RRDE, disk diameter: 0.180 inch, ring I.D.: 0.194 inch, ring O.D.: 0.212 inch; Pine Instrument co.). Rotation speed was controlled by a Model MSRX rotator (Pine Instrument Co.). Cyclic voltammetry was achieved by a Model AFRDE-4 potentiostat (Pine Instrument Co.) and $\mathrm{i}-\mathrm{E}$ curves were recorded on a Model $7035 \mathrm{~B} \mathrm{X}-\mathrm{Y}$ recorder (Hewlett Packard). All potential values were measured and are reported as volts: (V) Vs. the saturated calomel electrode (SCE).

Data in Figures 1,2 and 6 were obtained by computer control of the potentiostat. A program (see Appendix) written in QuickBASIC (Microsoft Corp.) generated a staircase waveform and $i-E$ data were collected using a 
Standard 286/10 microcomputer equipped with a DT $2801 / 5716$ input-output board and associated software (Data Translation, Inc.).

\section{Procedures}

The electrode surface was polished prior to each use with 0.05-um alumina (Buehler) on microcloth followed by thorough rinsing with deionized water. To ensure removal of all alumina residue, the electrode surface was then wiped with either a cotton swab, a Kimwipe tissue, or microcloth wetted with deionized water. Electrodes were electropolished by cyclic scans of the potential between 1.45 and $-0.25 \mathrm{~V}$ VS. SCE until $\mathrm{i}-\mathrm{E}$ curves were reproducible. The number of scans required to reach reproducible response varied from 20 to 200 scans depending on the type of material used to clean the alumina from the electrode. Unless specified to the contrary, voltammetric data shown correspond to the reproducible $i-E$ curves. 
RESULTS AND DISCUSSION

\section{Cyclic voltammetry}

Current-potential (i-E) curves are shown in Fig. I-1 obtained by cyclic voltammetry at the Pt RDE in $0.50 \mathrm{M} \mathrm{H}_{2} \mathrm{SO}_{4}$ before $(\ldots)$ and after $(-)$ addition of $5.0 \times 10^{-4} \mathrm{M} \mathrm{IO}_{3}{ }^{-}$. In the absence of $\mathrm{IO}_{3}{ }^{-}$, the snall anodic current observed during the positive potential scan in the region $\mathrm{E}_{\mathrm{d}}=0.1$ to $0.55 \mathrm{~V}$ 'resulted from double-layer charging. At $\mathrm{E}_{\mathrm{d}}>0.55 \mathrm{~V}$ on the positive scan, surface oxide was formed: PtoH and OHPt in the region $0.55 \mathrm{~V} \leq \mathrm{E}_{\mathrm{d}} \leq 1.0 \mathrm{~V}$ and Pto at $\mathrm{E}_{\mathrm{d}}>1.0 \mathrm{~V}$ (1). Because appreciable evolution of $\mathrm{O}_{2}$ occurred for $\mathrm{E}_{\mathrm{d}}>$ ca. $1.45 \mathrm{~V}$, the potential scan was reversed at that value. During the subsequent negative scan, reduction of the surface oxide produced the large cathodic peak in the region $0.8 \mathrm{~V} \geq \mathrm{E}_{\mathrm{d}} \geq 0.2 \mathrm{~V}$ with a peak potential $\left(\mathrm{E}_{\mathrm{p}}\right)$ of ca. $0.50 \mathrm{~V}$. The cathodic and anodic formation and dissolution, respectively, of adsorbed atomic hydrogen ( $\mathrm{H}_{\mathrm{ads}}$ ) occurred on the negative and positive scans, respectively, in the region $0.1 \mathrm{~V} \geq \mathrm{E}_{\mathrm{d}} \geq-0.2 \mathrm{~V}$. Cathodic evolution of $\mathrm{H}_{2}$ occurred for $\mathrm{E}_{\mathrm{d}}<-0.25 \mathrm{~V}$ and, therefore, the negative scan was reversed at that potential.

Following addition of $\mathrm{IO}_{3}^{-}$(-), Wave a was observed during the positive scan for $-0.25 \leq \mathrm{E}_{\mathrm{d}} \leq 0.15 \mathrm{~V}$. Wave a corresponded to reduction of $\mathrm{IO}_{3}{ }^{-}$to $\mathrm{I}^{-}$at the oxide-free $\mathrm{Pt}$ surface. A well-defined Wave $\underline{b}$ was also obtained during the 


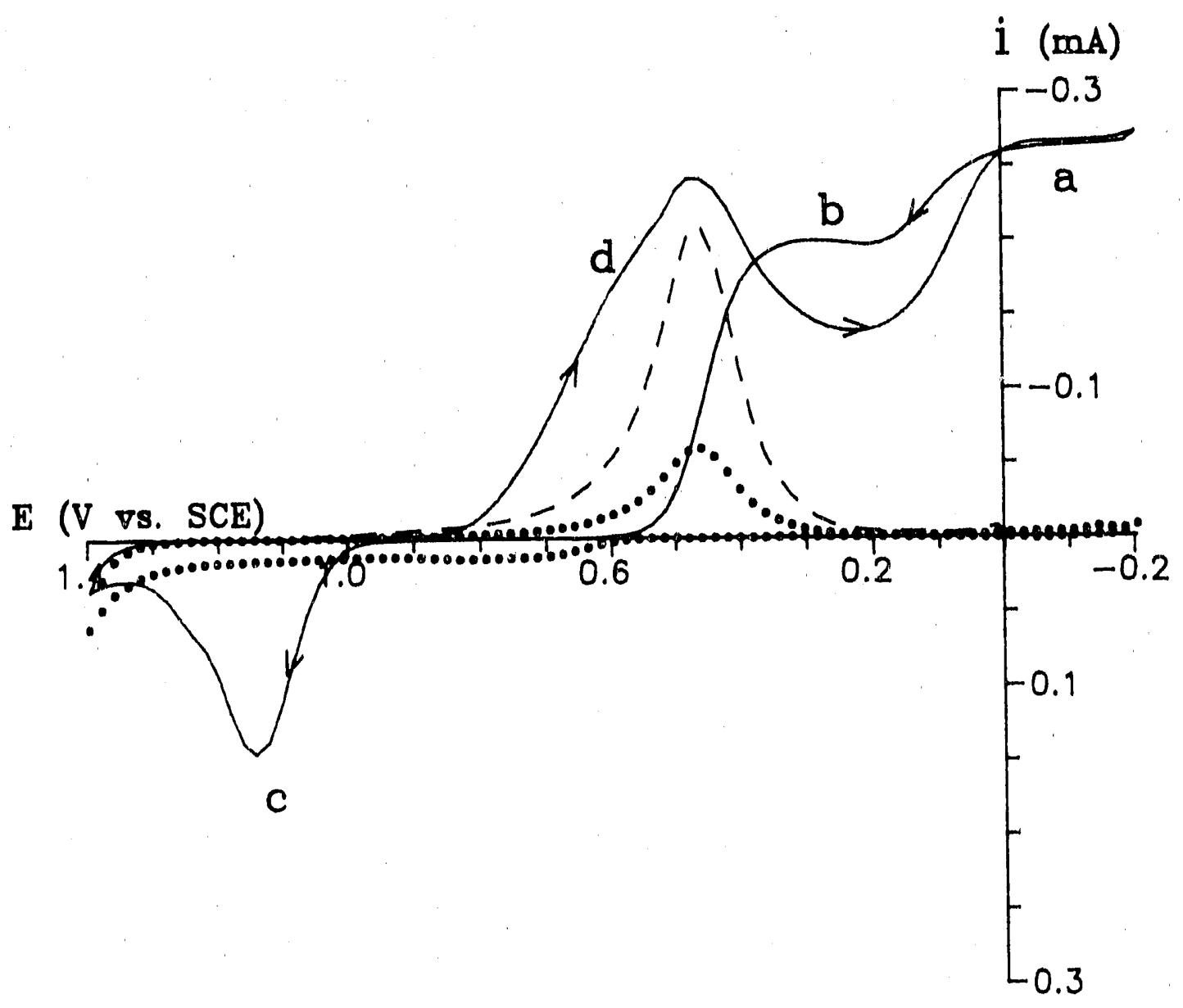

Scan rate $=6.0 \mathrm{~V} \mathrm{~min}-1$

Rotation speed $=1000 \mathrm{rev} \mathrm{min}^{-1}$

$(\ldots) 0.00 \mathrm{mM} \mathrm{IO}_{3}^{-} ;(-) 0.50 \mathrm{mM} \mathrm{IO}_{3}^{-}$;

$(--) 7 / 2$ times sensitivity for $(\ldots)$ Figure I-1. Current-potential curves for $\mathrm{IO}_{3}^{-}$at a Pt RDE
by cyclic voltammetry in $0.50 \mathrm{M} \mathrm{H}_{2} \mathrm{SO}_{4}$ 
positive scan in the region $0.15 \mathrm{~V} \leq \mathrm{E}_{\mathrm{d}} \leq 0.55 \mathrm{~V}$ which was initially concluded to correspond to the reduction of dissolved molecular lodine $\left(I_{2}, a q\right)$ formed in the diffusion layer according to Equation 4. Adsorbed atomic iodine ( Iåds) present on the electrode surface inhibited the

$$
\mathrm{IO}_{3}^{-}+5 \mathrm{I}^{-}+6 \mathrm{H}^{+} \longrightarrow 3 \mathrm{I}_{2}+3 \mathrm{H}_{2} \mathrm{O}
$$

formation of PtoH during the positive scan and, therefore, only charging current was observed for $0.55 \mathrm{~V} \leq \mathrm{E}_{\mathrm{d}} \leq 0.95 \mathrm{~V}$. At $E_{d}>0.95 \mathrm{~V}$, the anodic current increased rapidly (Peak c) reaching a maximum value at $\mathrm{E}_{\mathrm{p}}=\underline{\mathrm{ca}} \cdot 1.15 \mathrm{~V} \cdot$ Peak $\underline{\mathrm{c}}$ resulted from the concurrent anodic processes of oxidative desorption of $\mathrm{I}_{\text {ads' }}$, primarily as $\mathrm{IO}_{3}{ }^{-}$, and the formation of surface oxide (9). For the negitive scan (Fig. I-1), cathodic Peak d in the region $0.8 \mathrm{~V} \geq \mathrm{E}_{\mathrm{d}} \geq 0.4 \mathrm{~V}$, with $\mathrm{E}_{\mathrm{p}}=$ $0.48 \mathrm{~V}$, corresponded to the reduction of $\mathrm{Pt}$ oxide in the residual $i_{d}-E_{d}$ curve $(\ldots)$. However, the area under Peak $\underline{d}$ in the presence of $\mathrm{IO}_{3}{ }^{-}$was considerably greater than that for the absence of $\mathrm{IO}_{3}{ }^{-}$. Hence, $\mathrm{IO}_{3}{ }^{-}$is confirmed to be reduced concurrently with the oxide film. It was speculated initially that reduction of $\mathrm{IO}_{3}{ }^{-}$simultaneously with pto reduction might be promoted by adsorption of a reduction product, e.g., I. However, reduction of $\mathrm{IO}_{3}{ }^{-}$to $\mathrm{I}_{\text {ads }}$ at every Pt site would have produced an area under Peak d $7 / 2$ times larger than the peak for reduction of Pto. The dashed line in Fig. I-I represents that hypothetical $i_{d}-E_{d}$ response which is considerably smaller than the curve 
observed in the presence of $\mathrm{IO}_{3}{ }^{-}$. Hence, the turnover of $\mathrm{IO}_{3}{ }^{-}$at Pto sites was greater than $1.0 \mathrm{~mol} \mathrm{~mol}{ }^{-1}$. Based on the area measured for Peak $\underline{d}$ and assuming a 5-electron process, it was estimated that ca. three $\mathrm{IO}_{3}{ }^{-}$ions were reduced per Pt site. Anson has reported the reduction of as much as 1000 equivalents of $\mathrm{IO}_{3}{ }^{-}$per equivalent of Pto (17). Considerable hysteresis was observed in the region of Wave $\underline{b}$ for $\mathrm{IO}_{3}^{-}$(-) on the positive and negative scans (see Fig. I-1). This seemed inconsistent with prior conclusions that the cathodic signal in this region originated from reduction of $\mathrm{I}_{2}$, aq generated by the reaction of $\mathrm{IO}_{3}{ }^{-}$and $\mathrm{I}^{-}$within the diffusion layer. Such a mechanism would not be expected to depend on scan direction for the low scan rates applied in this study. Therefore, further mechanistic study was considered necessary.

\section{Rotated ring-disk studies}

Collection experiments were performed at a Pt-Pt rotated ring-disk electrode (RRDE) to obtain information about the product $(s)$ of the disk reaction in the region 0.5 $\mathrm{V} \geq \mathrm{E}_{\mathrm{d}} \geq 0.1 \mathrm{~V}$. The ring current response was recorded as a function of disk potential for two values of $E_{r}$. The resulting $i_{r}-E_{d}$ curves are shown in Fig. $I-2 A$. For $E_{r}=0.3$ $V$, very little cathodic response was obtained for $\mathrm{IO}_{3}{ }^{-}$. This is suspected to be a consequence of the combination of slow electrode kinetics for the rc ation and the higher flux 

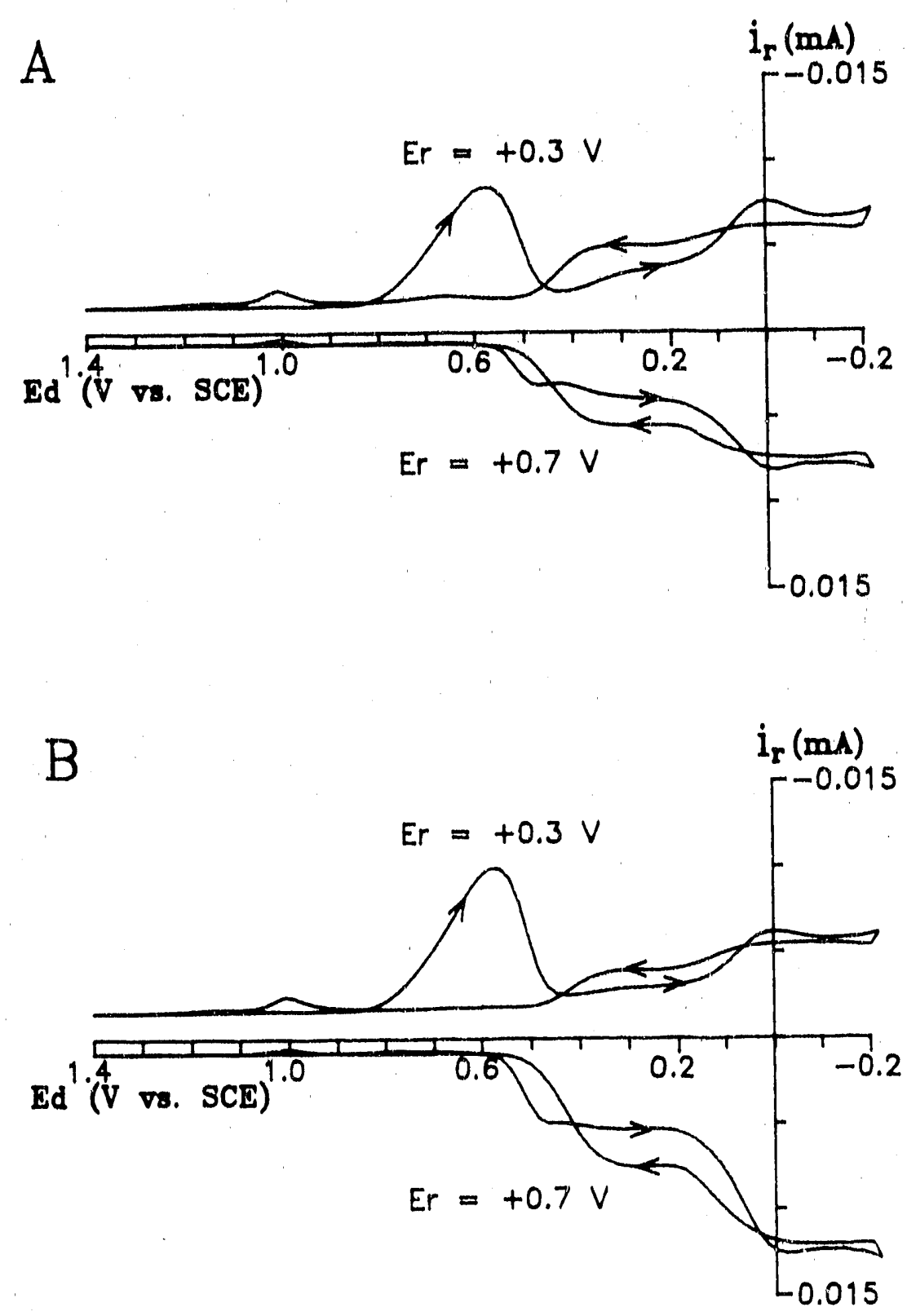

scan rate $=6.0 \mathrm{Vmin}^{-1}$

Figure I-2. Current-potential curves for $0.50 \mathrm{mM} \mathrm{IO}_{3}{ }^{-}$at a Pt RRDE by cyclic voltammetry in $0.50 \mathrm{M} \mathrm{H}_{2} \mathrm{SO}_{4}$

A) Ring response, $1000 \mathrm{rev} \mathrm{min}^{-1}$;

B) Ring response, 2000 rev $\mathrm{min}^{-1}$ 
density at the ring electrode. Conversely, reduction of $I_{2}$ aq to $I^{-}$proceeded readily at the ring electrode $\left(E_{r}=\right.$ $0.3 \mathrm{~V})$ and, therefore, the $i_{r}-F_{d}$ curve in Fig. I-2A gave direct evidence for $I_{2}$, aq production at the disk electrode corresponding to Waves $\underline{a}, \underline{b}$ and $\underline{d}$ (compare Figs. I- 1 and I2A). It is especially noteworthy that $I_{2}$, aq was produced at the disk electrode during the negative $\mathrm{E}_{\mathrm{d}}$ scan in the region of Wave $\underline{d}$, as predicted in Equation 5 .

$$
\mathrm{IO}_{3}^{-}+6 \mathrm{H}^{+}+5 \mathrm{e}^{-} \rightarrow 1 / 2 \mathrm{I}_{2}+3 \mathrm{H}_{2} \mathrm{O}\left(\mathrm{E}^{\circ}=1.195 \mathrm{~V}\right)
$$

The peak shape for detection of $\mathrm{I}_{2}$, aq at the ring electrode simultaneously with feak $\underline{\text { d }}$ at the disk was virtually symmetric with the cathodic peak for Pto reduction at the disk shown in Fig. I-1 (..). This is consistent with the conclusion that $\mathrm{IO}_{3}^{-}$is reduced to $\mathrm{I}_{2}$, aq by a mechanism coupled to the reduction of Pto (Equation 5).

Very little $I_{2}$, aq was detected at the ring electrode during the negative scan in the region $0.35 \mathrm{~V} \geq \mathrm{E}_{\mathrm{d}} \geq 0.25 \mathrm{~V}$ when the disk surface was virtually free of oxide. Because $I_{2, a q}$ is reduced to $I^{-}$for $E<0.55 \mathrm{~V}$, the cathodic ring current obtained at $\mathrm{E}_{\mathrm{r}}=0.3 \mathrm{~V}$ for $\mathrm{E}_{\mathrm{d}}<0.55 \mathrm{~V}$ resulted from detection of only that portion of $I_{2}$, aq produced by reaction of $\mathrm{IO}_{3}^{-}$and $\mathrm{I}^{-}$in the diffusion-layer region of the RRDE (Eqn. 4) which escaped reduction at the disk electrode. As discussed previously, some of that $I_{2}$, aq returned to the disk electrode for reduction to $\mathrm{I}^{-}$. 
Iodide ( $\left.{ }^{-}\right)$was detected anodically at the ring electrode for $\mathrm{E}_{\mathrm{r}}=0.7 \mathrm{~V}$ (Fig. $\left.\mathrm{I}-2 \mathrm{~A}\right)$. Hence, the peak in the $i_{r}-E_{d}$ curve observed during the negative scan of $E_{d}\left(E_{p}\right.$ $=0.48 \mathrm{~V})$ corresponded to the cathodic maximum observed for Wave d at the disk electrode (see Fig. I-1). This peak is attributed to direct reduction of $\mathrm{IO}_{3}{ }^{-}$to $\mathrm{I}^{-}$by a process catalyzed by pto reduction. In the region $0.55<\mathrm{E}_{\mathrm{d}}<-0.2$ $\mathrm{V}$, the anodic waves for $\mathrm{I}^{-}$detection $\left(\mathrm{E}_{\mathrm{r}}=0.7 \mathrm{~V}\right)$ were approximately symmetric to the cathodic waves for $I_{2}$ detection $\left(E_{r}=0.3 \mathrm{~V}\right)$. A small anodic signal appeared in the region $1.4 \mathrm{~V}>\mathrm{E}_{\mathrm{C}}>0.6 \mathrm{~V}$. However, no process occurs in that region and the signal is the result of an offset produced by the computer-controlied data acquisition device. It was expected that increases of rotation speed (w) for the RRDE would result in an increased ratio of $\mathrm{I}^{-} / \mathrm{I}_{2}$ detected at the ring in the region $0.5 \mathrm{~V} \geq \mathrm{E}_{\mathrm{d}} \geq 0.1 \mathrm{~V}$. This was verified by comparison of the $i_{r}-E_{d}$ response obtained at $2000 \mathrm{rev} \mathrm{min}^{-1}$ (Fig. I-2B) with data for $1000 \mathrm{rev} \mathrm{min}^{-1}$ (Fig. I-2A). The anodic value of $i_{r}$ at $E_{r}=0.7 \mathrm{~V}$ increased and the cathodic value of $i_{r}$ at $E_{r}=0.3 \mathrm{~V}$ was decreased, as predicted.

A peak in the $i_{r}-E_{d}$ response for $E_{r}=0.3 \mathrm{~V}$ was observed during the negative $\operatorname{scan}$ at $\mathrm{E}_{\mathrm{d}}=\mathrm{ca} .0 .0 \mathrm{~V}$ in the region of wave a in the $i_{d}-E_{d}$ response (Fig. I-2A-B). This is speculated to correspond to $\mathrm{I}_{2}$ generated by reaction of $\mathrm{IO}_{3}{ }^{-}$ with $\mathrm{I}^{-}$from cathodic desorption of $I_{\text {ads }}$ at the disk 
electrode by the formation of some $\mathrm{H}_{\text {ads }}$ or $\mathrm{H}_{2}$, ads as $\mathrm{E}_{\mathrm{d}}$ appreached the potential for onset of rapld $\mathrm{H}_{2}$ evolution at the Pt disk (9).

A cathodic ring current peak was observed at $\mathrm{E}_{\mathrm{d}}=1.0 \mathrm{~V}$ for both $E_{r}=0.3 \mathrm{~V}$ and $E_{r}=0.7 \mathrm{~V}$. It was speculated that this current maximum resulted from reduction of intermediate products formed at the onset of the oxidative desorption of Iads at the disk (e.g., IO $\mathrm{I}^{-}$and $\mathrm{IO}_{2}^{-}$). That anodic desorption process yields predominantly $\mathrm{IO}_{3}{ }^{-}$.

\section{Variation of scan rate}

Varlation of potential scan rate $(\varnothing)$ in voltammetric studies can be useful for discriminating between surfacecontrolled and transport-controlled faradalc processes. Current-potential curves recorded at the RDE as a function of $\varnothing$ are shown in Fig. I-3. The height of Peak $\subseteq$ observed during the positive scan, caused by simultaneous oxidations of $I_{a d s}$ and the Pt surface, varied nearly as a linear function of $\phi$, which is expected for surface-controlled reactions. The height of peak $\underline{d}$ on the negative scan varied in a nonlinear manner with $\varnothing$. This is indicative of mixed control by surface- and transport-controlled processes. The plateau current for $0.0 \mathrm{~V}>\mathrm{E}_{\mathrm{d}}-0.2 \mathrm{~V}$ (Wave a) was virtually independent of scan rate, which is representative of a purely transport-controlled process. For $0.4 \mathrm{~V}>\mathrm{E}_{\mathrm{d}}>0.1$ $v, \underline{i} . \underline{e}$. , the region of Wave $\underline{b}$, the variation of current with 


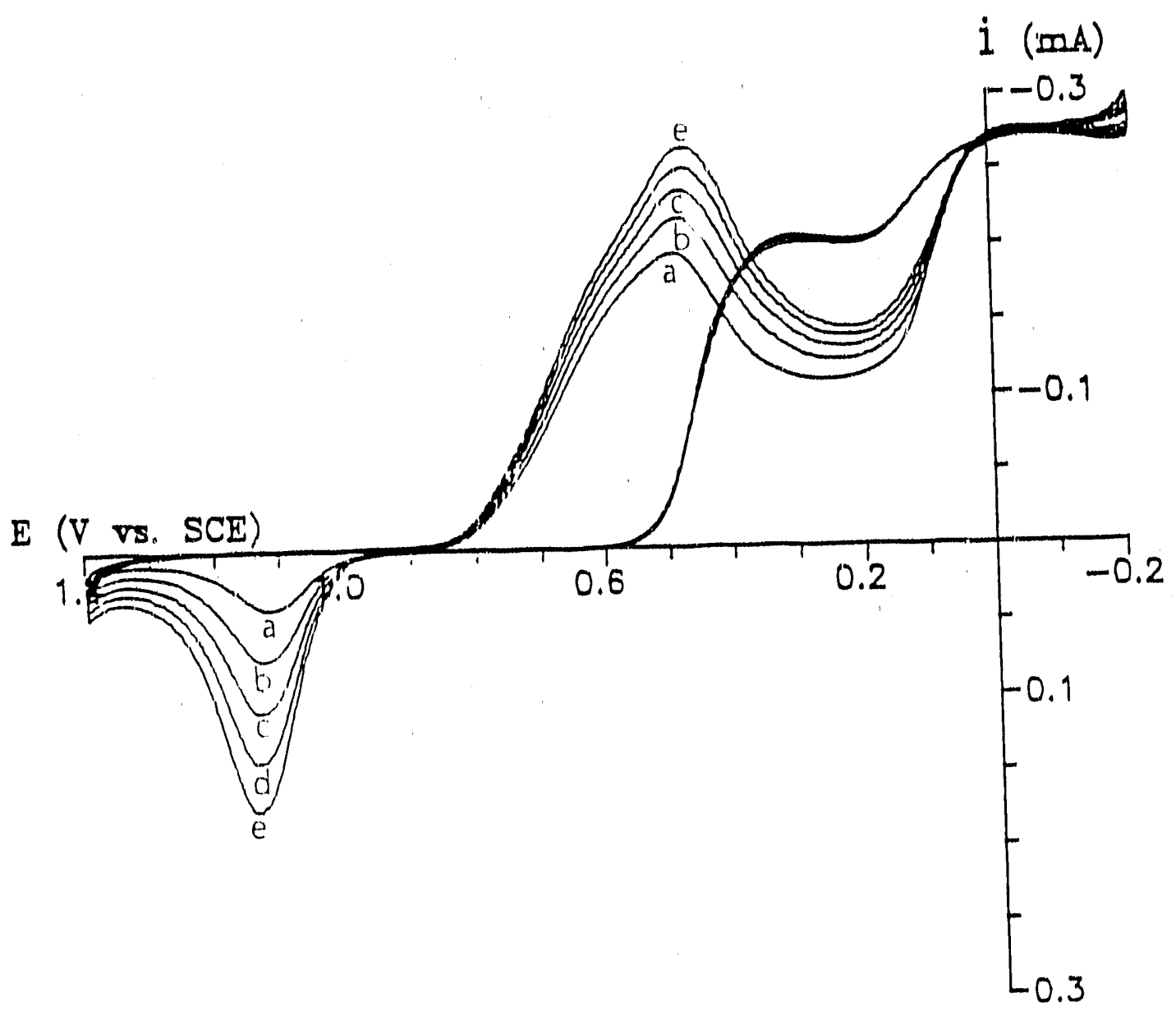

Rovation speed $=1000$ rev $\mathrm{min}^{-1}$
Scan rate $\left(\mathrm{V} \mathrm{min}^{-1}\right): \begin{aligned} & \text { a) } 1.0, \text { b) } 2.0, \text { c) } 3.0, \\ & \text { d) } 4.0, \text { e) } 5.0\end{aligned}$

Figure $\mathrm{I}-3$. Current-potential curves for $\mathrm{IO}_{3}^{-}$at a $\mathrm{Pt} \mathrm{RDE}$ 
changing $\varnothing$ was more promounced for the negative scan than the positive scan. This is indicative of a greater Influence by the surface-controlled component of total current during the negative scan.

\section{Variation of rotation speed}

Voltammetric results were recorded at the RDE as a functiur of rotation speed ( $w$ for a constant $\varnothing$ and the results are suiumarized in $F 1 g$. I-4. The value of $1_{d}$ at $E_{d}=$ $-0.05 \mathrm{~V}$ on the positive scan (Wave a) Increased as a Iinear function of $w^{1 / 2}(r=0.9997)$, which is inalcative of a transport-controlled reaction at the RDE. The slope of the $1-w^{1 / 2}$ plat for Wave as (Fig. 4) corresponded to a 4-electron process, as estimated from the Levich equation (25) using $D$ $=1.09 \times 10^{-5} \mathrm{~cm}^{2} \mathrm{~s}^{-1}$ for $\mathrm{IO}_{3}^{-}(26)$. This is lower than expected for the 6 -electron reduction of $\mathrm{IO}_{3}{ }^{-}$to $\mathrm{I}^{-}$ (Equation 6) and might have resulted, at least in part,

$$
\mathrm{IO}_{3}^{-}+6 \mathrm{H}^{+}+6 \mathrm{e} \longrightarrow \mathrm{I}^{-}+3 \mathrm{H}_{2} \mathrm{O}
$$

because some $I_{2}$ produced by the coupled homogeneous reaction of $\mathrm{IO}_{3}^{-}$from the bulk solution with $\mathrm{I}^{-}$coming from the disk (Egn. 4) can be lost from the diffusion layer without undergoing reduction to $\mathrm{I}^{-}$. The pseudo-limiting value of $i_{\mathrm{d}}$ in wave $\underline{b}$ reached a maximum at ca. $3000 \mathrm{rev} \mathrm{min}^{-1}$ and then decreased at higher rotation speeds. The distinct negative slope for wave $\underline{b}$ at high rotation speeds is considered 


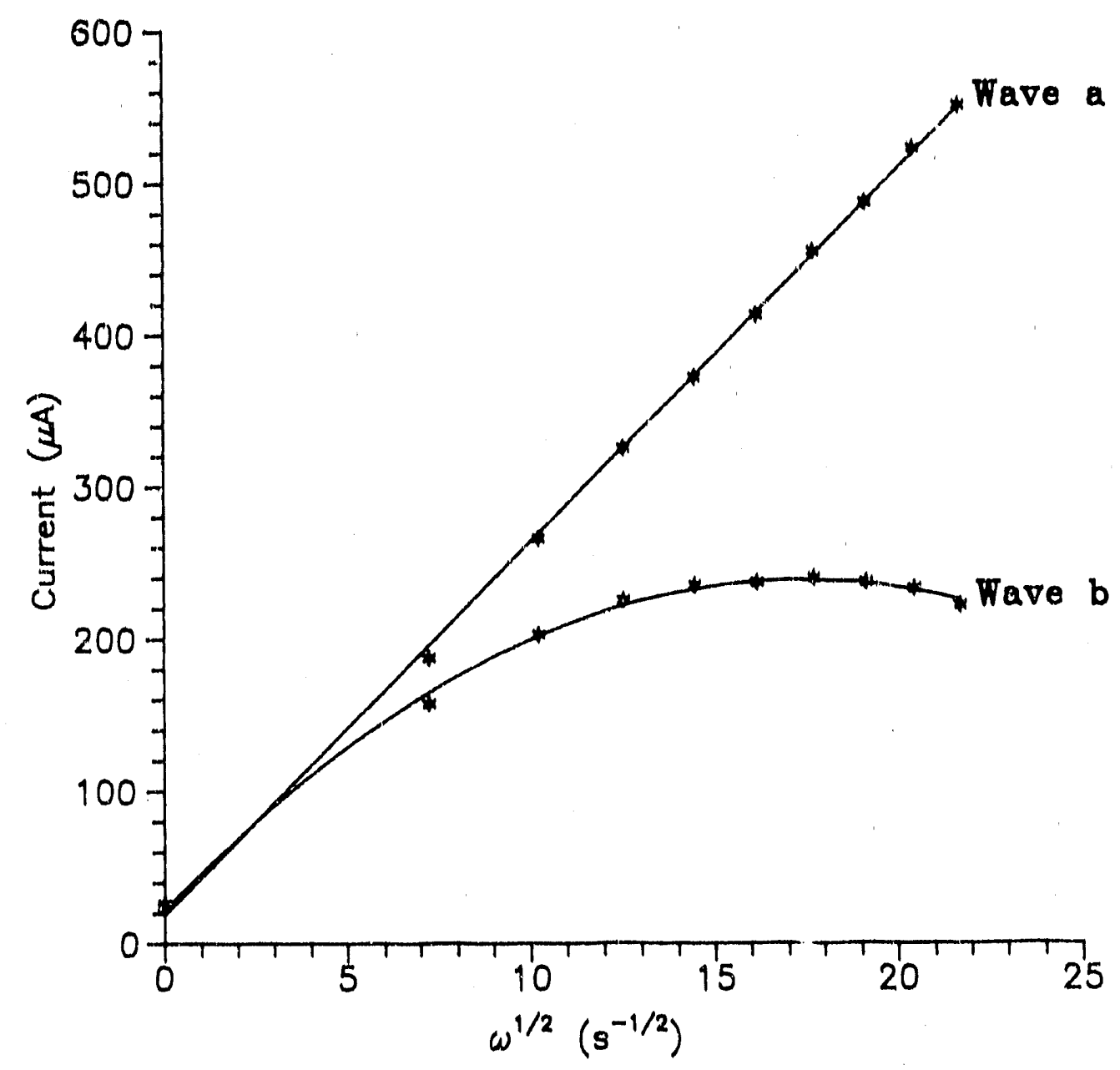

$\mathrm{E}_{\mathrm{d}}$ (Vs. SCE): Wave a) $-0.05 \mathrm{~V}$, Wave b) $0.25 \mathrm{~V}$

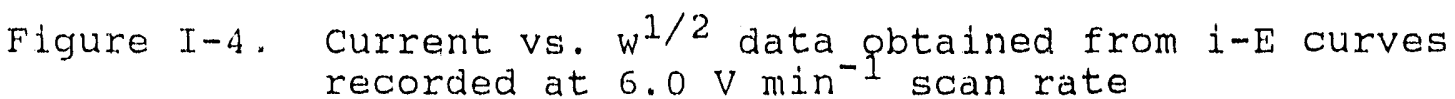


Indicative of loss of other intermediate reaction products, in addition to $I_{2}$, aq, from the electrode surface in the mechanism producing Wave $\underline{b}$.

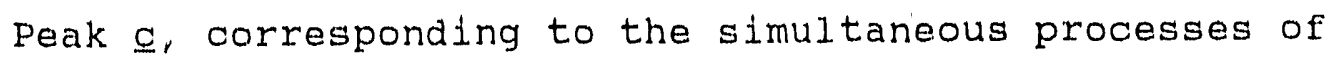
surface oxide formation and oxidative desorption of Iads' was determined to be independent of $w$, as expected for purely surface-controlled processes. The plot of $i_{p}$ vs. $w^{1 / 2}$ for Peak d was virtually linear for low values of $w$, but with a nonzero intercept. This is consistent with the simultaneous occurrence of the surface-controlled reduction of pto and transport-controlled reduction of $\mathrm{IO}_{3}{ }^{-}$by the surface-catalyzed mechanism.

\section{Variation of scan limits}

Current-potential curves were recorded at the RDE as a function of the negative scan limit. (E_) for a positive scan limit $\left(E_{+}\right)$of $1.4 \mathrm{~V}$ and the data is shown in Fig. I-5. Peak $\subseteq$ (positive scan) in the region $0.95 \mathrm{~V} \leq \mathrm{E}_{\mathrm{d}} \leq 1.3 \mathrm{~V}$ was only a small fraction of its limiting area for $E_{-}=0.45 \mathrm{~V}$. Hence, a relatively small amount of $I_{a d s}$ was formed at the disk electrode during the negative scar in the region $0.8 \mathrm{~V}$ $>\mathrm{E}_{\mathrm{d}} \geq 0.5 \mathrm{~V}$ in spite of the observation that a large amount of $\mathrm{I}_{2}$, aq was generated in this region (see Fig. I-2A). Feak c reached its limiting area for $E_{-} \leq 0.3 \mathrm{~V}$.

For $E_{-}<0.4 \mathrm{~V}$, Peak c shifted slightly to more negative values as $E_{\text {_ }}$ was made more negative, as is also 


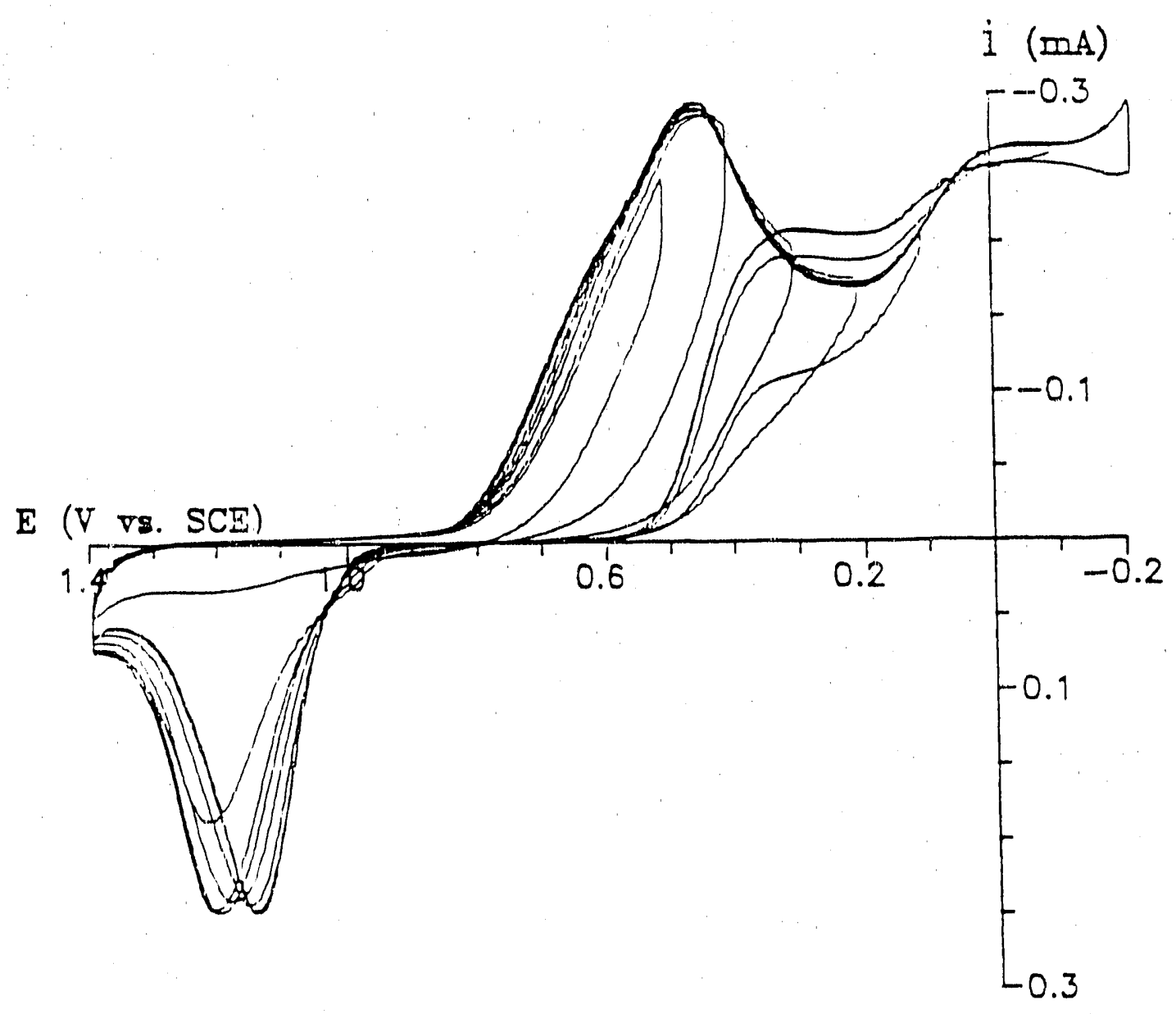

scan rate: $6.0 . \mathrm{V} \mathrm{min}^{-1}$

Rotation speed: $1000 \mathrm{rev} \mathrm{min}^{-1}$

Figure $I-5$. Effect on $i-E$ curves of changing the cathodic scan limit (E-) for $0.50 \mathrm{mM} \mathrm{\textrm {IO } _ { 3 }}$ at a Pt RDE in $0.50 \mathrm{M} \mathrm{H}_{2} \mathrm{SO}_{4}$ 
shown in Fig. I-5. Because the peak potential for an oxidative desorption reaction is indicative, in part, of the energy required to desorb $I_{\text {ads }}$ during the anodic process, the data indicate a decrease in adsorption stability as E_ was made more negative. It was also observed that wave $\underline{b}$ (positive scan) decreased dramatically for $\mathrm{E}_{-}>0.05 \mathrm{~V}$. The co-dependence of Waves $\underline{b}$ and $\underline{c}$ on $E_{-}$- suggests a mechanistic link between the stability of $I_{a d s}$ and faradaic mechanism producing wave $\underline{b}$. In a separate experiment, $i_{d}-E_{d}$ curves were recorded as a function of $E_{+}$for $E_{-}=-0.2 \mathrm{~V}$. For $E_{+} \leq$ $1.0 \mathrm{~V}$, only waves $\underline{\mathrm{a}}$ and $\underline{b}$ were observed during the negative scan. Peak $\underline{a}$ was absent because the presence of $I_{a d s}$ on the Pt surface inhibited anodic formation of pto during the positive scan to $E_{+} \leq 1.0 \mathrm{~V}$. The height and area of Peak $\mathrm{d}$ (negative scan) were observed to be increased linearly with increasing values of $E_{+}>1.0 \mathrm{~V}$. This increase was a direct consequence of the increasing quantity of oxide which formed for increasing values of $E_{+}$.

For any value of $E_{+}<1.0 \mathrm{~V}$, Waves $\underline{a}$ and $\underline{b}$ gradually decreased with successive scans. Figure I-6 contains i-E curves for $E_{+}=1.4 \mathrm{~V}$ and $E_{-}=-0.2 \mathrm{~V}$ that were recorded prior to the start and at the conclusion of a 4-hr period during which $E_{d}$ was cycled repetitively between $E_{+}=1.0 \mathrm{~V}$ and $E_{-}=-0.2 \mathrm{~V}$ using $\varnothing=6.0 \mathrm{~V} \mathrm{~min}{ }^{-1}$. The $i_{d^{-}} E_{d}$ response recorded prior to the start of this period represents the reproducible voltammetric response for $\mathrm{IO}_{3}{ }^{-}$at the $\mathrm{Pt}$ 


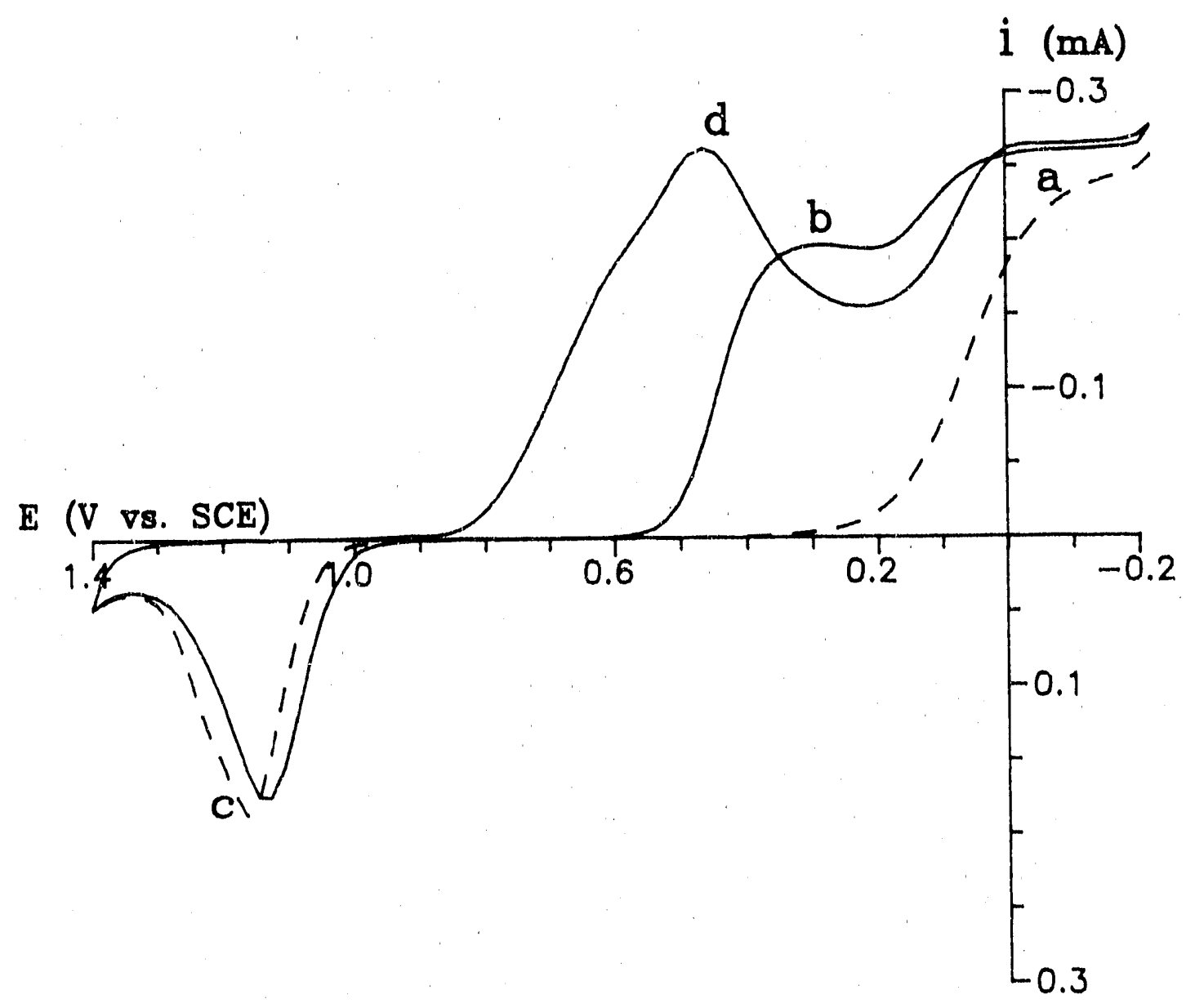

Scan rate: $6.0 \mathrm{~V} \mathrm{~min}^{-1}$

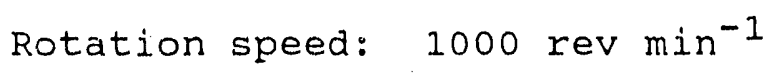

(-) Anodic scan limit of $1.40 \mathrm{~V}$

(--) Positive scan after repeated cycling for $4 \mathrm{hr}$ within the range $1.00 \mathrm{~V}$ to $-0.22 \mathrm{~V}$

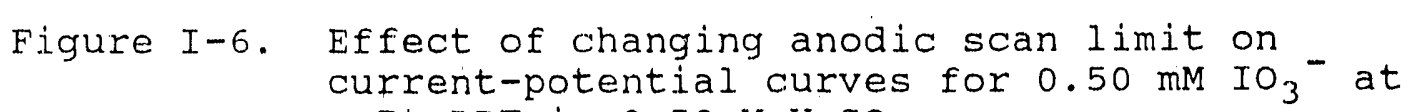
a Pt $\mathrm{RDE}$ in $0.50 \mathrm{M} \mathrm{H}_{2} \mathrm{SO}_{4}$ 
electrode. During the 4-hr period, Wave b disappeared completely and the height of wave a decreased by approximately 15-20\%. One possible cause of this effect is the accumulation of adsorbed impurities (e.g., trace organic compounds) from the solution onto the Pt electrode. For cyclic voltammetry with $\mathrm{E}_{+}=\underline{\mathrm{ca}} .1 .3 \mathrm{~V}$, the pt surface is maintained relatively free of excessive quantities of adsorbed impurities because of the benefit of oxidative desorption simultaneously with Pto formation (Peak $\underline{\text { c). This }}$ is supported by the observation that substitution of reagent grade $\mathrm{H}_{2} \mathrm{SO}_{4}$ for the Ultrex grade and the use of unfiltered $\mathrm{N}_{2}$ resulted in the disappearance of wave $\underline{b}$ in ca. $30 \mathrm{~min}$. It is readily apparent from Fig. I-6, that there was a slight change in the shape of peak $\subseteq$ but virtually no change in peak area during the $4-h r$ period. Hence, the supposed accumulation of adsorbed impurity had no effect on the surface coverage by $I_{a d s}$. On the basis of this supposition, the data are consistent with adsorption of the impurity onto the Iads. Furthermore, the disappearance of Wave $\underline{b}$ under these circumstances possibly indicates a reduction mechanism for $\mathrm{IO}_{3}{ }^{-}$requiring weak adsorption of $\mathrm{IO}_{3}{ }^{-}$to $\mathrm{I}_{\text {ads }}$ sites. Hence, a more strongly adsorbed impurity would prevent adsorption of $\mathrm{IO}_{3}{ }^{-}$and, thereby, suppress wave $\underline{\underline{b}}$.

The slight positive shift in $E_{p}$ for Peak $\subseteq$ could have resulted from adsorbed impurities. The shift could also indicate a slightly greater stability of $I_{\text {ads }}$ resulting from 
atomic rearrangements at the Pt surface during the prolonged period of cathodic polarization.

\section{Surface pretreatment}

The height of wave $\underline{b}\left(0.5 \mathrm{~V} \geq \mathrm{E}_{\mathrm{d}} \geq 0.2 \mathrm{~V}\right)$ was determined to be highly sensitive to alterations in the procedure for surface pretreatment. Prior to the start of experiments described above, the electrode was polished with 0.05-um alumina on microcloth wetted with deionized water. To ensure removal of residual adherent alumina, the surface was rinsed with deionized water, wiped with cotton swabs which had been profusely wetted with deionized water, and again rinsed with deionized water. The applied potential was then cycled repeatly within the designated potential limits until the $i_{d}-E_{d}$ response was reproducible.

In separate experiments, the $i_{d}-E_{d}$ response for $\mathrm{IO}_{3}{ }^{-}$ was compared for use of three different absorbent materials to remove residual alumina: cotton swabs, Kimwipe tissues, and microcloth. Alternatively, the electrode was merely rinsed after polishing without wiping. The evolution of the $i_{d}-E_{d}$ curves during repeated cycles of $E_{d}$ after each treatment is shown in Fig. I-7A-D. Waves a and $\underline{b}$ and peaks $\underline{c}$ and $\underline{d}$ were initially suppressed in all cases. However, the rate of recovery of wave $\underline{b}$ was especially sensitive to surface treatment. The most severe effect was observed when cellulosic materials (i.e., cotton swabs and Kimwipe 


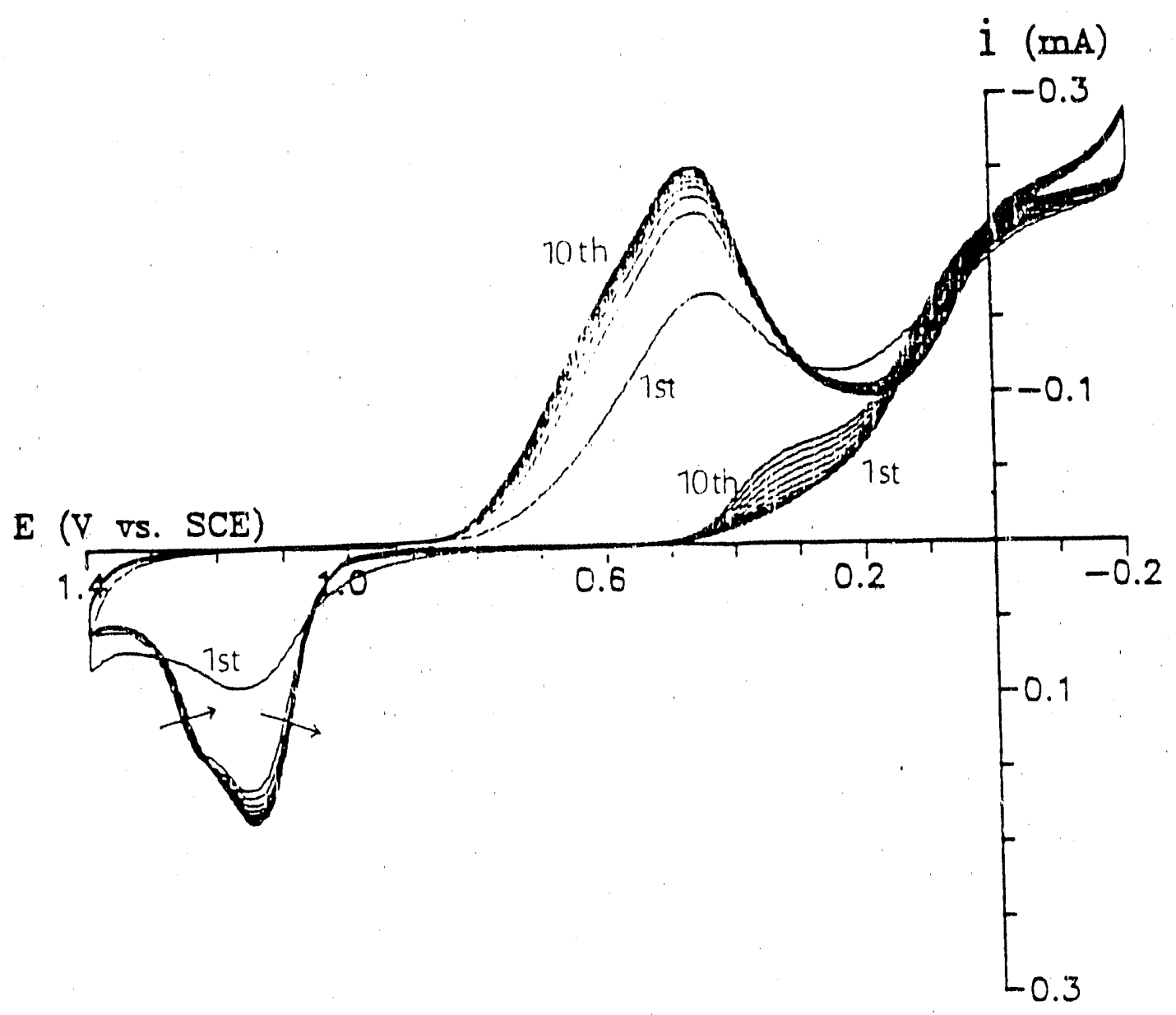

scan rate: $6.0 \mathrm{~V} \mathrm{~min}^{-1}$

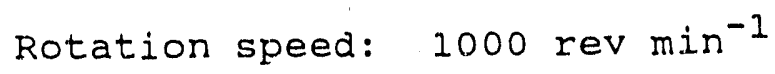

Figure I-7A. Effect of surface treatment on currentpotential curves for $0.50 \mathrm{mM} \mathrm{IO}_{3}{ }^{-}$at a Pt RDE in $0.50 \mathrm{M} \mathrm{H}_{2} \mathrm{SO}_{4}$. Electrode was polished with $0.05-u m$ alumina prior to treatment with $\mathrm{H}_{2} \mathrm{O}$ and a cotton swab. Arrows indicate scan direction 


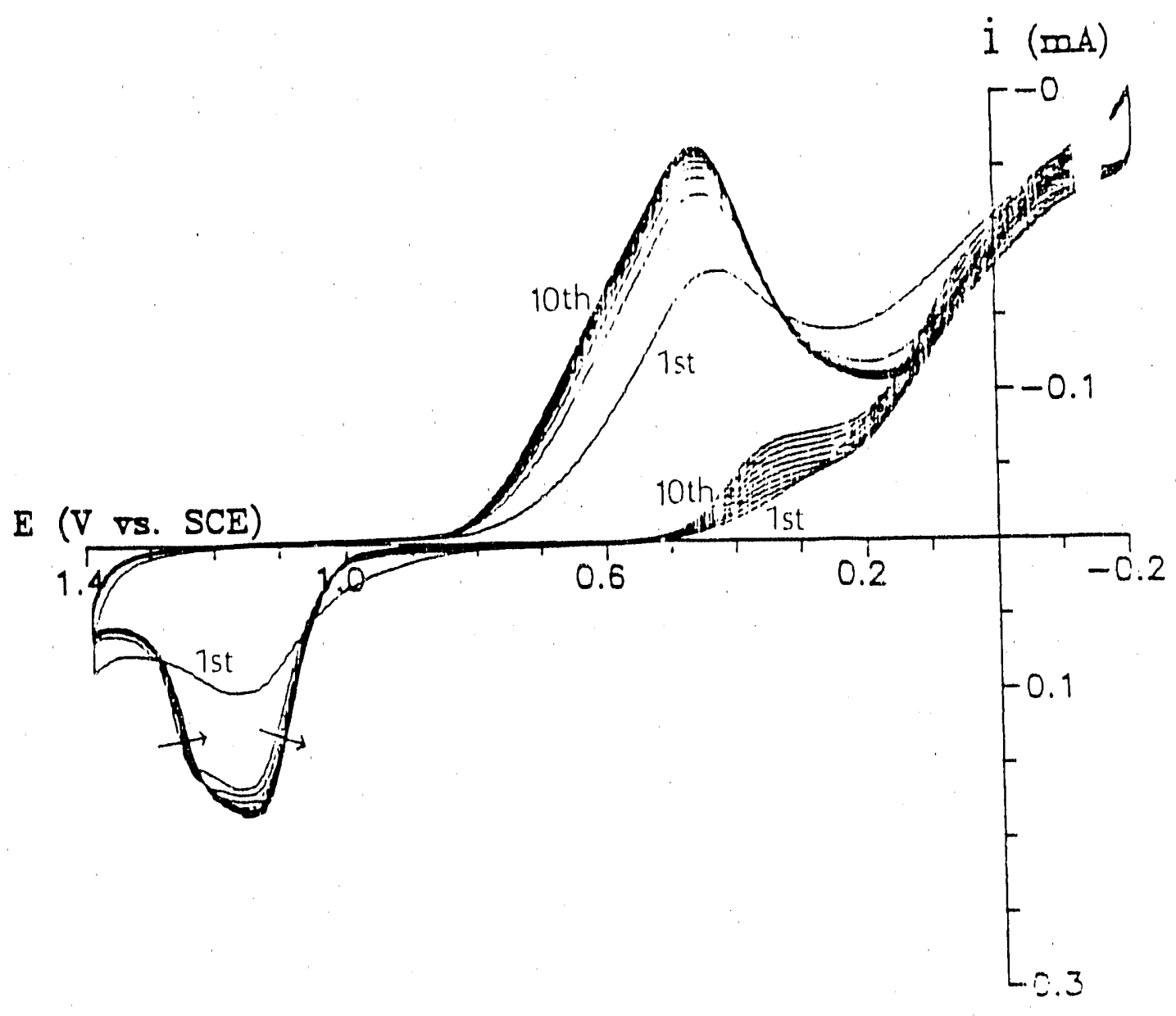

Scan rate: $6.0 \mathrm{~V} \min ^{-1}$

Rotation speed: $10.00 \mathrm{rev} \mathrm{min}^{-1}$

Figure I-7B. Effect of surface treatment on currentpotential curves for $0.50 \mathrm{mM} \mathrm{IO}_{3}{ }^{-}$at a Pt RDE in $0.50 \mathrm{M} \mathrm{H}_{2} \mathrm{SO}_{4}$. Electrode was polished with $0.05-u m$ alumina prior to treatment with $\mathrm{H}_{2} \mathrm{O}$ and a Kimwipe. Arrows indicate scan direction 


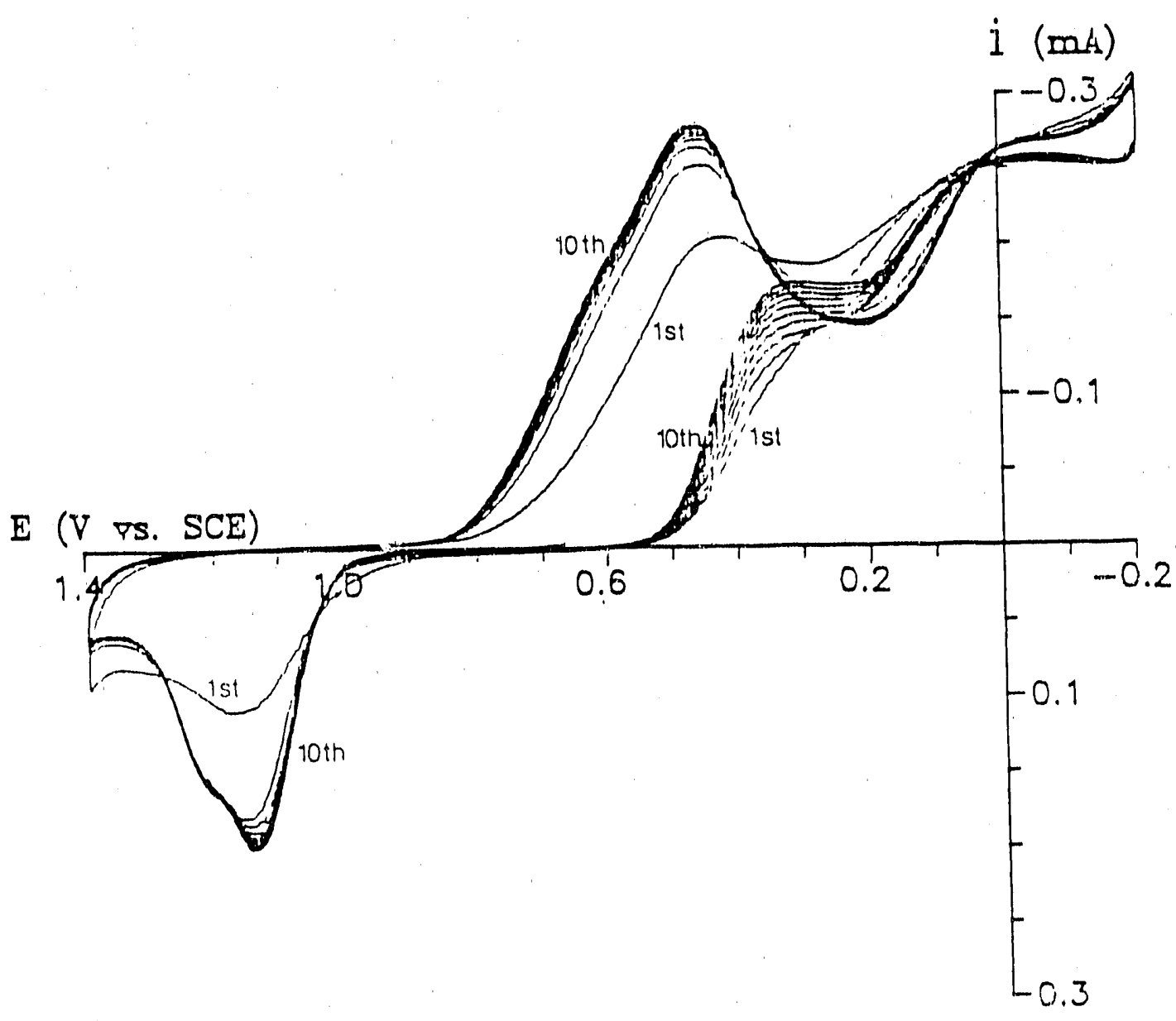

Scan rate: $6.0 \mathrm{~V} \mathrm{~min}^{-1}$

Rotation speed: $1000 \mathrm{rev}_{\mathrm{min}^{-1}}$

Figure I-7C. Effect of surface treatment on currentpotential curves for $0.50 \mathrm{mM} \mathrm{IO}_{3}$ at a Pt RDE in $0.50 \mathrm{M} \mathrm{H}_{2} \mathrm{SO}_{4}$. Electrode was polished with 0.05 -um alumina prior to treatment with $\mathrm{H}_{2} \mathrm{O}$ and a microcloth 


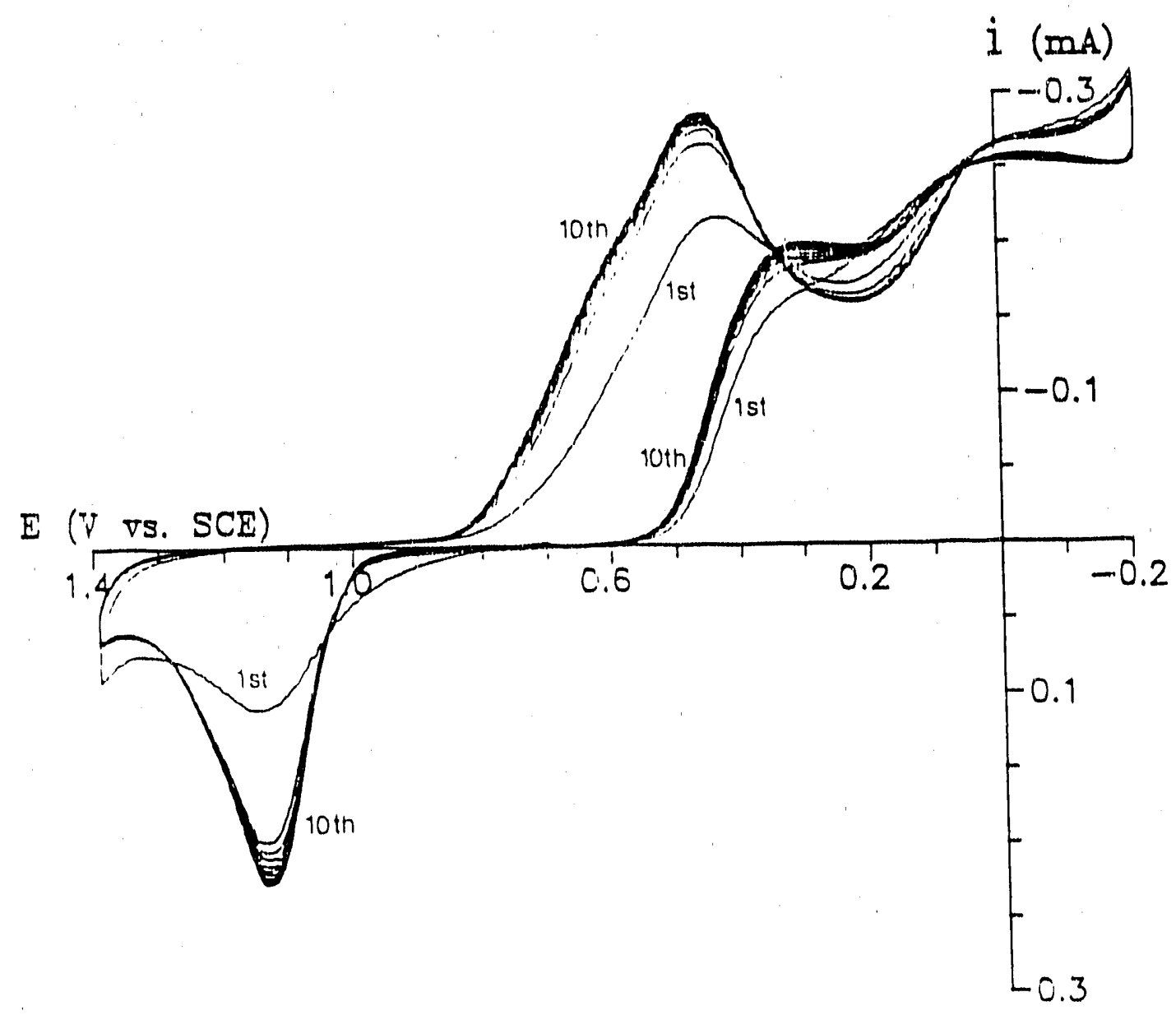

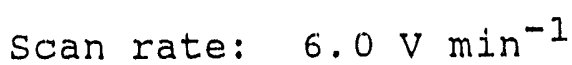

Rotation speed: $1000 \mathrm{rev} \mathrm{min}^{-1}$

Figure I-7D. Effect of surface treatment on currentpotential curves for $0.50 \mathrm{mM} \mathrm{IO}_{3}{ }^{-}$at a Pt RDE in $0.50 \mathrm{M} \mathrm{H}_{2} \mathrm{SO}_{4}$. Electrode was polished with $0.05-\mathrm{um}$ alumina prior to rinsing with $\mathrm{H}_{2} \mathrm{O}$ 
tissues) were usea (Figs. I-7A\& I-7B, respectively). simple rinsing without use of an absorbent material produced the least suppression of wave $\underline{b}$ and allowed the fastest recovery to its reproductble response (Fig. I-7D).

Examination of the residual $1_{d}-E_{d}$ response in $0.5 \mathrm{M} \mathrm{H}_{2} \mathrm{SO}_{4}$ in the absence of $\mathrm{IO}_{3}{ }^{-}$also revealed effects from varlation of the pretreatment conditions. Use of the cellulosic materials resulted in large initial suppressions of the waves for pto formation, Pto reduction, and H-adsorption and desorption. Continued potential cycling eventually (ca. 20 $\mathrm{min}$ ) restored these voltammetric features to the shape and areas normally expected for pure Pt electrodes. The $1_{\mathrm{d}}-E_{\mathrm{d}}$ response obtained immediately following subsequent addition of $\mathrm{IO}_{3}{ }^{-}$corresponded to the reproducible curve shown in Fig. $I-1(-\infty)$.

In other experiments it. was determined that the cathodic wave for reduction of $I_{2}$, aq in the same potential region as wave $\underline{b}$ was not decreased below the transportlimited value by alteration of the various pretreatment procedures. Furthermore, a Pt electrode for which wave $\underline{b}$ was absent in the presence of $\mathrm{IO}_{3}{ }^{-}$was rinsed in water and transferred to a solution of $\mathrm{I}_{2}$, aq in $0.5 \mathrm{M} \mathrm{H}_{2} \mathrm{SO}_{4}$. The wave for $I_{2, a q}$ was present in the $i_{d}-E_{d}$ curve obtained for the first cyclic $E_{d}$ scan. The electrode then was rinsed and returned to the $\mathrm{IO}_{3}{ }^{-}$solution. Still, wave $\underline{b}$ was absent from the $i_{d}-E_{d}$ curve. These results demonstrate: i) the 
mechanism produclng wave $p$ is more complex than previously thought (19), and probably involves weak adsorption of $\mathrm{IO}_{3}{ }^{-}$ to I ads sites on the pt surface, and 11) impurities can be transferred from absorbent materlals used in electrode pretreatment to electrode surfaces with dire consequence for some faradalc reactions. 


\section{CONCLIUSIONS}

The ortginal goal of this research was satisfied and evidence obtained indicates an electrocatalytic link between rediction of surface oxide and reduction of $\mathrm{TO}_{3}{ }^{-}$during the negative scan at an oxlde-covered pt electrode. Furthermore, the quantity of $\mathrm{IO}_{3}{ }^{-}$reduced is larger than calculated on the basis of a mechanlsm in which the process is promoted by the adsorpition of a reduction product (e.g., I0). The possiblilty still exists, therefore, that the $\mathrm{IO}_{3}^{-}$reduction process is coupled with the oxide reduction mechanism via adsorbed hydroxyl radicals ( $\mathrm{OH}_{\mathrm{ads}}$ ) assumed to be involved in both processes. However, a stronger statement supporting this conjecture must await the results of further investigations demonstrating that the cathodic oxygen-transfer process on Pt is not unique to $\mathrm{IO}_{3}{ }^{-}$. The ultimate fallure of the suggested mechanism to produce a persistent cathodic signal for $\mathrm{IO}_{3}{ }^{-}$on the oxidefree surface is thought to result from the eventual coverage of the pt surface by $I_{a d s}$. This is discussed in more detail. below.

Desideri $(19,20)$ observed that the cathodic wave for $\mathrm{IO}_{3}{ }^{-}$reduction on oxide-free $\mathrm{Pt}$ decreased with time. In one study (19), the decrease in wave height after prolonged use of a pt electrode was concluded to be caused by adsorption of $\mathrm{I}_{2}$. In another (20), the cathodic wave height was 
observed generally to be lower on a pre-reduced eleotrode than on a pre-oxidized electrode. Addition of $I_{2}$, aq was reported to eliminate differences in voltammetric response that were estimated to be caused by electrode pretreatment. Desidert concluded that the first stage of $\mathrm{IO}_{3}{ }^{-}$reduction is electrochemical and the second stage is chemical in nature, involving reduction of $\tau_{2}$, ag produced in the diffusioll layer by reaction of $\mathrm{IO}_{3}{ }^{-}$with $\mathrm{I}^{-}$.

The conclusions of. Desidert are shown to be incorrect by the observation that the reduction of $\mathrm{IO}_{3}{ }^{-}$on oxide-free $\mathrm{Pt}$ (Wave b) can be blocked even when reduction of $I_{2}$, aq persists. The results are consistent with the general description given by Equations 14-17. For a pre-anodized electrode, Pto is reduced to $\mathrm{Pt}$ during the negative scan in the region $0.8>E_{\mathrm{d}}>$ ca. $0.4 \mathrm{~V}$ (Equation 7 ).

$$
2 \mathrm{e}+2 \mathrm{H}^{+}+\mathrm{PtO} \longrightarrow \mathrm{Pt}+\mathrm{H}_{2} \mathrm{O}
$$

The reduction of $\mathrm{IO}_{3}{ }^{-}$during the negative scan at the oxidefree Pt can yield $\mathrm{I}_{2}\left(0.8>\mathrm{E}_{\mathrm{d}}>0.45 \mathrm{~V}\right)$ and $\mathrm{I}^{-}\left(\mathrm{E}_{\mathrm{d}}<0.45\right.$ v) with the immediate result that lodine ( $\left.{ }^{\circ}\right)$ is adsorbed at the Pt surface (Equation 8 ).

$$
6 \mathrm{H}^{+}+\mathrm{IO}_{3}^{-}+\mathrm{Pt}+5 \mathrm{e} \longrightarrow \mathrm{Pt}\left(\mathrm{I}_{\text {ads }}^{\circ}\right)+3 \mathrm{H}_{2} \mathrm{O}
$$

In the region $0.5>\mathrm{E}_{\mathrm{d}}>0.2 \mathrm{~V}$ (neg./pos. scans), the direct reduction of $\mathrm{IO}_{3}^{-}$to $\mathrm{I}^{-}$can occur at $\mathrm{Pt}\left(\mathrm{I}_{\text {ads }}\right)$ sites (Equation 9). 


$$
6 \mathrm{H}^{+}+\mathrm{IO}_{3}^{-}+6 e \stackrel{\mathrm{Pt}\left(\mathrm{I}_{\mathrm{adg}}\right)}{\longrightarrow} \mathrm{I}^{-}+3 \mathrm{H}_{2} \mathrm{O}
$$

That mechanism is not fast. and, consequently, the surface concentration of $\mathrm{IO}_{3}{ }^{-*}$ at the electrode surface is not zero. Hence, an appreciable quantity of $\mathrm{IO}_{3}{ }^{-}$reacts with $\mathrm{I}^{-}$in the diffusion layer to produce $I_{2}$, aq' a portion of which reacts at the electrode to yield $\mathrm{I}^{-}$and the remalnder esaapes the region of the disk electrode by convective-diffusional

processes. The consequence is that the plateau current for Wave $\underline{b}$ is below the transport-limited value for the 6electron reduction of $\mathrm{IO}_{3}{ }^{-}$. I.t is apparent that the reduction mechanism changes for $E_{d}<\underline{c a} .0 .15 \mathrm{~V}$ with the result that the concentration of $\mathrm{IO}_{3}{ }^{-}$is zero at the electrode surface and the amount of $I_{2}$, aq generated by homogeneous reaction in the diffusion layer is substantially decreased. Hence, the plateau current for wave a adheres more closely to the Levich response predicted for a transport-1imited process.

of greatest interest is the mechanistic reason that the $E_{1 / 2}$ for Wave $\underline{b}$ is virtualiy the same as that for $I_{2}$, aq. It is proposed that the mechanism for direct reduction of $\mathrm{IO}_{3}{ }^{-}$ in the region of wave $\underline{b}$ requires the adsorbtive association of $\mathrm{IO}_{3}{ }^{-}$with $\mathrm{Pt}\left(\mathrm{I}_{\mathrm{ads}}\right)$ sites. For $\mathrm{E}_{\mathrm{d}}>0.5 \mathrm{~V}, \mathrm{I}_{2}$, aq is not reduced and can be adsorbed at $P t\left(I_{a d s}\right)$ sites to produce the equivalent of $\mathrm{Pt}\left(\mathrm{I}^{\circ}-\mathrm{I}_{2}\right.$, ads $)$ (9). The adsorbed $I_{2}$ thereby blocks the direct reduction mechanism for $\mathrm{IO}_{3}{ }^{-}$(Equation 10 ). 


$$
\mathrm{IO}_{3}-\stackrel{\mathrm{Pt}\left(\mathrm{I}^{\circ}-\mathrm{I}_{2}, \mathrm{ads}\right)}{\longrightarrow} \text { no } \mathrm{rxn}
$$

Furthermore, the component of wave $\underline{b}$ from reduction of $I_{2}$, aq does not persist because $E_{d}>E_{1 / 2}$ for the $I_{2}$, aq ${ }^{-I^{-}}$half. reaction.

Any step-wise mechanism proposed for direct reduction of adsorbed $\mathrm{IO}_{3}^{-}$is tenuous at best. However, the mechanism given by Equations $11-17$ appears to be consistent with the observations presented here. Possible adsorption-desorption equilibria for the intermediate products, e.g., $\mathrm{IO}_{2}^{-}$and $\mathrm{IO}^{-}$ (Equations 12-15), could explain the effect of rotation speed on Wave $\underline{b}$ (see Fig. I-4). Alternatively, the disproportionation of iodite $\left(3 \mathrm{IO}_{2}^{-} \longrightarrow 2 \mathrm{IO}_{3}^{-}+\mathrm{I}^{-}\right)$ could be substituted for Equations 14-17.

$$
\begin{aligned}
& \mathrm{IO}_{3}{ }^{-} \longleftrightarrow\left(\mathrm{IO}_{3}{ }^{-}\right) \text {ads } \\
& \left(\mathrm{IO}_{3}{ }^{-}\right) \text {ads }+\mathrm{H}^{+} \longleftrightarrow\left(\mathrm{IO}_{2}{ }^{\circ}\right) \text { ads }+(\cdot \mathrm{OH}) \text { ads } \\
& \left(\mathrm{IO}_{2}{ }^{\circ}\right)_{\mathrm{ads}}+\mathrm{e} \longrightarrow\left(\mathrm{IO}_{2}{ }^{-}\right)_{\mathrm{ads}} \longleftrightarrow \mathrm{IO}_{2}{ }^{-} \\
& \left(\mathrm{IO}_{2}{ }^{-}\right) \mathrm{ads}+\mathrm{H}^{+} \longleftrightarrow\left(\mathrm{IO}^{*}\right) \mathrm{ads}+(\cdot \mathrm{OH}) \mathrm{ads} \\
& \left(\mathrm{IO}^{\circ}\right)_{\mathrm{ads}}+\mathrm{e} \longrightarrow\left(\mathrm{IO}^{-}\right) \mathrm{ads} \longleftrightarrow \mathrm{IO}^{-} \\
& \left(\mathrm{IO}^{-}\right) \mathrm{ads}+\mathrm{H}^{+} \longleftrightarrow(\mathrm{I} \cdot)_{\mathrm{ads}}+(\cdot \mathrm{OH}) \mathrm{ads}
\end{aligned}
$$

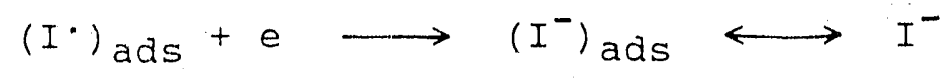

$$
\begin{aligned}
& 3(\cdot \mathrm{OH}) \mathrm{ads}+3 \mathrm{e}+3 \mathrm{H}^{+} \longrightarrow 3 \mathrm{H}_{2} \mathrm{O}
\end{aligned}
$$

net: $\mathrm{IO}_{3}^{-}+6 \mathrm{H}^{+}+6 \mathrm{e} \longrightarrow 3 \mathrm{H}_{2} \mathrm{O}+\mathrm{I}^{-}$

The dependence of wave $\underline{b}$ on the negative scan Iimit (E_) 
mentioned above indicates that not all forms of $I_{\text {ads }}$ sites on Pt are suitable for the direct reduction of $\mathrm{IO}_{3}{ }^{-}$. The possibility that a distribution of adsorption energies for Iads exists is supported by the observation that the potential of Peak $\subseteq$ shifted to less positive values as E_ was made more negative in the range $0.4-0.0 \mathrm{~V}$ (see Fig. $(-5)$. It is interesting to note that a well-formed wave $\underline{b}$ was developed only for values of $E_{\text {_ }}$ approaching ca. $0.05 \mathrm{~V}$ which corresponds to the onset of cathodic adsorption of hydrogen $\left({ }^{-} \mathrm{H}_{\text {ads }}\right)$. Surface rearrangement of $I_{a d s}$ is suspected to result and Johnson (9), using a ring-disk electrode, observed a portion of the $I_{a d s}$ undergo cathodic desorption with subsequent collection of the $\mathrm{I}^{-}$at the ring electrode during the negative scan. There was no evidence for the reverse process occurring during the following positive scan (9). It is speculated, then, that the process producing wave $\underline{b}$ involves association of $\mathrm{IO}_{3}{ }^{-}$with both $\mathrm{H}_{\text {ads }}^{\circ}$ and Iads on the Pt surface, perhaps as illustrated below. 
It is speculated that for the positive scan, following a negative scan to $E_{-}<0.0 \mathrm{~V}$, the electrode surface does not undergo change in the region $\mathrm{E}_{\mathrm{d}}=0.0-0.4 \mathrm{~V}$. Hence, it is significant to note that waves $\underline{a}$ and $\underline{b}$ are quite distinct for values of rotation speed used to obtain the data shown (see Fig. I-4). However, the values of limiting current for waves $\underline{a}$ and $\underline{b}$ were virtually identical for waves $\underline{a}$ and $\underline{b}$ at low rotation speeds (i.e.,$<400 \mathrm{rev} \mathrm{min}^{-1}$ ). Because a severe negative deviation from linearity occurs for the plateau current of Wave $\underline{b}$ as a function of increasing $\mathrm{w}^{1 / 2}$, it is concluded that intermediate products of the reduction reaction are soluble and, therefore, can escape the disk surface at high rotation velocities. However, the plot of $i_{l i m}$ vs. $w^{1 / 2}$ for wave a was linear for all values of rotational velocity. Therefore, it is speculated that a different mechanism exists for wave a for which the overall rate of electron transfer is sufficiently larger than for Wave bo so that negligible quantities of soluble intermediate products are formed. However, the cause of the difference in mechanisms for $\mathrm{IO}_{3}{ }^{-}$reduction in the regions of waves $\underline{a}$ and $\underline{b}$ during the negative scan is unknown at this time. 


\section{REFERENCES}

1. Angerstein-Kozlowska, H.; Conway, B. E.; Sharp, W. B. A. I. Electroanal. Chem. 1973, 43,9.

2. Austin, D. S.; Polta, J. A.; Polta, T. Z.; Tang, A. P.-C.; Cabelka, T. D.; Johnson, D. C. I. Electroanal. Chem. $1984,168,227$.

3. Damjanovic, A.; Jovanovic, B. I. Electrochem. SoC. $1976,123,374$.

4. Cabelka, T. D. ; Austiry, D. S.; Johnson, D. C. I. Electrochem. Soc. 1984, 131, 1595.

5. Austin, D. S.; Johnson, D. C.; Hines, T. G.; Berti, E. T. Anal. Chem. 1983, 155, 2222 .

6. Zakharov, V. A. ; Songina, O. A. Russ. I. Phys. Chem. 1964, 38, 412 .

7. Lown, J. A.; Johnson, D. C. Anal. Chim. Acta 1980, 116,41 .

8. Hubbard, A. T.; Osteryoung, R. A.; Anson, F. C. Anal. Chem. 1966, 38, 692 .

9. Johnson, D. C. I. Electrochem. SoC. 1972, 119, 331.

10. Zakharov, V. A.; Songina, O. A.; Kal'nitskaya, L. P. Elektrokhimiia 1971, I, 1702.

11. Eriich, Yu. I.; Anni, K. L.: Palm, U. V. Elektrokhimiia $1978, \underline{14}, 1066$.

12. Erlich Yu. I.; Anni, K. Elektrokhimiia 1979, 15, 1573.

13. Watanabe, M.; Motoo, S. I. Electroanal. Chem. 1975, $\underline{60}, 267$.

14. Tilak, B. V.; Conway, B. E.; Angerstein-Kozlowska, H. I. Electroanal. Chem. 1973, 48, 1 .

15. Feldberg, S. W.; Enke, C. G.; Bricker, C. E. I. Electrochem. Soc. 1963, 110, 826 .

16. Gossner, K.; Mizera, E. I. Electroanal. Chem. 1981, 125,347 .

17. Anson, F. C. I. Am. Chem. SoC. 1959, 81, 1554. 
18. Davis, D. G. Talanta $1960,3,335$.

19. Desideri, P. G. I. Electroanal. Chem. 1965, 9, 218.

20. Desideri, P. G. I. Electroanal. Chem. 1965, 9, 229.

21. Beran, P.; Bruckenstein, S. Anal. Chem. 1968, 40, 1044.

22. Beran, P.; Bruckenstein, S. I. Phys. Chem. 1968, 72, 3630 .

23. Vallat, A.; Person, M.; Laviron, E. Electrochim. Acta $1982,27,657$. 
$62 \mathrm{a}$

PART II. ELECTROCATALYTIC OXIDATION OF CYANIDE 
$62 b$

\section{INTRODUCTION}

The oxidative degradation of cyanide wastes can be important in industrial waste management and for wastewater treatment. Electrolytic methods of waste treatment can minimize the need for chemical additives and sludge disposal while offering the possibility of economic recovery of metals by simultaneous deposition at the cathode. Commonly used anodes (e..g., graphite and stainless steels) exhibit low current efficiency for $\mathrm{CN}^{-}$oxidation and are slowly degraded during electrolysis. Electrodeposited $\mathrm{PbO}_{2}$ has been demonstrated to be superior to graphite and stainless steels for $\mathrm{CN}^{-}$oxidation; however, poor current efficiency was observed for dilute solutions of $\mathrm{CN}^{-}(<0.2 \mathrm{M})$ (1).

Lead dioxide electrodes are easily obtained by electrodeposition from solutions of lead salts (2-5) or by anodization of lead $(2,3,6-8)$. Of the two crystallographic forms of lead dioxide, $B-\mathrm{PbO}_{2}$ (rutile) is more common. $B-$ Lead dioxide is deposited from $\mathrm{Pb} I$ solutions of low $\mathrm{pH}$. Anodization of lead electrodes in $\mathrm{H}_{2} \mathrm{SO}_{4}$ also yields $\mathrm{B}_{-} \mathrm{PbO}_{2}$. a-Lead dioxide (orthorhombic) is deposited from neutral or alkaline solutions of $\mathrm{Pb} I$. Likewise, anodization of lead in alkaline media yields $\underline{a}-\mathrm{PbO}_{2}$.

Lead dioxide is a good conductor having a resistance measured as $2 \times 10^{-4} \mathrm{ohm} \mathrm{cm}(9)$. a-Lead dioxide is slightly more conductive than the $\beta$-form. It has been suggested that 
the conductivity of $\mathrm{PbO}_{2}$ is associated with a deficiency of oxygen (10). This is supported by the observation that, in many cases, the oxygen content of $\mathrm{a}-\mathrm{PbO}_{2}$ is less than for $\mathrm{B}-$ $\mathrm{PbO}_{2}$. According to several workers $(11,12)$, the stoichiometry of lead dioxide approaches $\mathrm{PbO}_{1.98}$.

Perhaps the most important commercial use of $\mathrm{PbO}_{2}$ is as the anode in lead-acid batteries (13). An examination of the literature reveals that $\mathrm{PbO}_{2}$ is also widely used in electroorganic synthesis $(14,15)$. Lead dioxide anodes have been used in preparative chemistry to produce periodic acid $\left(\mathrm{HIO}_{4}\right)$ (16) and iodoform $\left(\mathrm{CHI}_{3}\right)$ (17). Lead dioxide electrodes have been described as inert, having no specific catalytic activity (2). The presence of other metal oxides in the $\mathrm{PbO}_{2}$ matrix has been observed to improve the reactivity and the stability of the electrode $(13,18)$.

Recently, Johnson et al. (19) took advantage of this effect in order to enhance the electrocatalysis of many oxygen-transfer reactions on $\mathrm{PbO}_{2}$. By analogy with $n$-type electronic semiconductors, doping $\mathrm{PbO}_{2}$ with Group $\mathrm{V}$ elements was concluded to produce an oxygen-rich mixed oxide of the general formula $\mathrm{PbO}_{2} \cdot \mathrm{MO}_{2} .5(20)$. The rate of oxidation of $\mathrm{Mn} I I$, phenol, hydroquinone, and several sulfur-containing organic compounds was determined to be increased at these mixed oxide electrodes (19). Although the oxidizing power of $B i^{V}$ and $A s^{V}$ differ substantially, the enhanced electrocatalytic activities for $\mathrm{PbO}_{2} \cdot \mathrm{BiO}_{2} .5$ and $\mathrm{PbO}_{2} \cdot \mathrm{AsO}_{2.5}$ 
were similar. The observed $\mathrm{E}_{1 / 2}$ values for $\mathrm{Mn}^{\mathrm{II}}$ and $\mathrm{As} I I$ were virtually the same at $\mathrm{PbO}_{2} \cdot \mathrm{BlO}_{2} .5$, even though the reversible potentials for $\mathrm{As}^{\mathrm{V}} / \mathrm{As}^{\mathrm{III}}(0.31 \mathrm{~V})$ and $\mathrm{MnVII} / \mathrm{MnII}^{\mathrm{I}}$ $(1.51 \mathrm{~V})$ are quite different. The observed $E_{1 / 2}$ was concluded to be characteristic of the discharge of $\mathrm{H}_{2} \mathrm{O}$ to produce the active adsorbed oxygen at the electrode surface. Although the electracatalytic benefit of doping $\mathrm{PbO}_{2}$ with $\mathrm{BiO}_{2} .5$ was concluded to be general, exceptions do exist. For example, the anodic oxidation of cyanide occurs slowly at $\mathrm{PbO}_{2}$ electrodes, and the rate of oxidation is not increased by doping with bismuth.

A consideration of possible cyanide oxidation products in alkaline media, based on standard reduction potentials given below, indicates that cyanate $\left(\mathrm{CNO}^{-}\right)$is thermodynamically preferred at low values of applied potential. However, oxidations to $\mathrm{CO}_{2}$ and $\mathrm{N}_{2}$, as well. as $\mathrm{CO}_{3}{ }^{2-}$ and $\mathrm{NO}_{3}^{-}$, are allowed at positive potential values easily achieved at common anodes in alkaline media.

$$
\begin{aligned}
& \mathrm{CNO}^{-}+\mathrm{H}_{2} \mathrm{O}+2 \mathrm{e} \longrightarrow \mathrm{CN}^{-}+2 \mathrm{OH}^{-} \mathrm{E}^{\circ}=-0.97 \mathrm{~V} \\
& \mathrm{CO}_{2}+0.5 \mathrm{~N}_{2}+2 \mathrm{H}^{+}+5 \mathrm{e} \rightarrow \mathrm{CN}^{-}+2 \mathrm{OH}^{-} \mathrm{E}^{\circ}=-0.49 . \mathrm{V} \\
& \mathrm{C}_{2} \mathrm{~N}_{2}+2 \mathrm{e} \rightarrow 2 \mathrm{CN}^{-} \quad \mathrm{E}^{\circ}=-0.18 \mathrm{~V} \\
& \mathrm{CO}_{3}^{2-}+\mathrm{NO}_{3}^{-}+6 \mathrm{H}^{+}+10 \mathrm{e} \longrightarrow \mathrm{CN}^{-}+6 \mathrm{OH}^{-} \mathrm{E}^{\circ}=+0.14 \mathrm{~V}
\end{aligned}
$$

The adition of small quantities of $\mathrm{Cu} I I$ to alkaline solutions was demonstrated by Katagiri et al. (21) to enhance the anodic oxidation of $\mathrm{CN}^{-}$at $\mathrm{Pt}$ electrodes. This 
observation, plus the common knowledge that cuII rapidly oxidizes $\mathrm{CN}^{-}$to cyanogen $\left(\mathrm{C}_{2} \mathrm{~N}_{2}\right)$ led Katagiri et al. (21) to suggest the mechanism given in Equations 5-9 for the anodic response of $\mathrm{CN}^{-}$. Accordingly, the cyclic interconversion of the $\mathrm{Cu}^{I I}-\mathrm{Cu}^{I}$ redox couple functions for electron-transfer mediation in the oxidation reaction. This mechanism predicts no $\mathrm{pH}$ dependency for the half-wave potential. $\left(\mathrm{E}_{1 / 2}\right)$ and a value of unity for $\underline{n}$ (eq $\mathrm{mol}^{-1}$ ).

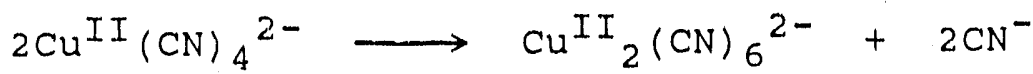

$$
\begin{aligned}
& \mathrm{CuII}_{2}(\mathrm{CN})_{6}^{2-} \longrightarrow 2 \mathrm{Cu}^{\mathrm{I}}(\mathrm{CN})_{2}^{-}+(\mathrm{CN})_{2} \\
& 2\left(\mathrm{Cu}^{\mathrm{I}}(\mathrm{CN})_{2}^{-}+2 \mathrm{CN}^{-} \longrightarrow \mathrm{Cu}^{\mathrm{I}}(\mathrm{CN})_{4}^{3-}\right) \\
& 2 \mathrm{Cu}^{I}(\mathrm{CN})_{4}^{3-} \longrightarrow 2 \mathrm{Cu}^{I I}(\mathrm{CN})_{4}^{2-}+2 \mathrm{e} \\
& 2 \mathrm{CN}^{-} \longrightarrow \mathrm{C}_{2} \mathrm{~N}_{2}+2 \mathrm{e}
\end{aligned}
$$

The availability of catalytically active anode materials for $\mathrm{CN}^{-}$oxidation at transport-limited rates could have importance for fabrication of amperometric sensors (22) as well as for waste management. Whereas copper, copper oxide, and copper-modified electrodes have been studied for the oxidation of amines $(23,24)$, amino acids (25), and carbohydrates (26), little work has been devoted to oxidation of $\mathrm{CN}^{-}$. In this research, an improved oxide electrode is sought for the anodic oxidation of cyanide. 


\section{EXPERIMENTAL}

\section{Chemicals and apparatus}

Chemicals used were reagent grade and water was

deionized in a NANOpure-II system (Barnstead). A rotated disk electrode ( $R D E ; 0.196 \mathrm{~cm}^{2}$ ) and a rotated pt-Pt ringdisk electrode (RRDE; disk diameter: 0.180 inch, ring I.D.: 0.194 inch, ring O.D.: 0.212 inch) were obtained from Pine Instrument Co. An MSRX speed controller and RDE4 potentiostat (Pine) were under the control of a STANDARD 286/10 microcomputer. A DT2801./5716A input/output board and accompanying software (Data Translation) were used in data acquisition. Current-potential (1-E) curves were recorded on a Model 7035B X-Y recorder (Hewlett Packard). Electrode potentials were controlled and are reported in volts (V) vs. a saturated calomel electrode (SCE; Fisher scientific). Micrographs were obtained using a JSM-840A scanning electron microscope (JEOL). X-ray diffraction was performed on a model D-500 diffractometer (Siemens). Elemental analysis was performed using a Model 5000 atomic absorption spectrometer (Perkin-Elmer) with a HGA-5000 graphite furnace.

\section{Procedures}

B-Lead dioxide A solution containing $10 \mathrm{mM} \mathrm{Pb}^{I I}$ and $0.1 \mathrm{M} \mathrm{HClO}_{4}$ was used for electrodeposition of $\mathrm{B}-\mathrm{PbO}_{2}$ films on rotated disk electrodes (RDE). Electrodeposition was 
performed under condtions of constant anodle current $(5.0$ $\mathrm{mA} \mathrm{cm}^{-2}$ ) for $5.0 \mathrm{~min}$. Electrode rotation speed during deposition was 1000 rev $\mathrm{min}^{-1}$.

\section{B1-doped $\mathrm{PbO}_{2}$ Solutions used for the}

electrodeposition of $\mathrm{Bl}$-doped $\mathrm{PbO}_{2}$ flims contained $0.1 \mathrm{M}$ $\mathrm{HClO}_{4}, 1.0 \mathrm{mM} \mathrm{PbII}$ and the indicated quantity of BiII. For example, an electrode deslgnated "30 mole of" would have been prepared from a $0.1 \mathrm{M} \mathrm{HClO}_{4}$ solution containing $1.0 \mathrm{mM} \mathrm{PbI}$ and $0.3 \mathrm{mM} \mathrm{BIII.} \mathrm{Electrodeposition} \mathrm{was} \mathrm{performed} \mathrm{at} 1.6 \mathrm{~mA}$ $\mathrm{cm}^{-2}$ for $15 \mathrm{~min}$. Electrodes were rotated at $1.000 \mathrm{rev} \mathrm{min}^{-1}$ during deposition.
alpha-Lead dioxide
A stock solution of $\mathrm{Pb} I$ was prepared by equilibrating $2.0 \mathrm{M} \mathrm{NaOH}$ with solid $\mathrm{PbO}$. Ten ml of this stock solution was diluted with $0.1 \mathrm{M} \mathrm{NaClO}_{4}$ to 100 ml for deposition. Electrodeposition was performed at a constant potential nf $0.65 \mathrm{~V}$ for $5 \mathrm{~min}$ after scanning the potential from $0.0 \mathrm{~V}$ to $0.60 \mathrm{~V}$ at $1.8 \mathrm{~V} \mathrm{~min} \mathrm{~m}^{-1}$. Electrodes were rotated at $400 \mathrm{rev} \mathrm{min}^{-1}$.

Cu-doped $\mathrm{PbO}_{2}$ The procedure for the preparation of Cu-doped $\mathrm{FbO}_{2}$ films was identical to the procedure for a$\mathrm{PbO}_{2}$ films with the exception that the stock solution contained solid Cuo, as well as Pbo.

Lead dioxide films were removed from substrates by immersion in a cleaning solution containing equal volumes of $\mathrm{H}_{2} \mathrm{O}_{2}(30 \%)$ and glacial acetic acid. Following removal of the films, the electrodes were rinsed with deionized water. 
New flima could be deposited without further treatment of the substrate.

The voltammetric behavior of these fllms was observed to be affected by deviation from the above deposition procedures.

Copper oxide electrodes A $0.10 \mathrm{M}$ stock solution of $\mathrm{Na}_{3} \mathrm{Cu}(\mathrm{CN})_{4}$ was prepared by mixing one part CuCN with three parts NaCN in water which had been previously purged with $\mathrm{N}_{2}$ to prevent oxidation of $\mathrm{Cu}^{\mathrm{I}}$ by dissolved $\mathrm{O}_{2}$. Unless stated to the contrary, electrodeposition of copper oxide films was achieved at the rotated disk electrode (RDE) using a constant anodic current of $5.0 \mathrm{~mA} \mathrm{~cm}{ }^{-2}$ applied for $20 \mathrm{~min}$ in an alkaline solution ( $\mathrm{pH} 12$ ) containing $3.0 \mathrm{mM} \mathrm{Na}{ }_{3} \mathrm{Cu}(\mathrm{CN})_{4}$. Alternately, $\mathrm{Na}_{3} \mathrm{Cu}(\mathrm{CN})_{4}$ was substituted by a $1: 4$ mixture of a CuII salt $\left(\mathrm{CuSO}_{4}\right)$ arid excess $\mathrm{NaCN}$. The concentration of $\mathrm{Na}_{3} \mathrm{Cu}(\mathrm{CN})_{4}$ was not critical for satisfactory film deposition. Use of excessively high $\mathrm{CN}^{-}$concentration (i.e., $\mathrm{CN}^{-} / \mathrm{Cu}^{I}>$ ca. $\left..8: 1\right)$ and high alkalinity $(\underline{e} . g ., 1 \mathrm{M}$ $\mathrm{NaOH}$ ) inhibited film formation. Prior to deposition, disk electrodes were rinsed in $1 \mathrm{M} \mathrm{H}_{2} \mathrm{SO}_{4}$ and deionized water. Electrode rotation speed during deposition was $100 \mathrm{rev} \mathrm{min}^{-1}$. speeds above $200 \mathrm{rev} \mathrm{min}^{-1}$ resulted in the deposition of copper oxide around the edge of the disk substrate, leaving the center of the disk bare. The diameter of the bare spot was observed to increase as rotation speed was increased. The films were not strongly adherent to the Pt/SS 
substrate. The use of CuII (ethylenediamine) 2 also produced a film (27), but without a distinct electrocatalytic advantage. Use of other Iigands ( $\mathrm{NH}_{3}, \mathrm{EDTA}$ ) was not suacessful in producing flims. Platinum interlayers were prepared by vapor deposition and electrodeposition. voltammetrio results were independent of the interlayer thickness and were virtualiy the same as for thick pt substrates. Prior to use, freshly deposited copper oxide flims were preconditioned in the electrolyte solution by potential cycles $\left(1.0 \mathrm{~V} \mathrm{~min}^{-1}\right)$ between the values $0.0 \mathrm{~V}$ and $0.75 \mathrm{~V}$ VS. SCE for $10 \mathrm{~min}$.

Minimum values of the thickness of copper oxide films were estimated from deposition current, deposition time, electrode area, the density of cuo $\left(6.3 \mathrm{~g} \mathrm{~cm}^{-3}\right)$, and the mass-to-charge ratio for the deposition $\left(0.10 \mathrm{mg} \mathrm{c}^{-1}\right)$ obtained with an electrochemical quartz crystal microbalance (EQCM). For a 20-min deposition at $5.0 \mathrm{~mA}$, the calculated thickness was $5 \mathrm{um}$. The fjlms were believed to be porous and, hence, the actual film thickness undoubtedly was greater than this minimal value. All values of thickness given here are the minimal calculated values because the extent of porosity was not known. All experiments were performed at ambient laboratory temperature (26-28 "C). 
RESULTS AND DISCUSSION

Doped $\underline{\mathrm{PbO}}_{2}$ electrodes

Voltammetric response The voltammetric response of $\mathrm{CN}^{-}$at a $\mathrm{B}^{-} \mathrm{PbO}_{2}$ electrode is shown in Figure II-1 for three values of the bulk concentration of $\mathrm{CN}^{-}\left(C_{C N}^{b}\right)$. oxygen evolution commenced at ca. $0.90 \mathrm{~V}$. It can be seen from Figure II-1 that the electrode response was virtually independent of $\mathrm{C}_{\mathrm{CN}}^{\mathrm{b}}$. The voltammetric response of $\mathrm{CH}^{-}$at a 30 mole\% $\mathrm{Bi}$-doped $\mathrm{PbO}_{2}$ electrode is shown in Figure II-2 for three values of $\mathrm{C}_{\mathrm{CN}^{-}}^{\mathrm{b}}$. The large cathodic and anodic peaks obsuved in the region $0.4 \mathrm{~V}<\mathrm{E}<0.7 \mathrm{~V}$ were concluded to result from redox processes of $\mathrm{Bi}$ ions in the $\mathrm{PbO}_{2}$ matrix. This conclusion is supported by the observation that peak heights were affected by bismuth doping levels. A slight increase in the anodic response was observed in the region of oxygen evolution ( $\mathrm{E}>0.75 \mathrm{~V}$ ) as $\mathrm{C}_{\mathrm{CN}^{-}}^{\mathrm{b}}$ increased. The voltammetric response of $\mathrm{CN}^{-}$at an a- $\mathrm{PbO}_{2}$ electrode is shown in Figure II-3 for three values of $\mathrm{C}_{\mathrm{CN}}^{\mathrm{b}}$. The anodic and cathodic charging currents were noticeably larger than for $\mathrm{B}^{-\mathrm{PbO}_{2}}$ (Figure II-1). This is likely to be the result of a more porous film. A small, anodic current was observed in the presence of cyanide, but this current was independent of rotation speed. These results indicate the occurrence of slow oxidation of cyanide controlled by electron-transfer kinetics. The voltammetric response of $\mathrm{CN}^{-}$at a $\mathrm{Cu}$-doped 


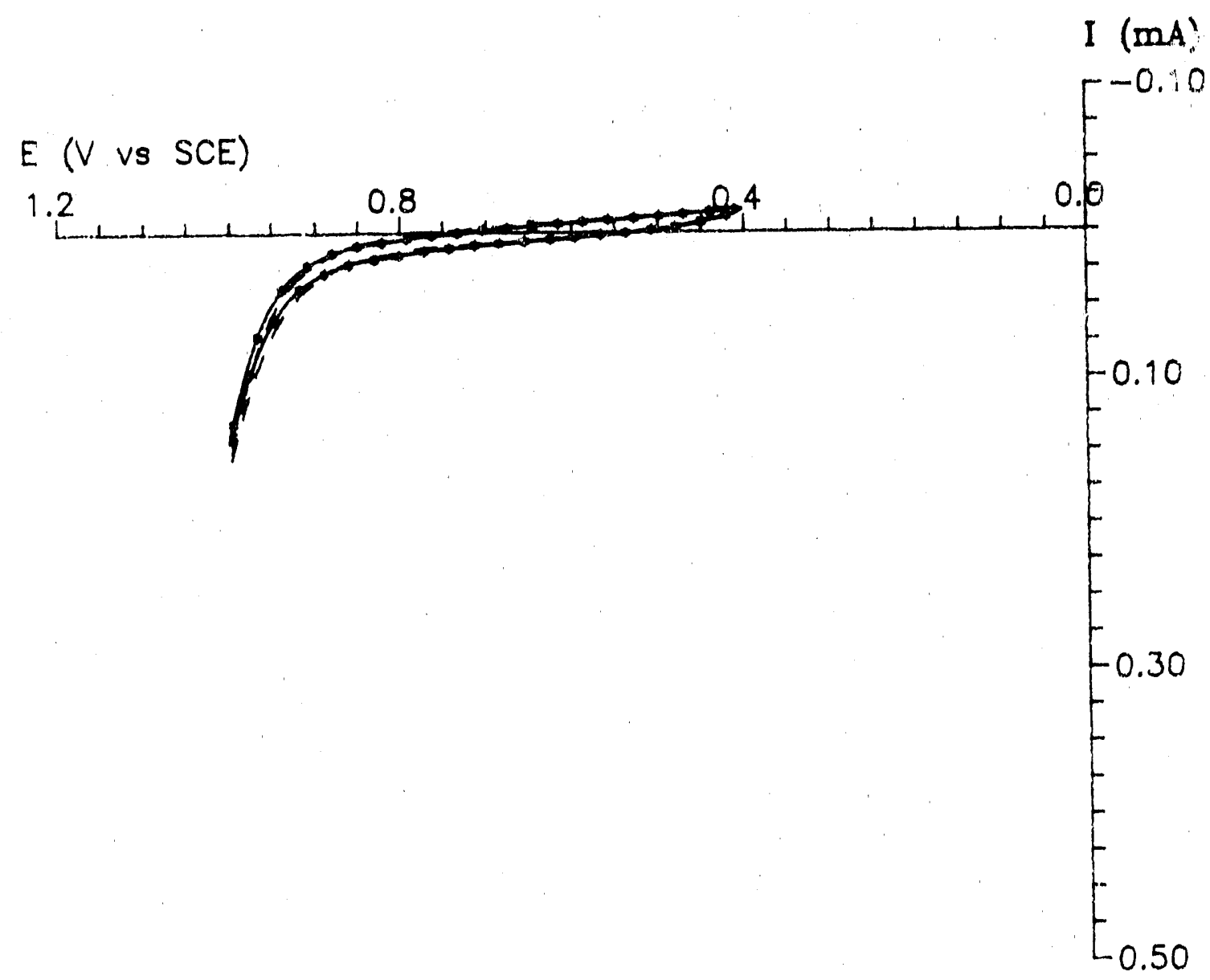

Scan rate $=3.0 \mathrm{~V} \mathrm{~min}-1$

Rotation speed $=1000$ rev min -1

$\mathrm{NaCN}$ concentration (mM): (--) 0.0 ,

$(-*-)$ 5.0.

Figure II-1. Current-potential curves for $\mathrm{CN}^{-}$at a $\mathrm{B}_{-} \mathrm{PbO}_{2}$ $\mathrm{RDE}$ in $0.1 \mathrm{M} \mathrm{NaClO} 4,10 \mathrm{mM} \mathrm{NaOH}$ 


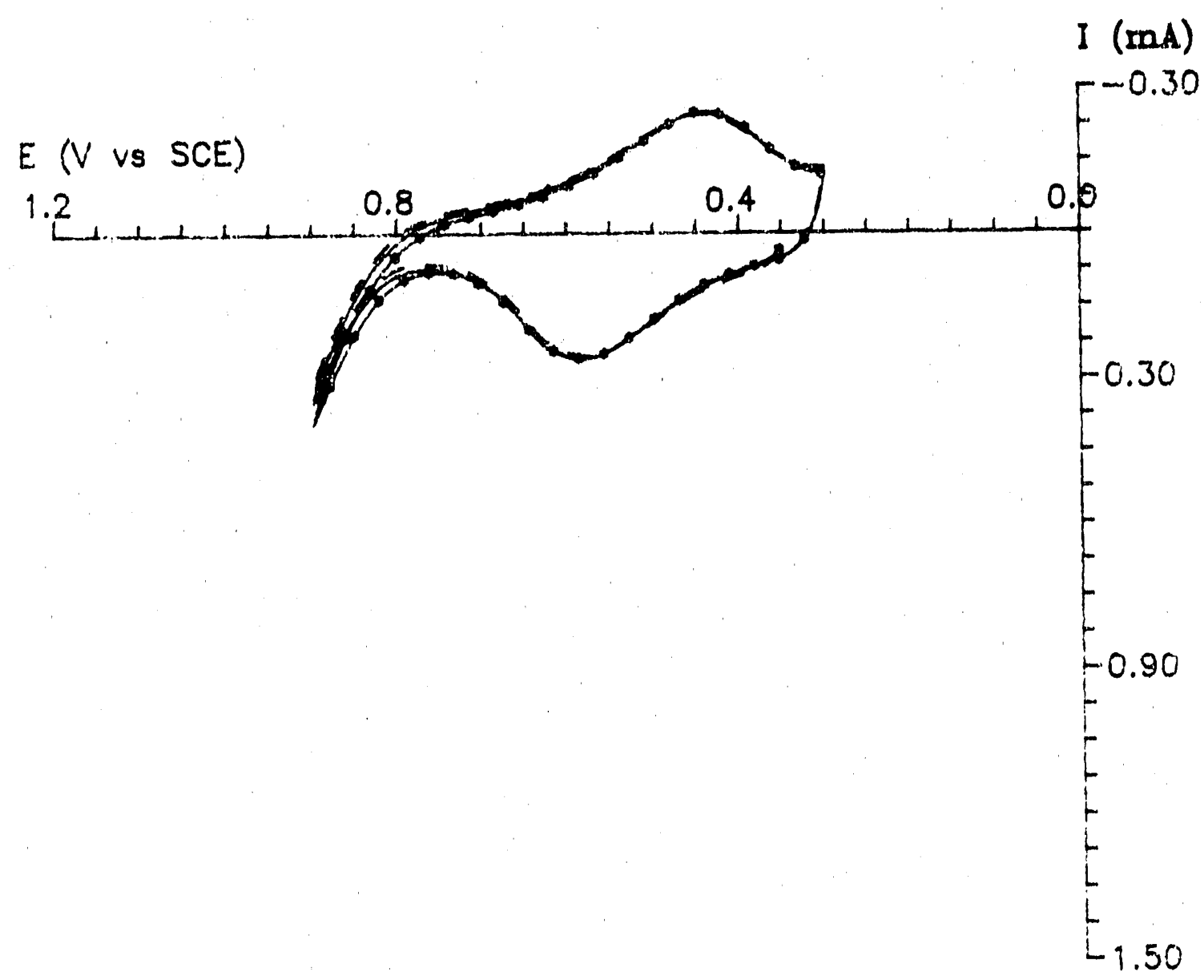

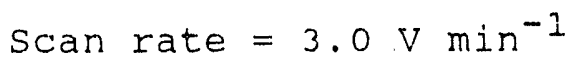

Rotation speed $=1000 \mathrm{rev} \mathrm{min}^{-1}$

$\mathrm{NaCN}$ concentration (mM): (---) 0.0 ,

$\left(-\frac{1}{(-*)} 5.0\right.$

Figure II-2. Current-potential curves for $\mathrm{CN}^{-}$at a $\mathrm{Bi}$-doped (30 mole \% $\mathrm{Bi}$ ) $\mathrm{PbO}_{2} \mathrm{RDE}$ in $0.1 \mathrm{M} \mathrm{NaClO}_{4}$, $10 \mathrm{mM} \mathrm{NaOH}$ 


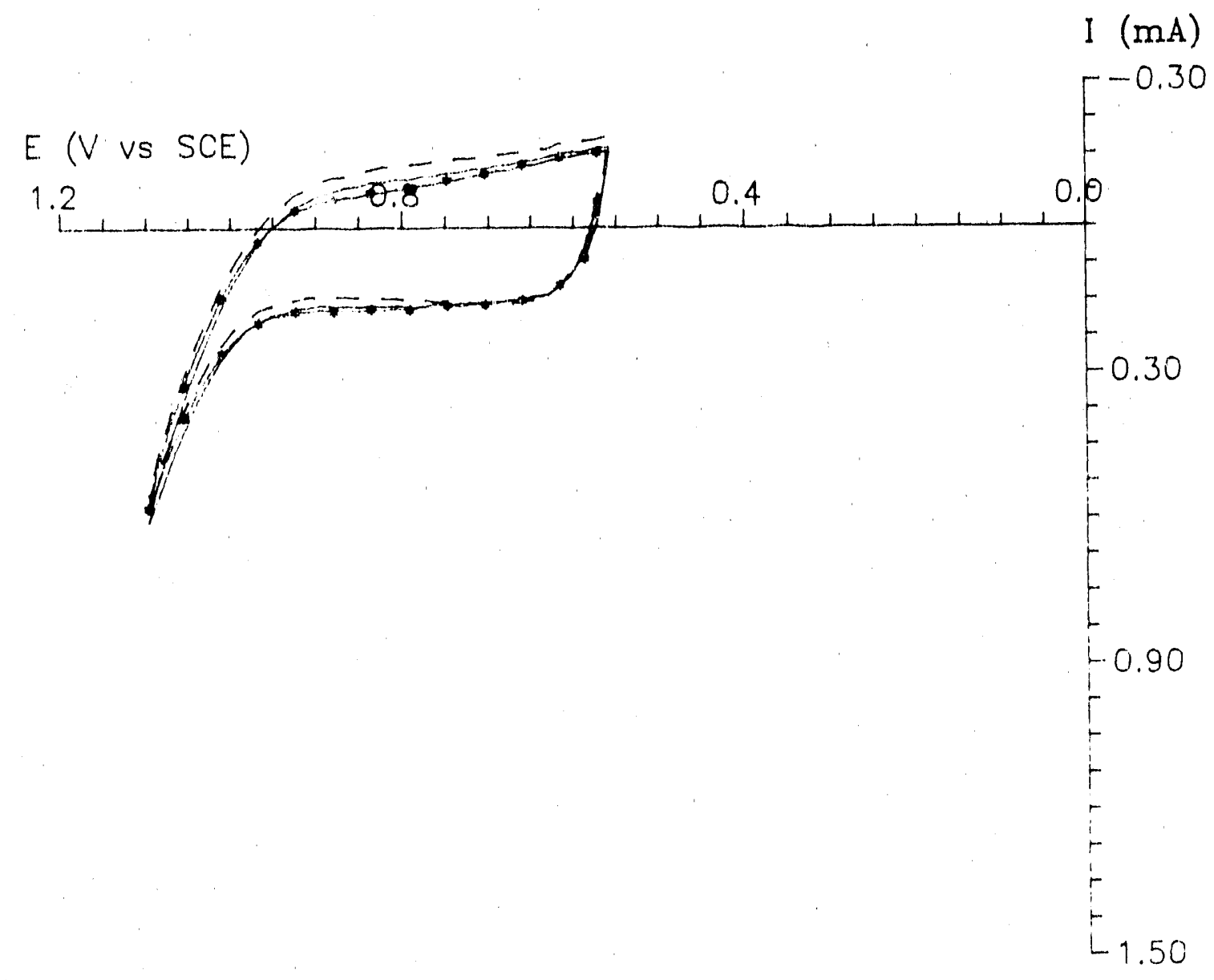

Scan rate $=3.0 \cdot \mathrm{V} \mathrm{min}^{-1}$

Rotation speed $=1000 \mathrm{rev} \mathrm{min}-1$

NaCN concentration (mM): (--) 0.0 , $(-*)$ 1.0,

Figure II-3. Current-potential curves for $\mathrm{CN}^{-}$at an $\underline{a}-\mathrm{PbO}_{2}$ RDE in $0.1 \mathrm{M} \mathrm{NaClO}_{4}, 10 \mathrm{mM} \mathrm{NaOH}$ 
$\mathrm{PbO}_{2}$ electrode is shown in Figure II-4 for three values of $\mathrm{C}_{\mathrm{CN}}^{\mathrm{b}}{ }^{-}$. A well-defined anodic wave was observed in the presence of $\mathrm{CN}^{-}$at $\mathrm{E}>0.55 \mathrm{~V}$. The plateau current was a function of $\mathrm{C}_{\mathrm{CN}}^{\mathrm{b}}$. The half-wave potential $\left(\mathrm{E}_{1 / 2}\right)$ was observed to shift more positive at higher values of $\mathrm{C}_{\mathrm{CN}^{-}}^{\mathrm{b}}$. This positive shift of $\mathrm{E}_{1 / 2}$ indicates that the electrode process is occurring under mixed control by electrontransfer and mass-transport kinetics.

Film characterization The mole ratio of $\mathrm{Cu}: \mathrm{Pb}$ in the $\mathrm{Cu}$-doped $\mathrm{PbO}_{2}$ films was determined to he $8 \times 10^{-3}$ by elemental analysis.

The X-ray diffraction data shown in.Figure II-5 were obtained from a $\mathrm{Cu}$-doped $\mathrm{PbO}_{2}$ film deposited on a stainless steel RDE. The film was identified as a- $-\mathrm{PbO}_{2}$ by comparison to a $\mathrm{PbO}_{2}$ standard (JCPDS \#11-0549). Spectral lines from the steel substrate were also identified (JCPDS \#33-0397). The extremely small quantity of $\mathrm{Cu}$ in the film resulted in only weak spectral lines in Figure II-5 which could be associated with cuo. Nevertheless, a computerized library search identified CuO (JCPDS \#5-0661) based on residual intensities in the spectium. The existence of cuo crystallites is indicated by these data rather than a mixed oxide of specific stoichiometry. The sharpness of the spectral lines suggests large crystallite size in the film. Increasing the concentration of $\mathrm{Cu} I \mathrm{I}$ in the deposition solution resulted in broadening of the spectral lines. No 


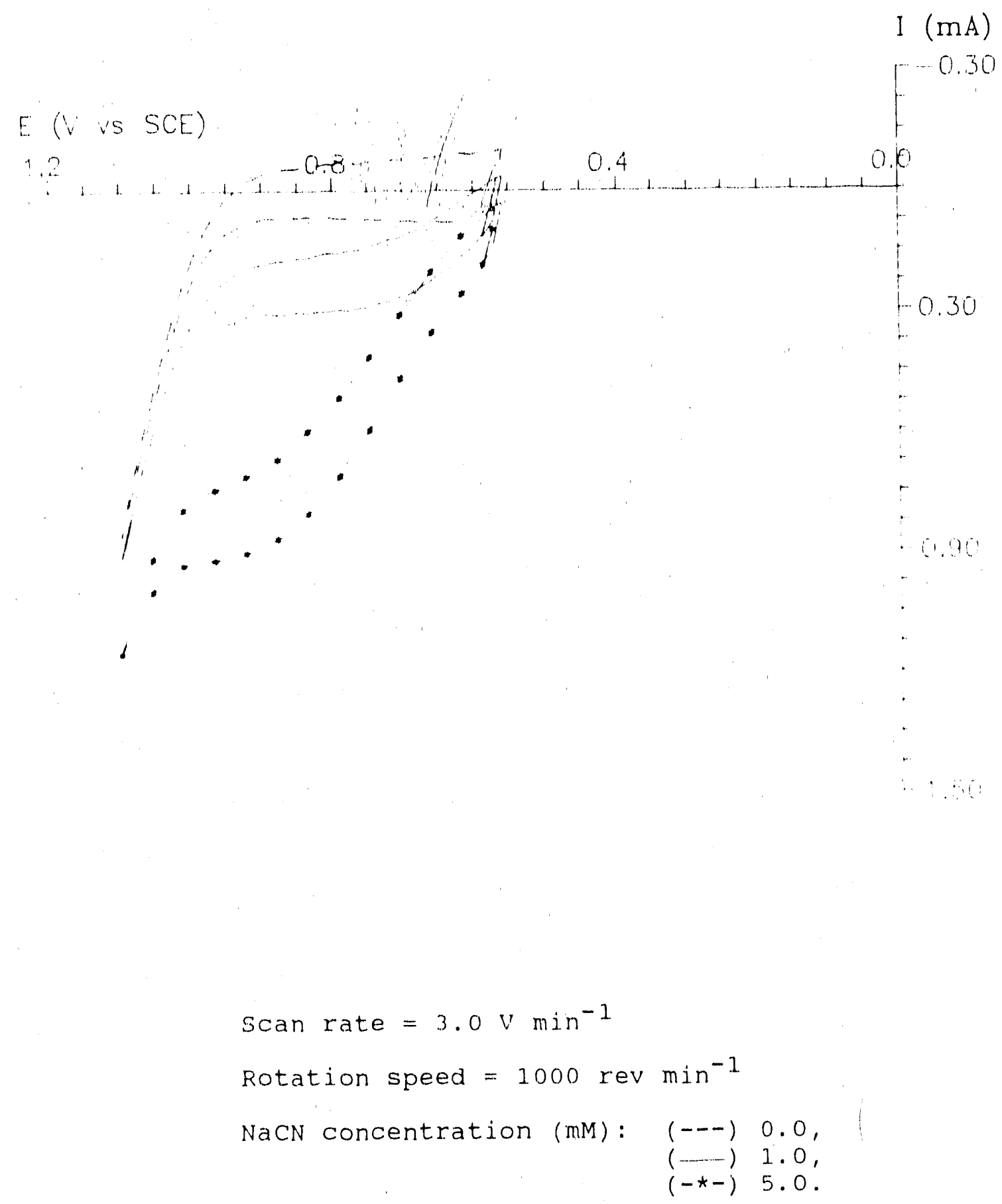

Figure II-4. Current-potential curves for $\mathrm{CN}^{-}$at a Cu-doped $\mathrm{PbO}_{2} \mathrm{RDE}$ in $0.1 \mathrm{M} \mathrm{JaClO}_{4}, 10 \mathrm{mM} \mathrm{NaOH}$ 


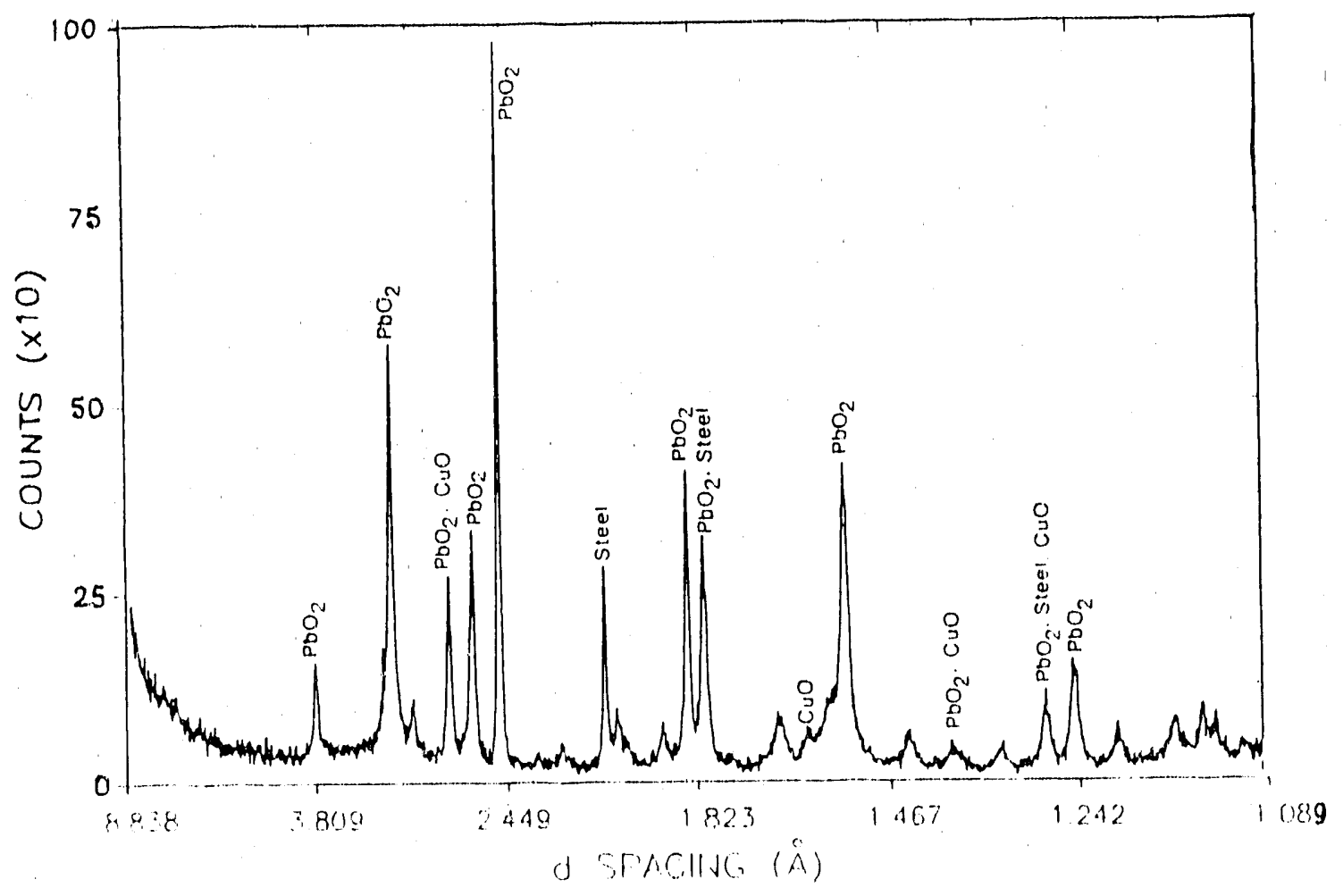

Figure II-5. X-ray diffraction spectra of $\mathrm{Cu}$-doped $\mathrm{PbO}_{2}$ 
increase in the cuo content of the film was indicated.

The response of $\mathrm{CN}^{-}$at $\mathrm{Cu}$-doped $\mathrm{PbO}_{2}$ electrodes shown in Figure II-4 was observed to decrease with subsequent scans. A likely explanation for this decrease in signal is that the cuo erystalittes are slowly dissolved by $\mathrm{CN}^{-}$. In order to obtain a response of lnnger duration for scientific study, a higher concentration of cuo in the electrode would be required. For this reason, cuo-film electrodes were prepared.

\section{Copper oxide electrodes}

\section{Film characterization A scanning electron} micrograph is shown in Figure II-6A for a copper oxide film deposited on a thin (ca. 1 um) Pt interlayer at a stainless steel (SS) substrate. The film was prepared with a constant anodic current of $4 \mathrm{~mA} \mathrm{~cm}-2$ applied for $80 \mathrm{~min}$ with a rotation speed of $200 \mathrm{rev} \mathrm{min}^{-1}$ in $0.10 \mathrm{M} \mathrm{Na}_{2} \mathrm{SO}_{4}$ containing $0.010 \mathrm{M} \mathrm{NaOH}$ and $4 \mathrm{mM} \mathrm{Na}_{3} \mathrm{Cu}(\mathrm{CN})_{4}$. This film had a finegrain appearance with cracks that, presumably, were formed during the air-drying process. Figure II-6B shows the

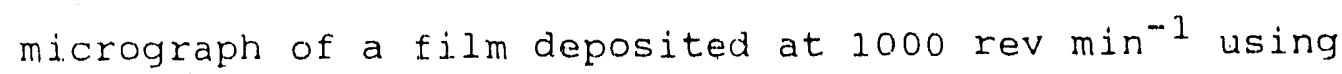
multiple cyclic potential scans $\left(5 \mathrm{~V} \mathrm{~min}^{-1}\right)$ for $20 \mathrm{~min}$ within the potential limits $0.1 \mathrm{~V}$ and $0.8 \mathrm{~V}$ in $0.10 \mathrm{M} \mathrm{Na}_{2} \mathrm{SO}_{4}$ containing $0.01 \mathrm{M} \mathrm{NaOH}$ and $2 \mathrm{mM} \mathrm{Na}_{3} \mathrm{Cu}(\mathrm{CN})_{4}$. This micrograph clearly shows a surface composed of closely packed spheres. The films appeared to be porous. 

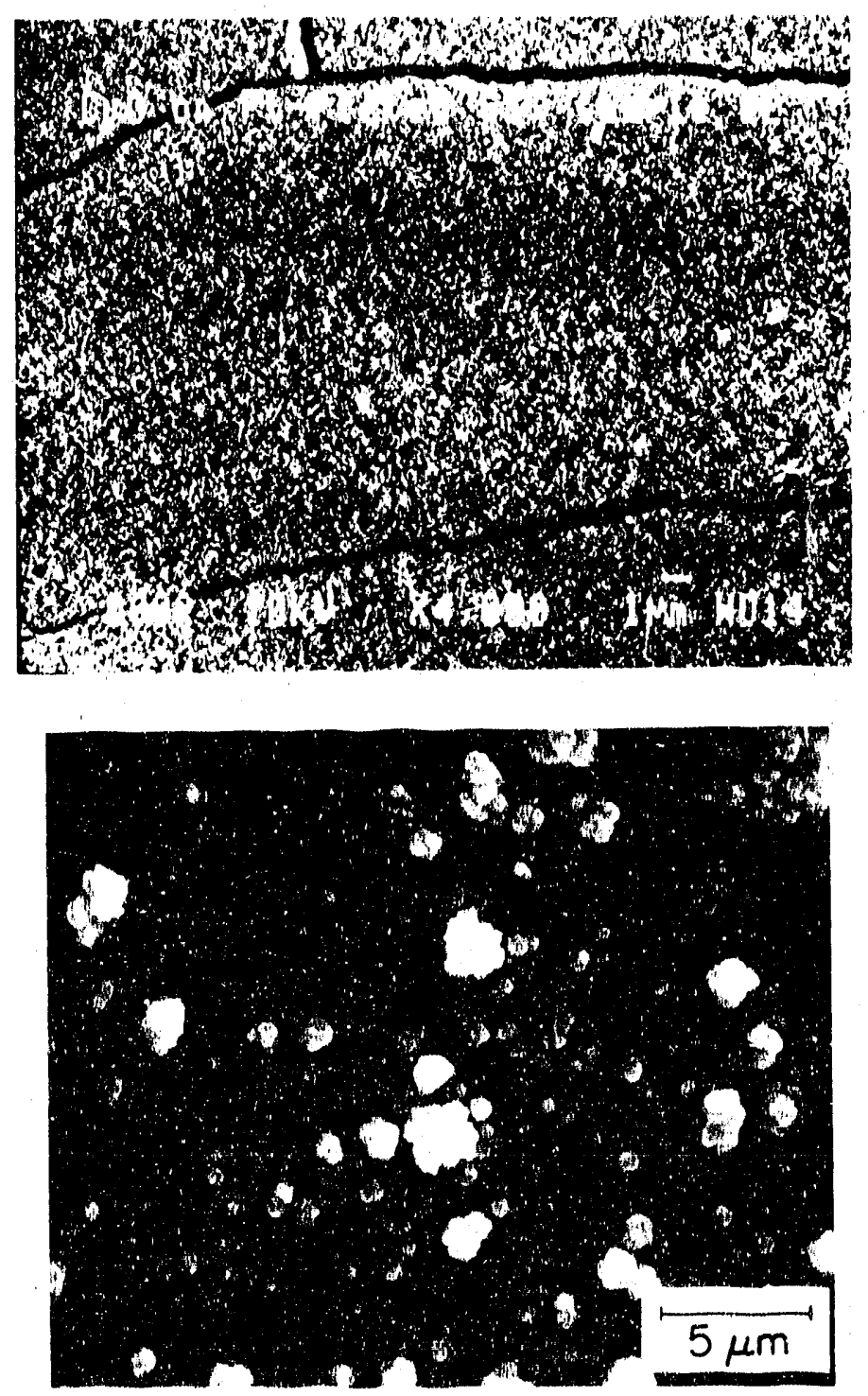

Figure II-b. Scanning electron micrographs of copper oxide films

(A) Stainless steel substrate with pt interlayer. Constant current deposition $\left(4 \mathrm{~mA} \mathrm{~cm}^{-1}\right)$ for $80 \mathrm{~min}$ from $4 \mathrm{mM} \mathrm{Na}_{3} \mathrm{Cl}_{1}(\mathrm{CN})_{4}$ at 200 rev min-1.

(B) Stainless steel substrate without Pt interlayer. Controlled potential deposition with cyclic scan $(0.1$ to $0.8 \mathrm{~V} ; 5 \mathrm{~V} \mathrm{min-1)}$ for $20 \mathrm{~min}$ from $2 \mathrm{mM}$ $\mathrm{Na}_{3} \mathrm{Cu}(\mathrm{CN})_{4}$ at 1000 rev min-1. 
The deposited films were identified as copper(II) oxide (CUO) on the basis of $x$-ray diffraction data shown in Figure II-7 and compared to a CuO standard (JCPDS \#5-0661). Because of the thinness of both the cuo film (ca. $5 \mathrm{um}$ ) and Pt interlayer (ca. $1 \mathrm{um}$ ), the diffraction pattern was dominated by strong reflections from the ss substrate (Fe, $\mathrm{Cr}, \mathrm{Ni}$ ). Peaks $\mathrm{A}-\mathrm{C}$ were not present in the diffraction pattern of the substrate with the interlayer and were, therefore, concluded to be representative of the copper oxide film. peaks $A$ and $B$ correspond to the $(-1,1,1)$ plane and the $(1,1,1)$ plane of Cuo, respectively. Peak $C$ was tentatively concluded to correspond to the $(-1,1,3)$ plane of cuo.

\section{Voltammetric response of cyanide The voltammetric} response of $\mathrm{CN}^{-}$at a thin $(5 \mathrm{um})$ cuo-film electrode is shown in Figure II-8 for four values of the bulk concentration of $\mathrm{CN}^{-}\left(\mathrm{C}_{\mathrm{CN}}^{\mathrm{b}}\right)$. oxidation of $\mathrm{CN}^{-}$occurred for $\mathrm{E}>\mathrm{Ca} \cdot 0.25 \mathrm{~V}$ with a half-wave potential $\left(E_{1 / 2}\right)$ of $0.35 \mathrm{~V}$ for $1.0 \mathrm{mM} \mathrm{CN}^{-}$ and a current plateau in the region $0.45 \mathrm{~V}$ to $0.65 \mathrm{~V}$. The $E_{1 / 2}$ value increased slightly as $\mathrm{C}_{\mathrm{CN}}^{\mathrm{b}}$ - was increased (ca. + 30 $\mathrm{mV} \mathrm{mM}^{-1}$ ). A current maximum was obtained near the onset of the current plateau during the positive scan for $1.0 \mathrm{mM} \mathrm{NaCN}$ (Fig. II-8, Curve b), but decreased in prominence at higher concentrations. The current at $0.6 \mathrm{~V}$ was a linear function of $C_{C, j}^{b}$ to ca. $5 \mathrm{mM}$; plots are shown in Figure II-9 for $\mathrm{C}_{\mathrm{CN}^{-}}^{\mathrm{b}}$ to $1 \mathrm{mM}$ at three rotation speeds. 


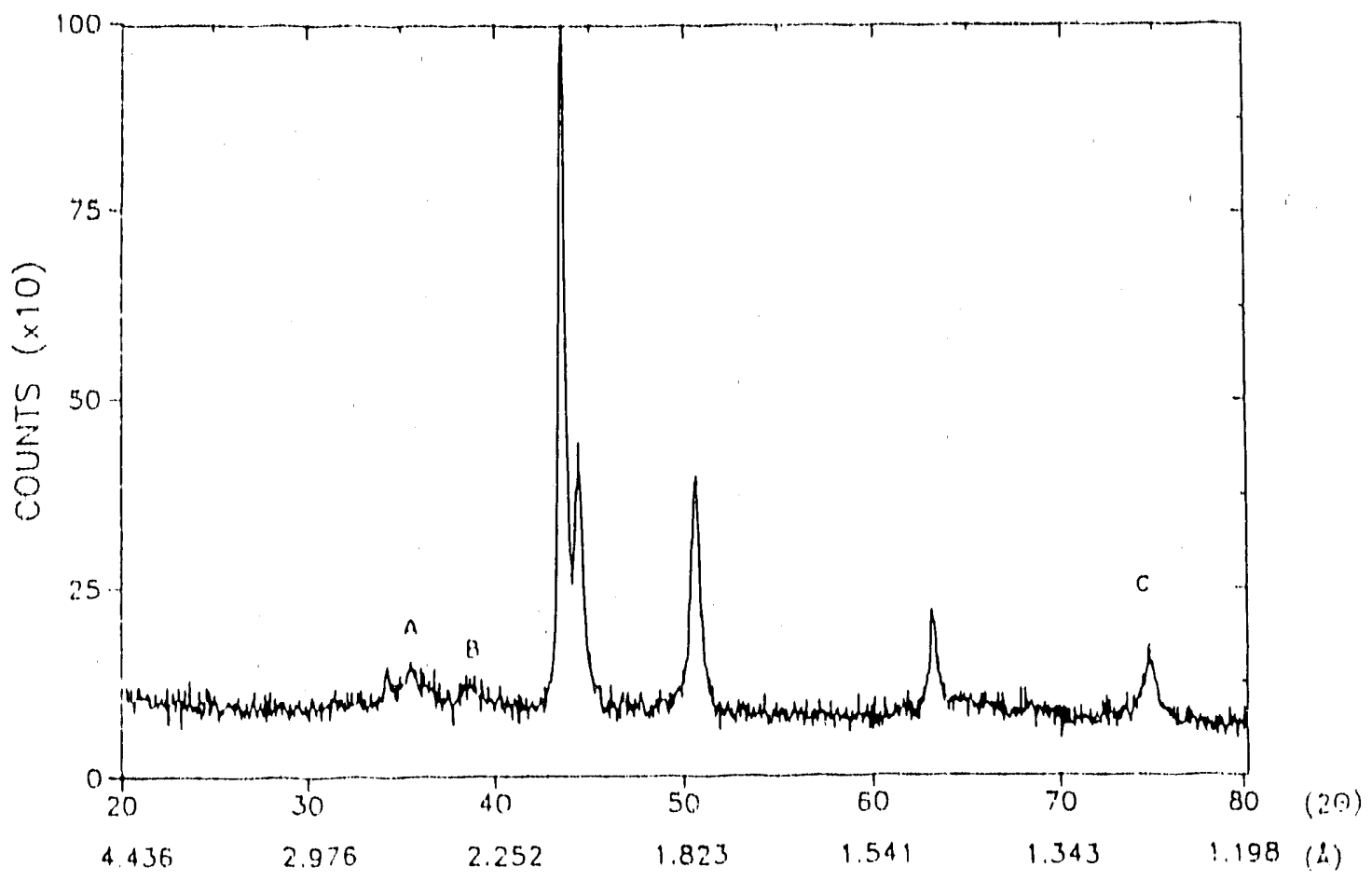

Figure II-7. X-ray diffraction spectra of copper oxide films from Figure II- $6 \mathrm{~A}$
Diffraction
peaks $(\AA)$ :
(A) 2.51 ,
(B) 2.32 ,
(C) 1.47 . 


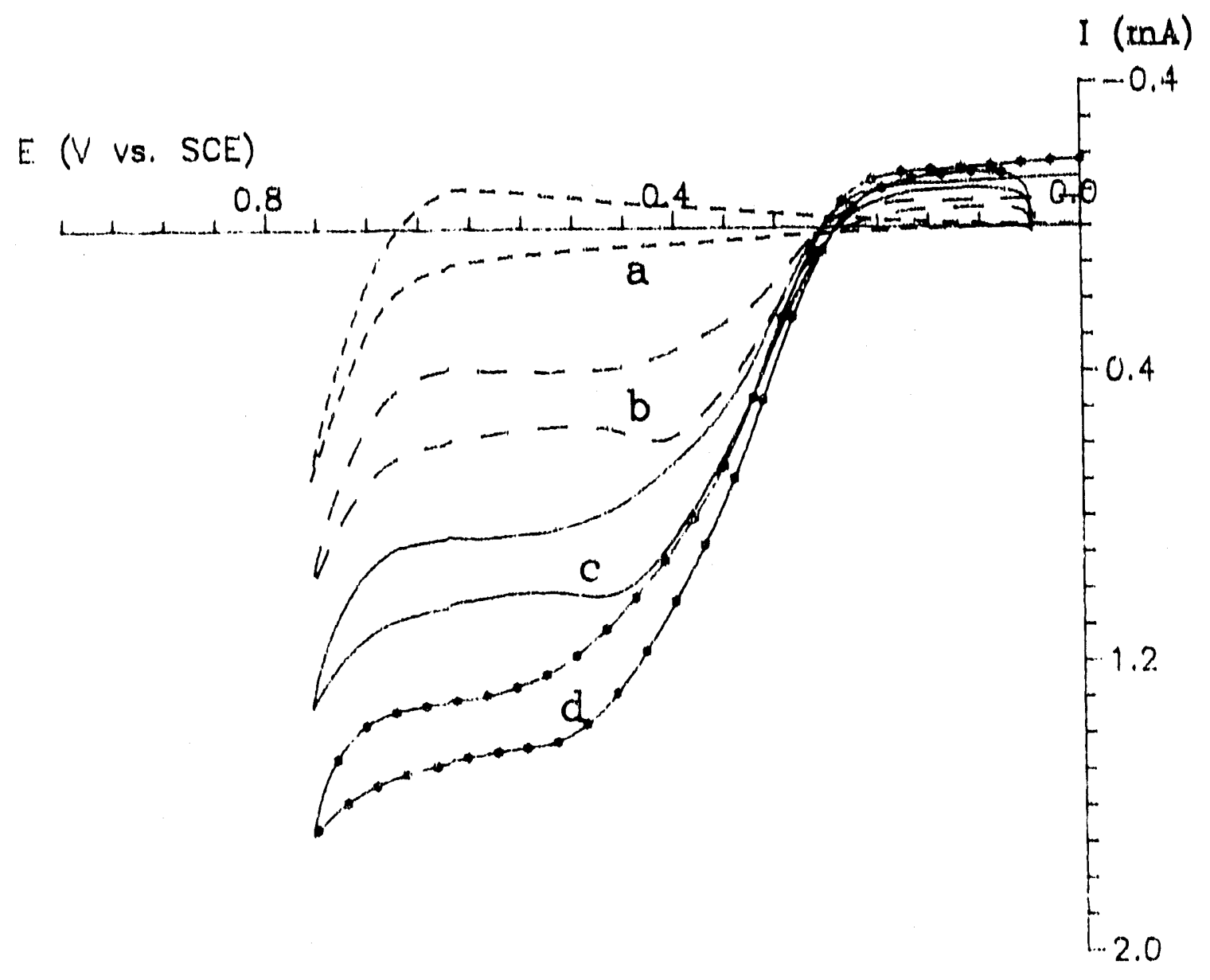

$\begin{aligned} \text { Conditions: } & 1600 \mathrm{rev} \mathrm{min}^{-1} \text { rotation speed, } \\ & 1.0 \mathrm{~V} \text { min }\end{aligned}$ $\mathrm{C}_{\mathrm{NaCN}}^{\mathrm{b}}(\mathrm{mM}):$ (a) $0,(\mathrm{~b}) 1.0$, (c) 2.0, (d) 3.0 .

Figure II-8. Voltammetric response of $\mathrm{NaCN}$ at a rotated, cuo-film, disk electrode as a function of concentration in $0.10 \mathrm{M} \mathrm{Na}_{2} \mathrm{SO}_{4}$ with $0.010 \mathrm{M}$ $\mathrm{NaOH}$ 


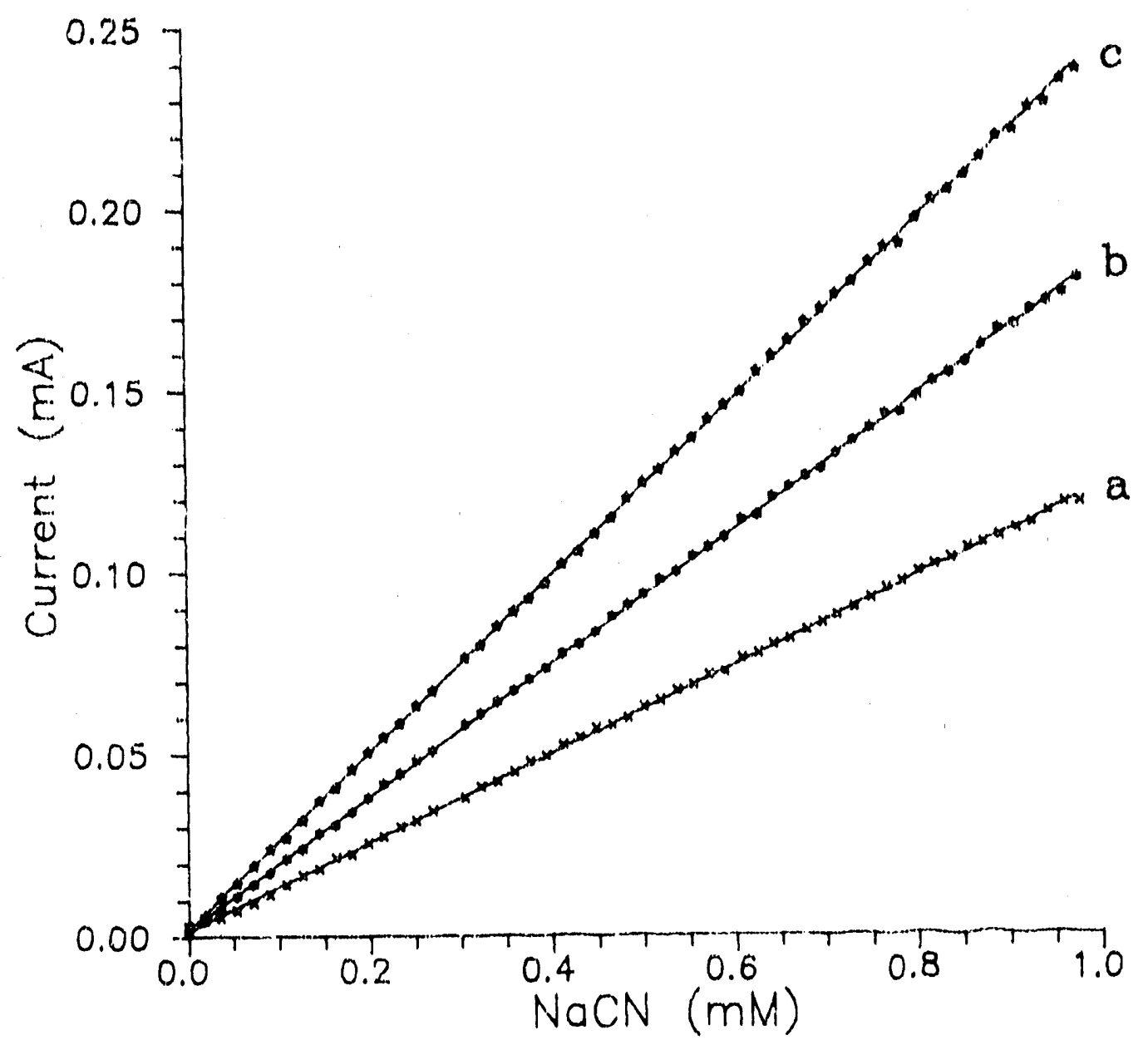

Conditions: +0.60 V Vs. SCE applied potential. Rotation speed (rev $\mathrm{min}^{-1}$ ): (a) 100 , (b) 225 , (c) 400 .

Figure II-9. Amperometric response for $\mathrm{NaCN}$ at a rotated, cuo-film, disk electrode as a function of concentration in $0.10 \mathrm{M} \mathrm{Na}_{2} \mathrm{SO}_{4}$ with $0.010 \mathrm{M}$ $\mathrm{NaOH}$ 
A soluble, electroactive product of the disk reaction at $E_{\text {disk }}>$ ca. $0.65 \mathrm{~V}$ was detected using the Pt-Pt RRDE with a cuo-plated disk. The voltammetric response of the product detected at the ring was identical to that of dissolved $\mathrm{O}_{2}$.

A study was made of the origin of the small anodic current maximum at ca. $0.35 \mathrm{~V}$ (see Fig. II-8, Curve b). The peak current $\left(i_{p}\right)$, measured with respect to the plateau current, increased for larger values of potential scan rate $(\varnothing)$. This is indicative of a surface-controlled faradaic process tentatively concluded to be the oxidation of $\mathrm{CN}^{-}$ that was weakly adsorbed on the cuo surface. For increasing values of $\mathrm{C}_{\mathrm{CN}}^{b}$ above $1.0 \mathrm{mM}$, the maximum was not evident because the $E_{1 / 2}$ of the wave was shifted to more positive values with the result that the current maximum from oxidation of adsorbed $\mathrm{CN}^{-}$contributed to the rising portion of the wave (Fig. II-8, Curve d). Increased rotation speeds above 1600 rev $\min ^{-1}$ also caused the $\mathrm{E}_{1 / 2}$ to shift slightly more positive and the current maximum was not evident. The positive shift of $\mathrm{E}_{1 / 2}$ for increased values of $\mathrm{C}_{\mathrm{CN}^{-}}^{\mathrm{b}}$ and rotation speed is diagnostic evidence for a faradaic process under mixed control by electron-transfer and mass-transport kinetics.

Reaction stoichiometry Exhaustive electrolyses were performed in a stirred solution of $0.10 \mathrm{M} \mathrm{Na}_{2} \mathrm{SO}_{4}$ containing $0.010 \mathrm{M} \mathrm{NaOH}(\mathrm{pH} 12)$ for a constant potential of $0.60 \mathrm{~V}$ at a cuo-film deposited on a pt-gauze electrode. The 
concentration of $\mathrm{CN}^{-}$was $2.5 \mathrm{mM}$ and electrolyses were completed in ca. $15 \mathrm{~min}$. The background charge determined in the absence of $\mathrm{CN}^{-}$was subtracted from the total current in the presence of $\mathrm{CN}^{-}$to give the net charge for $\mathrm{CN}^{-}$ oxidation. From data for nine consecutive electrolyses, the value of $\underline{n}$ for the reaction was calculated to be $1.9 \pm 0.1 \mathrm{eq}$ $\operatorname{mol}^{-1}$ (90\% confidence interval). This value is consistent with production of $\mathrm{CNO}^{-}$according to Equation 10.

$$
\mathrm{CN}^{-}+2 \mathrm{OH}^{-} \longrightarrow \mathrm{CNO}^{-}+2 \mathrm{H}_{2} \mathrm{O}+2 \mathrm{e}
$$

Residual response The voltammetric curves in Figure II-8 revealed a rather large hysteresis between the anodic and cathodic currents obtained for the positive and negative scans, respectively, with a maximum hysteresis at ca. $0.6 \mathrm{~V}$. since the cuo films were suspected as being very porous, double-layer charging was expected to contribute to the hysteresis. Charging currents are proportional to the true surface area, rather than the geometric area, and it was expected that the hysteresis would be significantly larger for a thicker cuo-film electrode.

The residual voltammetric response is shown in Figure II-IOA for two films having significantly different thicknesses. The film thicknesses were estimated on the basis of the applied current $\left(5.0 \mathrm{~mA} \mathrm{~cm}^{-2}\right)$ and deposition times of $5 \mathrm{~min}$ and $20 \mathrm{~min}$ to be ca. 1.2 um (Curve a) and 5 um (Curve b), respectively. As predicted, hysteresis in the 

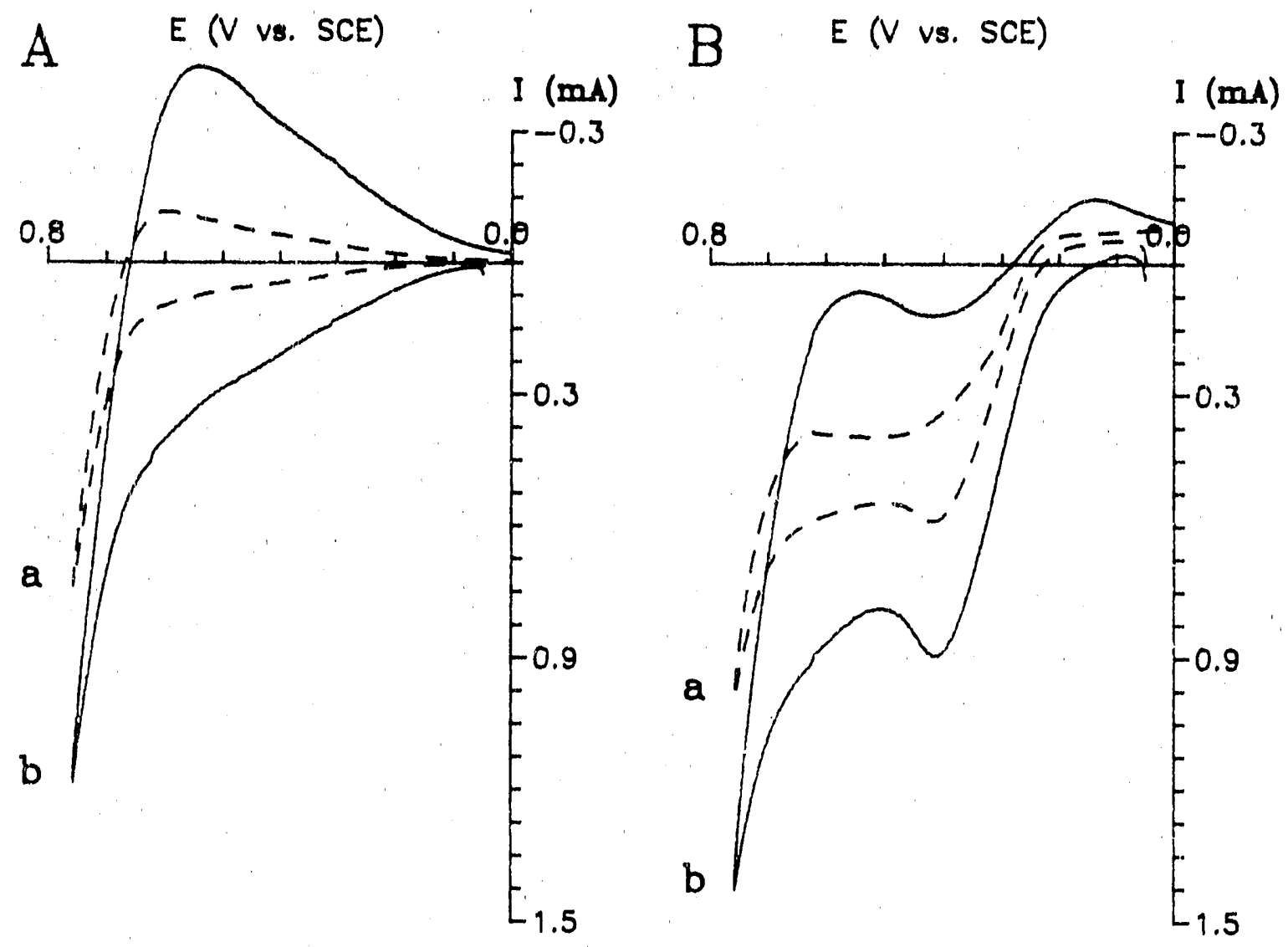

$$
\begin{aligned}
\text { Conditions: } & 1600 \mathrm{rev} \mathrm{min}^{-1} \text { rotation speed, } \\
& 1.0 \mathrm{~V} \mathrm{~min}^{-1} \text { scan rate. }
\end{aligned}
$$$$
\text { Minimum estimated }
$$$$
\text { film thickness (um): (a) } 1.2 \text {, (b) } 5 \text {. }
$$

Figure II-10. Voltametric response of a rotated, cuo-film, disk electrode as a function of film thickness in $0.10 \mathrm{M} \mathrm{Na}_{2} \mathrm{SO}_{4}$ with $0.010 \mathrm{M} \mathrm{NaOH}$
(A) Residual response.
(B) Response for $1.0 \mathrm{mM} \mathrm{NaCN}$. 
residual curve was significantly greater for the thicker film (Curve $\underline{b}$ ). The effect of cuo-film thickness on the $i-E$ response of $\mathrm{CN}^{-}$is illustrated in Figure II-IOB for the two films that produced the data in Figure II-10A. Again, hysteresis was greatest for the thickest film (Curve b) .

Figure II-11A contains residual i-E curves obtained as a function of variations in the positive scan limit. As the limit increased from ca. $0.6 \mathrm{~V}$ to $0.8 \mathrm{~V}$, the cathodic charge increased dramatically for the subsequent negative scan. We attribute the increase in cathodic charge to the reduction of a product of an anodic reaction occurring at $\mathrm{E}>\underline{\mathrm{ca}} .0 .5 \mathrm{~V}$. We tentatively conclude the oxidation product to be a CuIII-oxide, perhaps $\mathrm{CuO}(\mathrm{OH})$. The anodic evolution of $\mathrm{O}_{2}$ was concluded above to occur for $E>c a .0 .7 \mathrm{~V}$ and the increase of positive scan limit from $0.8 \mathrm{~V}$ to $1.0 \mathrm{~V}$ produced a relatively small increase in the subsequent cathodic charge (Fig. II-IIA). From the cathodic charge for a scan limit of $0.8 \mathrm{~V}$, the quantity of $\mathrm{CuO}(\mathrm{OH})$ formed was estimated to be ca. 60 umol. This corresponds to an anodic conversion of less than $1 \%$ of the original cuo film. Considering the probability that double-layer charging contributes to the total charge observed, the percent of the film converted is even less than this estimate. We suspect that only the surface layer of cuo contacting the electrolyte solution is converted to $\mathrm{Cuo}(\mathrm{OH})$ during the positive scan.

Figure II-IIB contains residual $i-E$ curves as a 

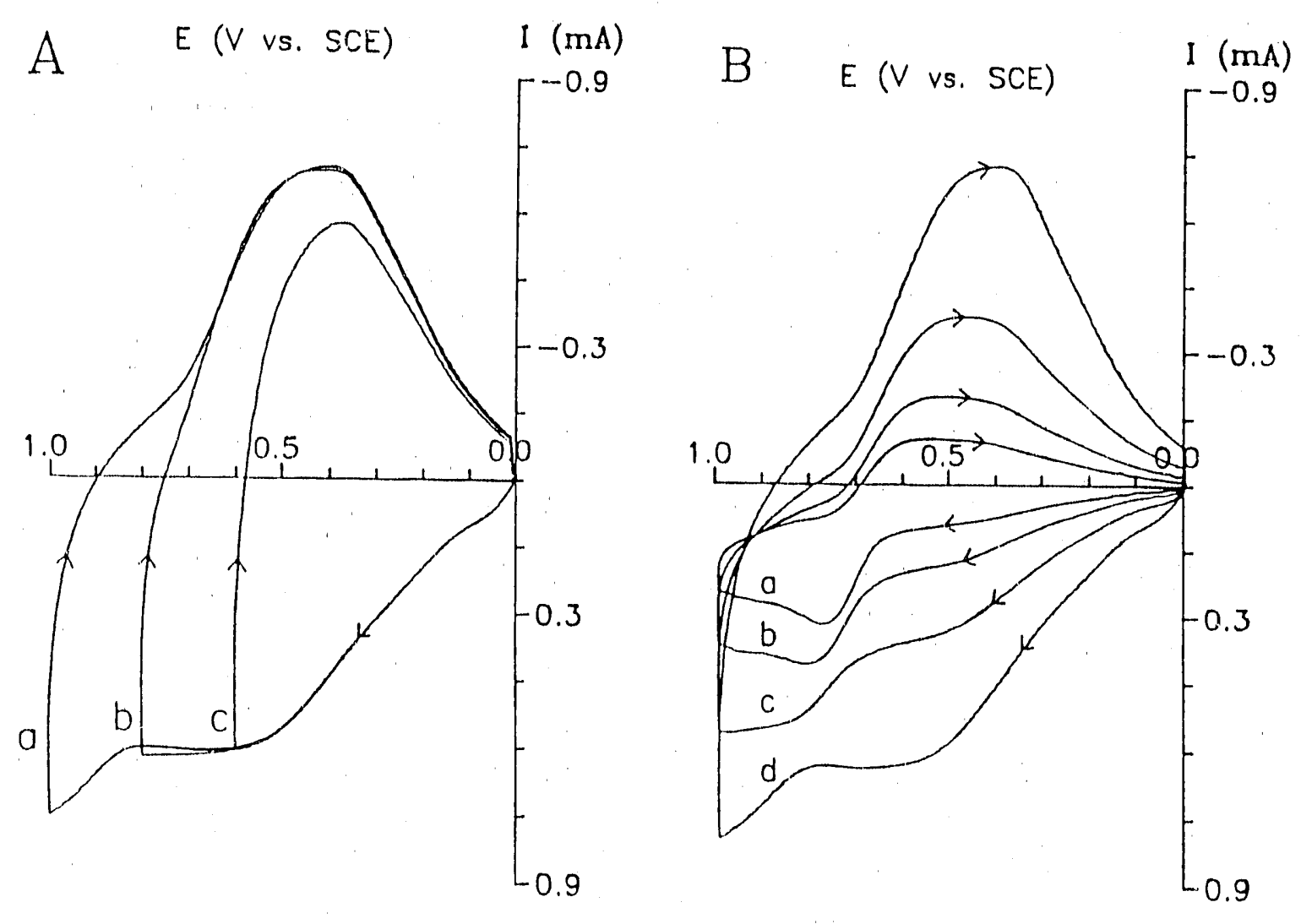

Conditions: 1600 rev $\mathrm{min}^{-1}$ rotation speed.

Figure II-11. Residual voltammetric response of a rotated, CuO-film, disk electrode in $0.10 \mathrm{M} \mathrm{Na}_{2} \mathrm{SO}_{4}$
with $0.010 \mathrm{M} \mathrm{NaOH}$

(A) Variation of positive scan limit. Scan rate $\left(\mathrm{V} \mathrm{min}^{-1}\right): 4.0$.

Scan limit ( $V$ VS. SCE): (a) 0.60 ,

(b) 0.80 ,

(c) 1.00 .

(B) Variation of potential scan rate. Scan rate $\left(\mathrm{V} \mathrm{min}^{-1}\right):$ (a) 0.5, (b) 1.0 ,

(c) 2.0, (d) 4.0 . 
function of scan rate $(\varnothing)$ for a constant positive scan limit. The potential for the cathodic peak current shifted slightly to more negative values as $\varnothing$ was increased. This is evidence of a slow faradaic process and is consistent with the estimation that a product of the anodic reaction during the positive scan was subsequently reduced during the subsequent negative scan.

pH effects The $i-E$ curves show'n in Figure II-12 were obtained with identically prepared cuo films (5 um) as a function of $\mathrm{pH}$. The ionic strength of the test solutions was maintained at $1.0 \mathrm{M}$ using $\mathrm{Na}_{2} \mathrm{SO}_{4}$. Because of the similarity of film thickness used to obtain the curves, the differences observed in the $\mathrm{i}-\mathrm{E}$ curvres are attributed to $\mathrm{pH}$ effects. The $E_{1 / 2}$ value of the $\mathrm{CN}^{-}$wave slifted to more

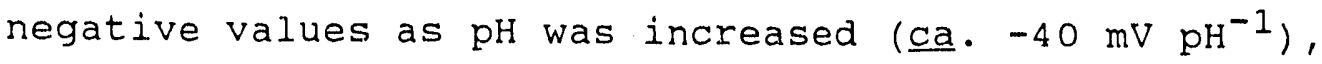
indicating involvement of $\mathrm{OH}^{-}$in the reaction mechanism. The apparent reversibility of the anodic waves was a maximum at $\mathrm{pH} 12$, as estimated from the slope of the $i-E$ curve at $E_{1 / 2}$. The anodic current plateau also had a maximum value at $\mathrm{pH} 12$.

The current maximum at ca. $0.35 \mathrm{~V}$ on the positive scan was observed only at pH 12 (Fig. II-12, Curve ) ; however, this maximum was not observed for a $0.1 \mathrm{M}$ phosphate buffer at $\mathrm{pH}$ 12. It is apparent that the extent of adsorption of $\mathrm{CN}^{-}$, believed to be the source of the maximum, is a sensitive function of $\mathrm{pH}$ as well as other anionic components 


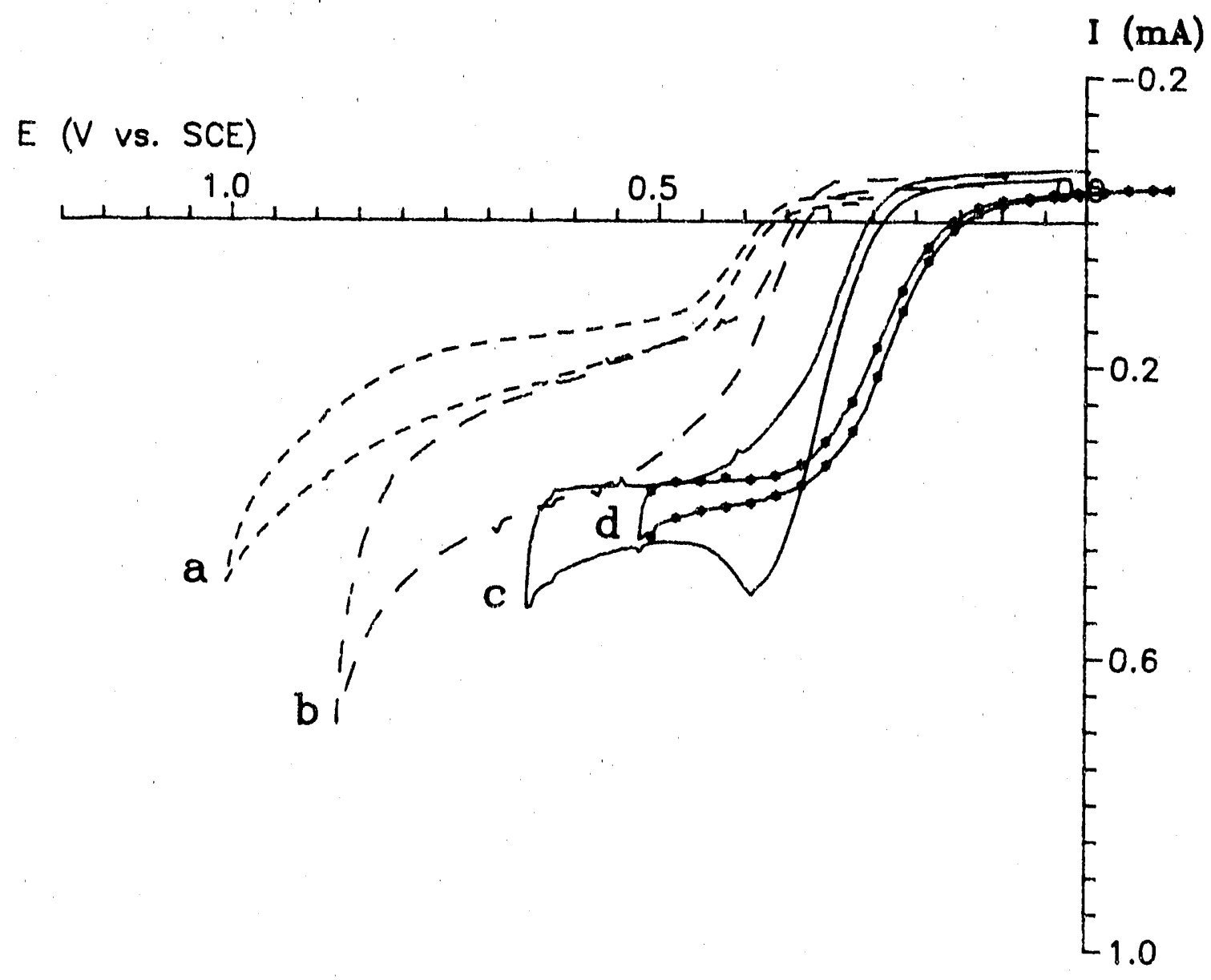

Conditions: $\begin{aligned} & 1600 \mathrm{rev} \mathrm{min}^{-1} \text { rotation speed, } \\ & 1.0 \mathrm{Vin}\end{aligned}$

Electrolytes: (a) $0.10 \mathrm{M}$ borate with $0.30 \mathrm{M}$ $\mathrm{Na}_{2} \mathrm{SO}_{4}(\mathrm{pH} 8.0)$;

(b) $0.10 \mathrm{M}$ borate with $0.30 \mathrm{M}$ $\mathrm{Na}_{2} \mathrm{SO}_{4} \quad(\mathrm{pH}$ 10.0);

(c) $0.33 \mathrm{M} \mathrm{Na}_{2} \mathrm{SO}_{4}$ with $0.010 \mathrm{M}$ $\mathrm{NaOH}(\mathrm{pH} 12.0)$;

(d) $1.0 \mathrm{M} \mathrm{NaOH}(\mathrm{pH} \mathrm{14).}$

Figure II-12. Effect of $\mathrm{pH}$ on the voltammetric response for $1.0 \mathrm{mM} \mathrm{NaCN}$ at a rotated, Cuo-film electrode at constant ionic strength 
in the solution which can compete for adsorption sites. The hysteresis between the i-E curves for the positive and negative scans was at a maximum for $\mathrm{pH}$ 10, indicating a strong $\mathrm{pH}$ effect on double-layer properties which contributed to the hysteresis. The addition of phosphate also decreased the hysteresis.

Heterogeneous rate constant The apparent heterogeneous rate constant $\left(k_{a p p}\right)$ for the anodic reaction of $\mathrm{CN}^{-}$was estimated on the basis of so-called KouteckyLevich plots (28) of $1 / i$ vs. $-1 / 2$, as illustrated in Figure II-13 for data obtained at constant potential values of 0.35 $\mathrm{V}$ (Curve a ) and $0.60 \mathrm{~V}$ (Curve $\underline{b}$ ). The slope and intercept of these plots are predicted by Equations 11 and 12 , where $F, A$, and $D$ have their usual electrochemical significance, $\nu$ is kinematic viscosity of the solution $\left(0.010 \mathrm{~cm}^{2} \mathrm{sec}^{-1}\right)$, and $\underline{n}=2$ eq $\mathrm{mol}^{-1}$.

$$
\begin{aligned}
\text { slope } & =\left(0.62 \underline{\mathrm{nFAD}} \mathrm{F}^{2 / 3} \nu^{-1 / 6} \mathrm{C}^{\mathrm{b}}\right)^{-1} \\
\text { intercept } & =\left(\underline{\mathrm{n} F A k} \mathrm{app}^{\mathrm{b}}\right)^{-1}
\end{aligned}
$$

The potential-independent rate constant $\left(k_{0}\right)$ was assumed to be related to $k_{a p p}$ by Equation 13, where $\underline{a}_{a}$ is the asymmetry constant for the 2 -electron process. The $\underline{a}_{a}$ term was eliminated by use of $k_{a p p}$ values measured at the two potentials $(0.35 \mathrm{~V}$ and $0.60 \mathrm{~V})$. The $k_{0}$ values are given in Table II- 1 for $1.0 \mathrm{mM} \mathrm{NaCN}$ vs. $\mathrm{pH}$.

$$
k_{\text {app }}=k_{0} \exp \left\{\left(a_{a} / 0.059\right)\left(E-E^{\circ}{ }^{\prime}\right)\right\}
$$




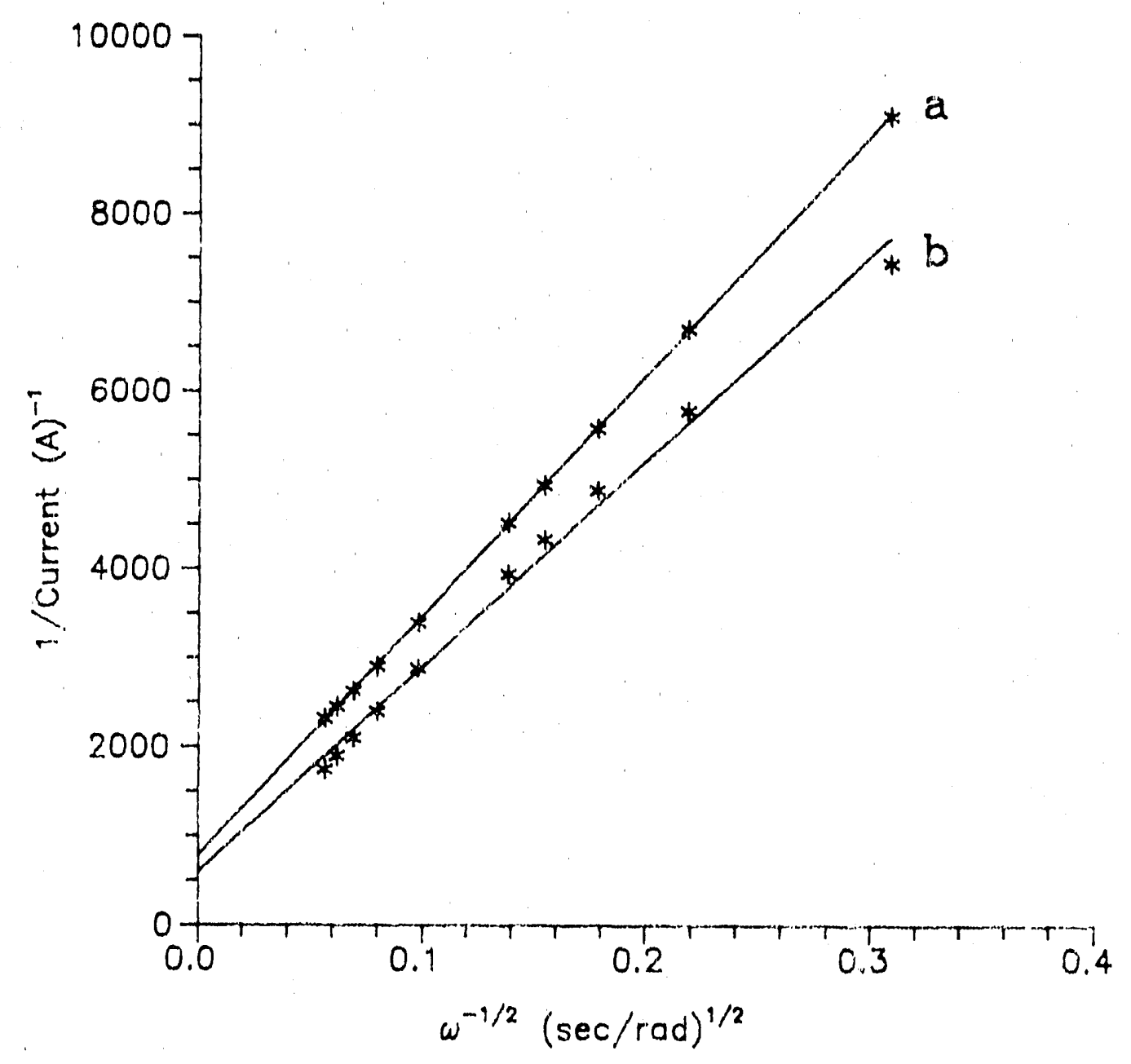

Potential (V VSi. SCE): (a) +0.35, (b) to.60.

Figure II-13. Koutecky-Levich plot for $1.0 \mathrm{mM} \mathrm{NaCN}$ at a rotated, Cuo-fj.lm, disk electrode in $0.10 \mathrm{M}$ $\mathrm{Na}_{2} \mathrm{SO}_{4}$ with $0.010 \mathrm{M} \mathrm{NaOH}$ 
The maximum value of $\mathrm{k}_{0}, 8.0 \times 10^{-3} \mathrm{~cm} \mathrm{~s}^{-1}$, was obtained at $\mathrm{pH} 12$ with $\mathrm{Na}_{2} \mathrm{SO}_{4}$ present to maintain constant ionic strength. This value for $\mathrm{CN}^{-}$oxidation at the catalytic cuo electrode is ca. $4 \times 10^{5}$ times larger than the value of $2.1 \times 10^{-8}$ reported by sawyer and Day (29) for a Pt electrode. The value $\mathrm{f} f \mathrm{k}_{\mathrm{o}}$ at $\mathrm{pH} 12$ was determined to be depressed significantly by addition of phosphate (see Table II-1). This is concluded to result from changes in double-layer structure resulting from adsorption of phosphate anions and competition by phosphate for adsorption sites needed by $\mathrm{CN}^{-}$ in the catalytic oxidation. The presence of carbonate also slightly decreased $k_{0}$ (see Table II-1).

The large value of $k_{0}$ obtained for $\mathrm{pH} 12$ corresponds nearly to a reaction rate controlled by convectivediffusional mass transport. Accordingly, a Levich plot of $i_{l i m}$ vs. $1 / 2$ was nearly linear for small values of rotation speed. The value of $D$ was calculated from the slope to be $1.4 \times 10^{-5} \mathrm{~cm}^{2} \mathrm{sec}^{-1}$.

\section{Film stability The cuo-film electrodes (ca. $5 \mathrm{um}$ )}

were observed to dissolve slowly over a period of ca. $30 \mathrm{~min}$ during voltammetric experiments in the presence of high concentrations of $\mathrm{CN}^{-}$(i.e., > $1 \mathrm{mM}$ ). The rate of dissolution increased as values of $\mathrm{C}_{\mathrm{CN}^{-}}^{\mathrm{b}}$ and rotation speed were increased. The dissolution is suspected to occur by Equations 14 and 15 . 
Table II-1. Kinetic data for oxidation of $1.0 \mathrm{mM} \mathrm{NaCN}$ at the rotated, Cuo-film, disk electrode

\begin{tabular}{cll}
\hline $\mathrm{pH} a$ & electrolyte & $\mathrm{k}_{0}\left(\mathrm{~cm} \mathrm{~s}^{-1}\right)$ \\
\hline 8.0 & $0.1 \mathrm{M}$ borate & $1.4 \times 10^{-6}$ \\
10.0 & $0.1 \mathrm{M}$ borate & $2.4 \times 10^{-4}$ \\
10.0 & $0.1 \mathrm{M}$ carbonate & $2.0 \times 10^{-6}$ \\
12.0 & $10 \mathrm{mM} \mathrm{NaOH} /$ & $8.0 \times 10^{-3}$ \\
12.0 & $0.1 \mathrm{M} \mathrm{Na} \mathrm{SO}_{4}$ & $3.0 \times 10^{-8}$ \\
14 & $1.0 \mathrm{M} \mathrm{NaOH}$ & $4.9 \times 10^{-9}$ \\
\hline
\end{tabular}
$\mathrm{H}_{3} \mathrm{PO}_{4}$.

$a_{\mathrm{pH}}$ adjusted by addition of $\mathrm{NaOH}, \mathrm{H}_{2} \mathrm{SO}_{4}$, or 


$$
\begin{aligned}
\mathrm{Cu}^{I I} \mathrm{O}+\mathrm{H}_{2} \mathrm{O}+4 \mathrm{CN}^{-} & \longrightarrow \mathrm{Cu}^{I I}(\mathrm{CN})_{4}^{2-}+2 \mathrm{OH}^{-} \\
2 \mathrm{Cu}^{I I}(\mathrm{CN})_{4}^{2-}+2 \mathrm{CN}^{-} & \longrightarrow 2 \mathrm{Cu}^{I}(\mathrm{CN})_{4}^{3-}+\mathrm{C}_{2} \mathrm{~N}_{4}
\end{aligned}
$$

Application of a constant large positive potential in the region of the current plateau decreased the rate of $\mathrm{film}$ dissolution, undoubtedly because the anodic reaction of $\mathrm{CN}^{-}$ resulted in a surface concentration $\left(\mathrm{C}_{\mathrm{CN}^{-}}^{-}\right)$substantially lower than $\mathrm{C}_{\mathrm{CN}^{-}}^{\mathrm{b}}$. Furthermore, visual inspection of Cuofilm electrodes after ca. I hr of electrolysis in NaCN, showed less deterioration when the potential was controlled at $0.6 \mathrm{~V}$ rather than at $0.35 \mathrm{~V}$. Slow film dissolution can occur even for $E \gg E_{1 / 2}$ because $C_{C N}^{S}-$ always has a finite value, even in the potential region of the current plateau. These results indicate that cuo-film electrodes as prepared in this research would be unsuitable for treatment of industrial wastes containing large amounts of $\mathrm{CN}^{-}$. The cuofilm electrodes withstood gentle rinsing by a stream of water. However, the slightest mechanical abrasion removed portions of the films from the Pt/SS substrates. Furthermore, occasional peeling of the cuo-films occurred during air-drying unless the films had been pretreated after deposition by application of repetitive cyclic scans. 


\section{CONCLUSIONS}

Several amines have been reported to undergo oxidation at cuo electrodes and the anodic reaction has been attributed to the oxidizing power of a $\mathrm{Cu}$ II species in the oxide film, perhaps $\mathrm{CuO}(\mathrm{OH})$, generated at increasingly positive potential values $(23,27)$. The formal reduction potential for the $\mathrm{CuO}(\mathrm{OH})$-Cuo couple was estimated as $0.65 \mathrm{~V}$ vs. the $\mathrm{Hg} / \mathrm{HgO}$ (i.e., $0.51 \mathrm{~V}$ vs. SCE) at pH 14 (23). Some $\mathrm{CuO}(\mathrm{OH})$ is expected to be formed at $\mathrm{E}<0.5 \mathrm{~V}$ and the observation that $\mathrm{E}_{1 / 2}=\underline{\mathrm{ca}} \cdot 0.3 \mathrm{~V}$ for $\mathrm{CN}^{-}$oxidation to $\mathrm{CNO}^{-}$ in $1 \mathrm{M} \mathrm{NaOH}$ is consistent with a mechanism in which the CuIII-CuII redox couple functions an electron-transfer mediator.

It does not seem reasonable to ascribe the electrocatalytic activity of cuo-film electrodes merely to chemical oxidation at the electrode-solution interface. The applied potential for $E>E_{1 / 2}$ is more than sufficient to bring about charge transfer. Hence, the faradaic transformation of redox state for surface sites located within the applied electric field hardy seems sufficient for promoting the anodic process unless there is a dramatic change in the associated chemical steps available for the reaction mechanism.

It is proposed that anodic conversion of $\mathrm{cu}^{I I}$ to $\mathrm{cu}$ III starting at $E>\underline{c a} .0 .2 \mathrm{~V}$ provides a favorable mechanism for 
the oxygen-transfer step which must occur concomitantly with electron transfer in the oxidation of $\mathrm{CN}^{-}$to $\mathrm{CNO}^{-}$. We propose that the appropriate activated state of oxygen at $\mathrm{Cu} I I I$ sites is the adsorbed hydroxyl radical $(\cdot \mathrm{OH})$ ads generated by anodic discharge of $\mathrm{H}_{2} \mathrm{O}$. Such an o-transfer mediated mechanism is described by Equations 16-13, where $\underline{S}$ represents an active surface sites.

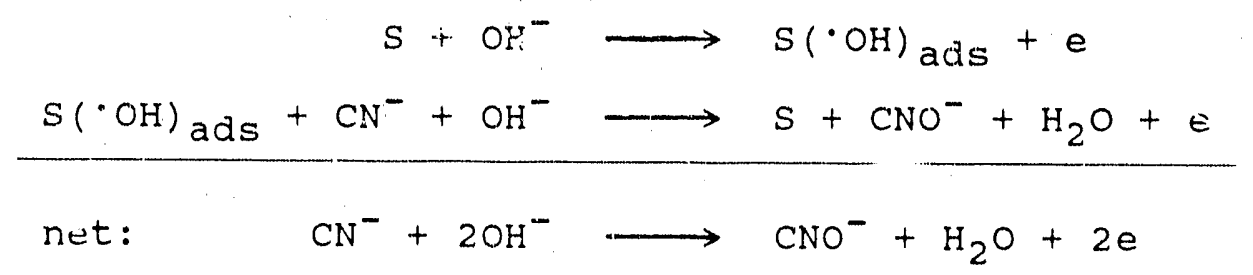

Adsorbed $\cdot \mathrm{OH}$ has been proposed as an intermediate product in the anodic evolution of $\mathrm{O}_{2}(30)$. Based on the standard reduction potentials firr the half reactions in Equations 19 and 20 , the oxidation of $\mathrm{CN}^{-}$is predicted to be much more favorable than anodic evolution of $\mathrm{O}_{2}$.

$$
\begin{aligned}
\mathrm{CNO}^{-}+\mathrm{H}_{2} \mathrm{O}+2 \mathrm{e} \rightarrow \mathrm{CN}^{-}+2 \mathrm{OH}^{-} ; \mathrm{E}^{\circ}=-0.72 \mathrm{~V}(\mathrm{SCE}) \\
\mathrm{O}_{2}+2 \mathrm{H}_{2} \mathrm{O}+4 \mathrm{e} \longrightarrow 4 \mathrm{OH}^{-} ; \quad \mathrm{E}^{\circ}=+0.15 \mathrm{~V} \text { (SCE) }
\end{aligned}
$$

Nevertheless, $E_{1 / 2}$ for the anodic conversion of $\mathrm{CN}^{-}$to $\mathrm{CNO}^{-}$ was ca. $0.3 \mathrm{~V}$ VS. SCE ill $1 \mathrm{M} \mathrm{NaOH.} \mathrm{This} \mathrm{large} \mathrm{overpotential}$ for $\mathrm{CN}^{-}$oxidation is consistent with the concept that ${ }^{\circ} \mathrm{OH}$ ads generated at CuII sites as an intermediate product in $\mathrm{O}_{2}$ evolution can participate in the oxidation of $\mathrm{CN}^{-}$. As the applied potential is increased to values approaching the 
region for onset of rapid $\mathrm{O}_{2}$ evolution, the surface activity of $(\cdot \mathrm{OH})$ ads is increased substantially by adsorption at cuIII sites and, hence, the mechanism described by Equations 16-18 is enabled.

Electrocatalytic electrodes described previously for anodic o-transfer reactions have made use of mixed oxide films deposited from solutior, of $\mathrm{Pb}^{2+}$ and various metal cations $(20)$. Most notable is the case of $\mathrm{Bi}^{\mathrm{V}}$-doped $\mathrm{PbO}_{2}-$ film electrodes. However, $\mathrm{CN}^{-}$was observed not to be reactive at $\mathrm{Bi}-\mathrm{PbO}_{2}$ electrodes, and the mere creation of catalytic sites for adsorption of $\cdot O H$ is apparently not sufficient to catalyze oxidation of $\mathrm{CN}^{-}$. It is proposed that an oxygen tunneling mechanism comparable to electron tunneling does not occur at the electrode-solution interface. Therefore, successful electrocatalysis of all anodic o-transfer reactions also requires that surface sites exist for adsorption of the reactant with the consequence that reaction sites on reactants are fully desolvated. Hence, metallic candidates for the doping of $\mathrm{PbO}_{2}$ electrodes to achieve oxidation of $\mathrm{CN}^{-}$have been chosen on the basis of the existence of a strong coordination bond between $\mathrm{CN}^{-}$and the metal ion in homogeneous aqueous solutions. The logic is that trends observed in solution-phase d-orbital (coordination) chemistry are reflected by trends in chemisorption of ligands on metal and metal oxide electrodes which are a consequence of interaction with surface d-orbitals. Based 
on the knowledge of the high stability of $\mathrm{Fe}(\mathrm{CN}) 6^{3-}$ and $\mathrm{Fe}(\mathrm{CN}) 6^{4-}$, Feng and Johnson (31) tested the activity of Fe III-doped $\mathrm{PbO}_{2}$ electrodes and discovered that oxidation of $\mathrm{CN}^{-}$proceeded at a mass transport-controlled rate in alkaline media.

Following similar logic, it is expected that $\mathrm{CN}^{-}$can be adsorbed at oxygen-deficient defect sites in the surface lattice with adsorption of $\cdot \mathrm{OH}$ at other sites. Hence, the elec rocatalytic oxidation of $\mathrm{CN}^{-}$might proceed by a synergistic cooperation of surface sites in dissimilar states. It is possible that cuIII sites might function both for adsorption of $\mathrm{OH}$ and the reactant. We note that the formation constant for Pt $(\mathrm{CN}) 4^{2-}\left(10^{+40} \mathrm{M}^{-4}\right)$ is much larger than that for $\mathrm{Cu}(\mathrm{CN})_{4}^{2-}\left(10^{+26.7} \mathrm{M}^{-4}\right)$ (32). Nevertheless, $\mathrm{CN}^{-}$is not electroactive at Pt electrodes under conditions of constant appiied potential (33). This can be explained from the observation that oxidative desorption of the strongly adsorbed $\mathrm{CN}^{-}$on Pt occurs at sufficiently large positive potentials so that the electrode surface is virtually instantaneously converted to the corresponding inert oxide (34).

The interpretation of the $\mathrm{pH}$ dependency of $\mathrm{k}_{\mathrm{o}}$ values shown in Table $I$ is even more speculative. If the preferred oxidation mechanism occurs with pre-adsorption of $\mathrm{CN}^{-}, \mathrm{pH} \leq$ ca. $\mathrm{pK}_{\mathrm{a}, \mathrm{HCN}}$ (í.e., ca. . 9) would be expected to interfere because of the protonation of $\mathrm{CN}^{-}$. Furthermore, extremely 
high values of $\mathrm{pH}$ would be expected to interfere because of the competitive adsorption by $\mathrm{OH}^{-}$.

The cuo-film electrodes were stable when used in

alkaline solutions of $\mathrm{CN}^{-}$at concentrations of $\mathrm{ca} .1 \mathrm{mM}$ and lower. Whereas application of the electrodes for industrial treatment of cyanide wastes appears not to be feasible, the electrodes can have significance as analytical transducers for detection of $\mathrm{CN}^{-}$at low concentrations. Preliminary results have shown a 6-fold improvement in the response at a Au electrode following the deposition of a thin cuo film. 
SUMMARY

In Part I, it was learned that the reduction of $\mathrm{IO}_{3}^{-}$at Pt electrodes was catalyzed by the reduction of surface oxide (Pto). The turnover number per pto site was

determined to be greater than one, virtually eliminating the possibility of an adsorbed reactant or reduction product.

The involvement of ${ }^{\prime} \mathrm{OH}_{\mathrm{ads}}$, which is an intermediate product in the reduction of $\mathrm{PtO}$, was suggested.

On oxide-free Pt electrodes, the reduction of $\mathrm{IO}_{3}^{-}$was found to be strongly influenced by surface treatment. Previous investigations have relied on a chemical reduction step to explain the electrochemical reduction of $\mathrm{IO}_{3}^{-}$on oxide-free Pt electrodes. Data presented here are consistent with the conclusion that $\mathrm{IO}_{3}^{-}$reduction occurs by a mechanism which involves adsorption of $\mathrm{IO}_{3}^{-}$to the electrode surface. The adsorption of zero-valent iodine $\left(I^{\circ}\right)$ on oxide-free $P t$ is well-known. Thus, the adsorption sites for $\mathrm{IO}_{3}^{-}$were proposed to be $\mathrm{Pt}\left(\mathrm{I}_{\mathrm{ads}}\right)$.

In Part II, data were presented that indicates the electrocatalytic oxidation of $\mathrm{CN}^{-}$requires the existence of adsorption sites for $\mathrm{CN}^{-}$. Anodic currents attributable to the oxidation of $\mathrm{CN}^{-}$were not observed at $\mathrm{PbO}_{2}$ or $\mathrm{Bi}$-doped $\mathrm{PbO}_{2}$ electrodes. However, an anodic wave for the oxidation of $\mathrm{CN}^{-}$was obtained at $\mathrm{Cu}$-doped $\mathrm{PbO}_{2}$ and $\mathrm{CuO}$ film electrodes. The half-wave potential and the heterogeneous 
rate constant $\left(k_{0}\right)$ were determined to be a function of $\mathrm{pH}$. In addition, $k_{0}$ was strongly influenced by addition of anions.

While electron tunneling has been used to explain some electrocatalytic phenomena, the possibility of tunneling oxygen atoms cannot be considered as likely to occur. The adsorption of $\mathrm{CN}^{-}$at $\mathrm{Cu}$ sites was proposed as the necessary prerequisite for this anodic oxygen-transfer. Likewise, adsorption of $\mathrm{IO}_{3}^{-}$was concluded necessary for direct reduction of that species on Pt electrodes.

Adsorption of reactants to the electrode surface was concluded to be an important requirement for electrocatalysis in both part I and Part II of this dissertation. Whereas it was not the original intention of this research to draw such a parallel, it was a serendipitous discovery that has far-reaching implications for development of new electroratalytic materials. 


\section{SUGGESTIONS FOR FUTURE RESEARCH}

The study of oxygen-transfer reactions should not be limited to $\mathrm{PbO}_{2}$ electrodes. The numerous oxygen evolution catalysts currently being investigated should be studied for their suitability as oxygen-transfer electrocatalysts.

Use of fabrication techniques other than

electrodeposition will permit investigation of a wider variety of electrodes. For example, it can be postulated that improved caialytic activity will be observed if adsorption sites for $\mathrm{CN}^{-}$(í.e., $\mathrm{Cu}$ ) and $\cdot \mathrm{OH}_{\text {ads }}$ (i.e., $\mathrm{Bi}$ ) were introduced into the same $\mathrm{PbO}_{2}$ electrode. This is not possible using electrodeposition since incorporation of $\mathrm{Cu}$ and $\mathrm{Bi}$ into $\mathrm{PbO}_{2}$ require widely different $\mathrm{pH}$ conditions.

The possible application of electrocatalytic electrodes as chemical sensors should be investigated. Electrolytic treatment of hazardous chemical waste was alluded to in this research. The practicality of such an application needs to be tested further by constructing a bench-scale reactor. 
1. Hine, F.; Yasuda, M.; Iida, T.; Ogata, Y. Electrochim. Acta 1986, 31, 1389 .

2. Carr, J. P.; Hampson, N. A. Chem. Rev. 1972, 72, 679.

3. Sharpe, T. F. in Encyclopedia of Electrochemistry of the Elements; Bard, A. J., Ed.; Marcel Dekker: New York, 1973; Vol. 1, Chapter 5.

4. Ruetschi, P.; Angstadt, R. T.; Cahan, B. D. I. Electrochem. Soc. 1959, 106, 547.

5. Mindt, W. I. Electrochem. Soc. 1969, 116, 1076.

6. Baker, R. A. I. Electrochem. Soc. 1962, 109, 337.

7. Ruetschi., P.; Cahan, B. D. J. Electrochem. Soc. 1957, 104, 406 .

8. Ruetscni, P.; Cahan, B. D. I. Electrochem. Soc. 1958, 105,369 .

9. Thomas, U. B. Trans. Electrochem. Soc. 1948, 94, 42.

10. Frey, D. A.; Weaver, H. E. I. Electrochem. Soc. 1960, 107,930 .

1.1. Collat, J. W.; Lingane, J. J. I. Am. Chem. Soc. 1954, 76, 4214 . 12. Duisman, J. A.; Giaque, W. F. I. Phys. Chem. 1968, 72,
562.

13. Vinal, G. W. Storage Batteries; John Wiley: New York, 1965.

14. Organic Electrochemistry; Baizer, M. M., Ed.; Marcel Dekker: New York, 1973.

15. Weinberg, N. L.; Weinberg, H. P. Chem. Rev. 1968, 68, 449 .

16. Willard, H. ; Ralston, R. R. Trans. Electrochem. Soc. $1932,62,239$.

17. Ramaswamy, R.; Venkatachalapathy, M. S.; Udupa, H. V. K. I. Electrochem. Soc. 1963, 110, 294 . 
18. Sinfelt, J. H. Catal. Rev. $1974,9,147$.

19. Johnson, D. C.; Polta, J. A.; Polta, T. Z.; Neuburger, G. G.; Johns ,n, J.; Tang, A. P-C. ; Yeo, I-H.; Baur, J.

I. Chem. Soc. Faraday Trans. 1 1986, $82,1081$.

20. Yeo, I-H.; Johnson, D. C. I. Electrochem. SoC. 1987 , 134,1973 .

21. Katagiri, A.; Yoshimura, S.; Deguchi Y.; Yoshizawa, S. Proceedings of the Symposium on Electrocatalysis;

O'Grady, W. E.; Ross, P. N.; Will, F. G., Eds.;

The Electrochemical Society: Pennington, NJ, 1982;

pp. $336-346$.

22. Rocklin, R. D.; Johnson, E. L. Anal. Chem. 1933, 55, 4.

23. Flelschmann, M. ; Korinek, K.; Pletcher, D. I. Chem. Soc, , Perkin Trans. II, 1972, 10, 1396.

24. Stulik, K.; Pacakova, V.; Le, K.; Hennissen, B. Talanta $1988, \underline{35}, 455$.

25. Kok, W. Th.; Hanekamp, H. B.; Bos, P.; Frei, R. W. Anal. Chim. Acta 1982, 142, 31.

26. Prabhu, S. V.; Baldwin, R. P. Anal. Chem. 1989, 61, 852 .

27. Meyerstein, D.; Hawkridge, F. M. ; Kuwana, T. J.

Electroanal. Chem. 1972, 40, 377 .

28. Bard, A. J.; Faulkner, L. R. Electrochemical Methods;

John Wiley \& Sons: New York, 1980; pp. 286-292.

29. Sawyer, D. T.; Day, R.J. J. Electroanal. Chem. 1963, 5 , 195.

30. Hoare, J. P. The Electrochemistry of oxygen;

Interscience Publishers: New York, 1968; pp. 86-112.

31. Feng, J.; Johnson, D. C. I. Electrochem. Soc. 1987, 137, 507 .

32. Sharpe, A. G. The Chemistry of Cyano Complexes of the Transition Metals; Academic Press: New York, 1976.

33. Austin, D. S.; Polta, J. A.; Polta, T. Z.; Tang, A. P-C.; Cabelka, T. D. ; Johnson, D. C. I. Electroanal. Chem. $1984, \underline{168}, 227$.

34. Polta, T. A.; Johnson, D. C. Anal. Chem. 1985, 57, 1373. 


\section{ACKNOWLEDGMENTS}

I would like to express my appreciation to professor Dennis Johnson for his guidance and enthusiastic support during my years of graduate study at Iowa state University. I would like to thank Dr. William Lacourse as well as other members of the electrochemistry group for their friendship and support. I especially wish to thank my mother and brother for their encouragement and interest in my education.

I gratefully acknowledge the assistance of Jerry Amenson and scott Schlorholtz in obtaining scanning electron micrographs and $x$-ray diffraction data. I am indebted to James Gordon for his assistance in obtaining the ratio of mass:charge for deposition of cuo films.

This work was performed at Ames Laboratory under contract no. W-7405-eng-82 with the U. S. Department of Energy. The United states government has assigned the DOE Report number IS-T 1450 to this thesis. 


\section{APPENDIX}

This append:.x contains the printout of the computer program used for the collection of voltammetric data. It is written in QuickBASIC, version 3.0. Documentation has been inserted for the reader's clarffication. A glossary of variable names used in the program has been included at the end of the prirtout.

\section{Description}

Subroutines supplied by Data Trarslation, Inc. perfor:n digital-to-analog (D/A) conversions using analog data values (ADV) as input axguments. The ADV and the desired output voltage are related by the expression given below.

$$
A D V=(\text { voltage }-10 \mathrm{w}) \times \frac{N C}{(\text { high }-10 \mathrm{w})}
$$

"High" and "low" refer to the high and low voltage values of the analog range. For this system, these values are $+70 \mathrm{~V}$ and $-10 \mathrm{~V}$, respectively. The number of codes (NC) is determined by raising the number 2 to the power " $n$ " where $n$ is the resolution of the converter. A 12 -bit D/A converter was supplied with this system, therefore $\mathrm{NC}=2^{12}=4096$.

The voltage analog of the electrode current is measured at the potentiostat using an analog-to-digital (A/D) converter. Analog data values are returned by the $A / D$ subroutine. These ADVs are converted to voltages by a separate subroutine supplied by Data Translation, Inc. 
This program calculates the ADVs corresponding to each applited potential comprising the voltammogram and stores them in an array. A serles of electrode current measurements is at a preselected frequency following a time delay which is also preselected by the user. Analog data values returned by the $A / D$ subroutine are also stored in the array before being converted to current values for use in preparing data plots.

DIM rawo $(11,1500)$, buf\% $(960)$ common shared $1, k \$, y q$

zero $\%=2048$ : schan $\%=0$

dac $0 \%=0:$ echan $\%=0$

$\operatorname{dac} 1 \%=1 \quad: \operatorname{ts} \%=0$

nov $\%=11 . \quad:$ gain $\%=2$

freq $!=100:$ dry $\$=" C: \backslash D A T A \backslash "$

vimsg $\$(0)=$ "Import file of experimental paramerers from disk."

vlmsg\$(1)="Save experimental parameters to disk file."

vimsg $(3)=$ "Modify present experimental parameters."

v2msg $(0)=$ "Data from prescans are not saved."

v2msg $\$(1)=$ "Enter rotation speed $(0-1.0000 \mathrm{rpm}) . "$

v2msg $(2)=$ "Enter potential step (Multiple of $5 \mathrm{mV}$ )."

v2msg\$ (3)="Length of delay (ms) following potential step."

$v 2 \mathrm{msg} \$(4)=$ "Anodic potential limit in $\mathrm{mV}$."

v2msg $(5)=$ "Cathodic potential limit in $\mathrm{mV} . "$

v2msg $\$(6)="$ Choose starting potential (mV) in low current region."

slmsg $(0)=$ "Change file directory."

slmsg\$(1)="Change frequency with which current is sampled." slmsg $(2)="(1,2,4,8)$ Maximum current $(\mathrm{mA})=10 / \mathrm{GAIN} "$

slmsg $(3)=" 0=$ soft trig/int clock $1=$ soft/ext $2=$ ext/int $3=e x t /$ ext"

s1msg $(4)=110-8$ Requires hardware change."

'Setup screen for menu...

SCREEN $9,1,1$

COLOK 7,1

PRINT SPC (26); "ELECTROCHEMISTRY SOFTWARE"

PRINT SPC (26); "Support for the Rotated Disc" 


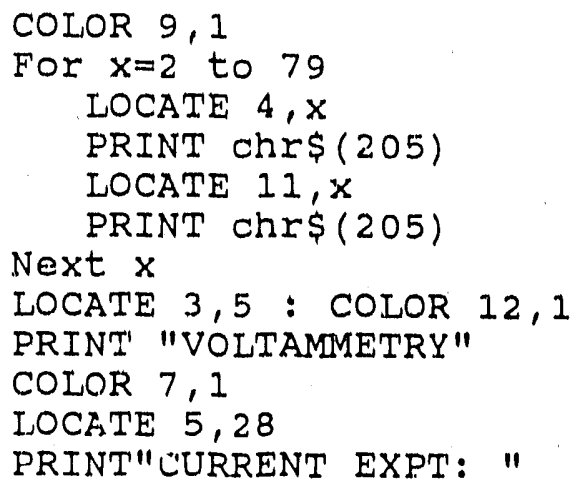

'Assign more variables...

DAT'A Import experiment, Save experiment, Run experiment

DATA Change parameters, Configure system, Prescans, RPM

DATA Step, Delay, Anodic limit, Cathodic limit,

DAIA Start potential, Directory, Clock frequency

DATA Gain, Timing source, ADC channel

DATA $6,10,6,50,7,10,7,50,8,10,8,50,9,10,9,50,10,10,10,50$

For $x=0$ to 4

READ VMI $\$(x)$

Next $x$

For $x=0$ to 6

Next $x$

R.EAD vm2\$(x)

For $x=0$ to 4

READ $\sin 1 \$(x)$

Next $x$

For $x=0$ to 9

Next $x$

READ rOW $(x), \operatorname{col}(x)$

CALL set.clock. frequency (freq!)

CALL dac.value (daco\%, zero\%)

CALL dac.value (daclo, zeroo)

CALL setup.adc(ts\%, schan\%, echan $\%$, gain $\%$ )

'Transfers control to

' Data Translation

'subroutines.

Install menu...

WHILE kuit $=0$

CALL menu(vml\$(), row(), $\operatorname{col}(), 4, \operatorname{vimsg} \$())$

If $\operatorname{asc}(k \$)=27$ then

LOCATE 13,5: Print spc(65)

LOCATE 13,5: Input"Exit to DOS"; $x \$$

If $x \$=" y$ " then kuit $=1$

LOCATE 13,5

Print spc(15) 


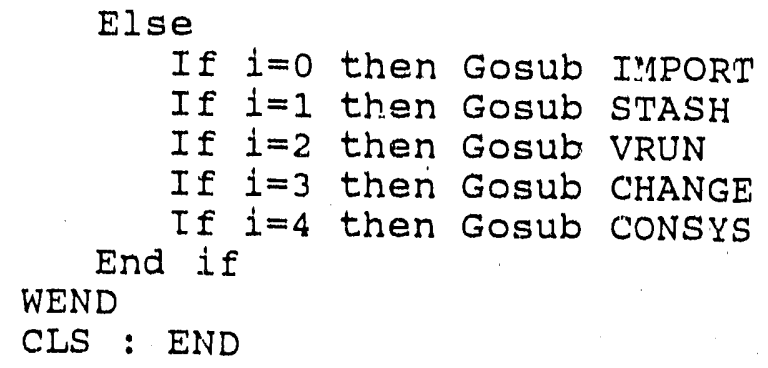

\section{'Menu subroutine...}

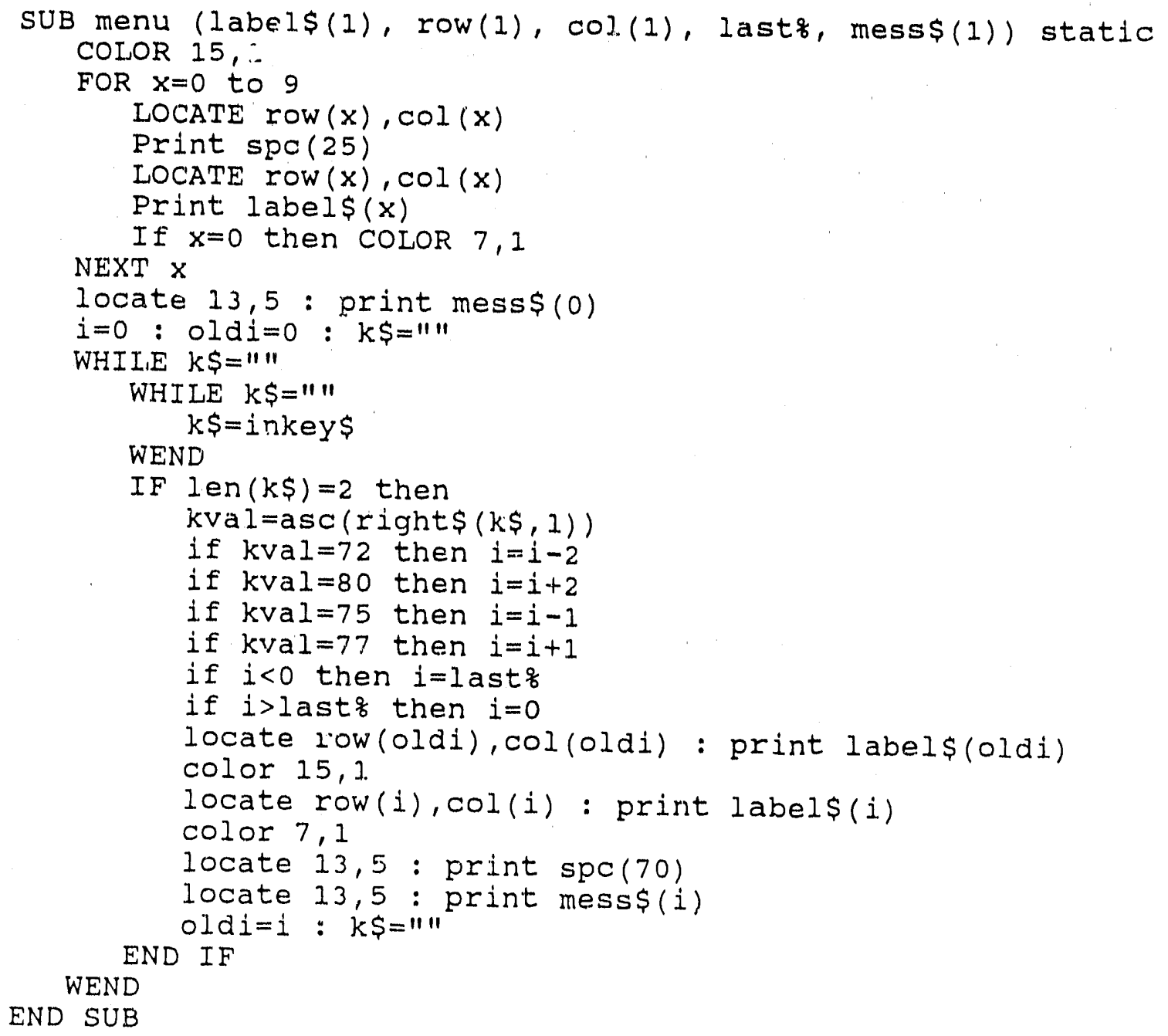


IMPORT:

locate 15,5

input"Name of file to import: ", names open dry $\$+$ name $\$+$. vex" for input as \#2 input\#2, pscano, rpmo input\#2, t3\%, alims, c.limo input\#2, starts, vstep\% close \#2

locate 5,42 : print names RETURN
'Previously

'saved exper'imental param-

'eters are

' loaded...

STASH:

locate 15,5

input"Name of file to save: ", names

open dry\$+name\$+"vex" for output as \#2

for $x=0$ to 4

print\#2, pscan\%; spro\%

print\#2, t3\%; alim\%; clim\%

next $x$

print\#2, start\%; vstep\%

close \#2

locate 5,42 : print name $\$$

RETURN

locate 15,5 : print $\operatorname{spc}(32)$

VRUN :

DIM proc $(1,1500)$

LOCATE 13,5

INPUT"Current converter setting on RDE 4 (mA/V): ";etoi

LOCATE 13,5: PRINT spe(55)

nop $\%=2.048 *($ al im $\%$-clim $\%) / v s t e p \%$

If nop $\% 1500$ then

PRINT "ARRAY OVERFLOW!"

RETURN

End if

raw $(0,0)=.2048 *($ start $\%+10000)$

low\% $=.2048 *(\mathrm{clim} \%+10000)$

hi $\%=.2048 *($ alim $\%+10000)$

incr\% $=.2048 *$ vstep\%

' Calculate number

'of points in

'voltammogram...

- parameters

' are saved to

'a data file

FOR $z=1$ to rop\%

' Calculate analog

'data values for

'start potential,

'potential limits,

'and potential step

NEXT $z$

$\operatorname{raw} \%(0, z)=\operatorname{raw} \%(0, z-1)+$ incro

If raw $(0, z)+i n c r \%<10 w \%$ then incro=-incr\%

If raw $(0, z)+i n c r \%>h i \%$ then incro $=-$ incr $\%$

'Fill array with

'analog data viues 


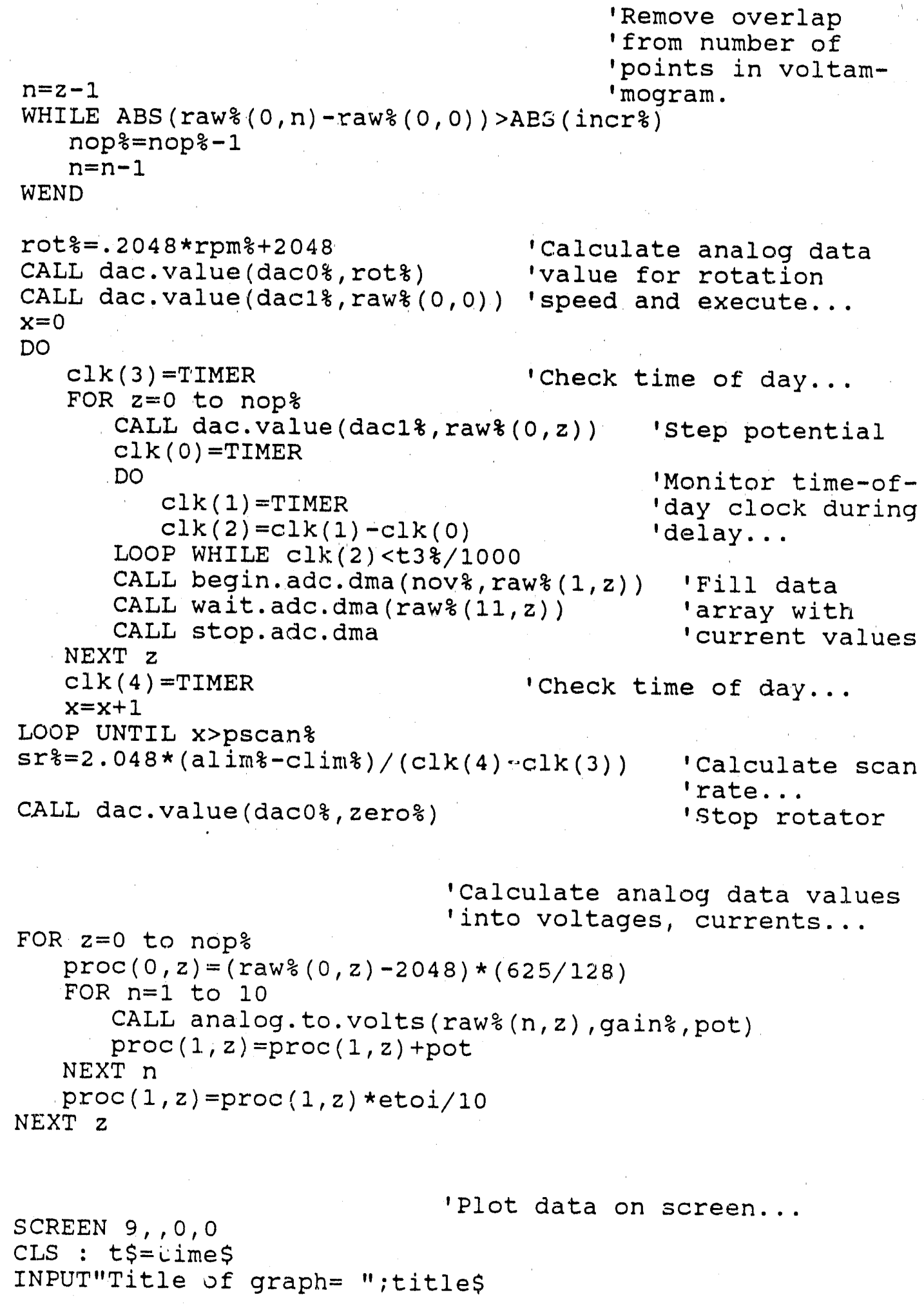


DO

INPUT"Name of data file= "; filnams

IF len(filnam\$) $>7$ then PRINT " 7 characters only!" LOOP UNTIL len (filnam\$) $<8$

CLS : d\$=date $\$$

COLOR 7,0

PRINT"Current expt: "inames; tab(30); t ; tab (45); d\$

PRINT"RPM: ";rpmo; tab (30); "Scan rate:"; srq;"mV/s"

PRINT"Title: "; title\$

PRINT spc(62);"+/- Zoom"

PRINT spc (62); "<enter> Save"

PRINT spc $(62) ; "<e s c>$ Exit"

PRINT : PRINT

ic $=-1$ : ec=-climo

$i a=1: e a=-a l i m$ \%

COLOR 7,0

VIEW $(5,45)-(470,330),, 7$

DO

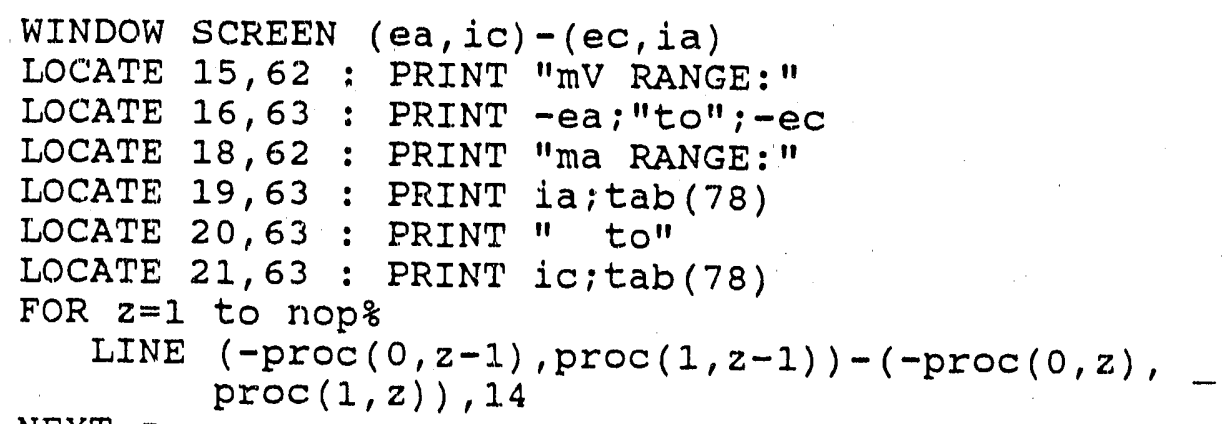

'Save data on disk...

OPEN dry\$+filnam\$+".dat" for output as \#1 


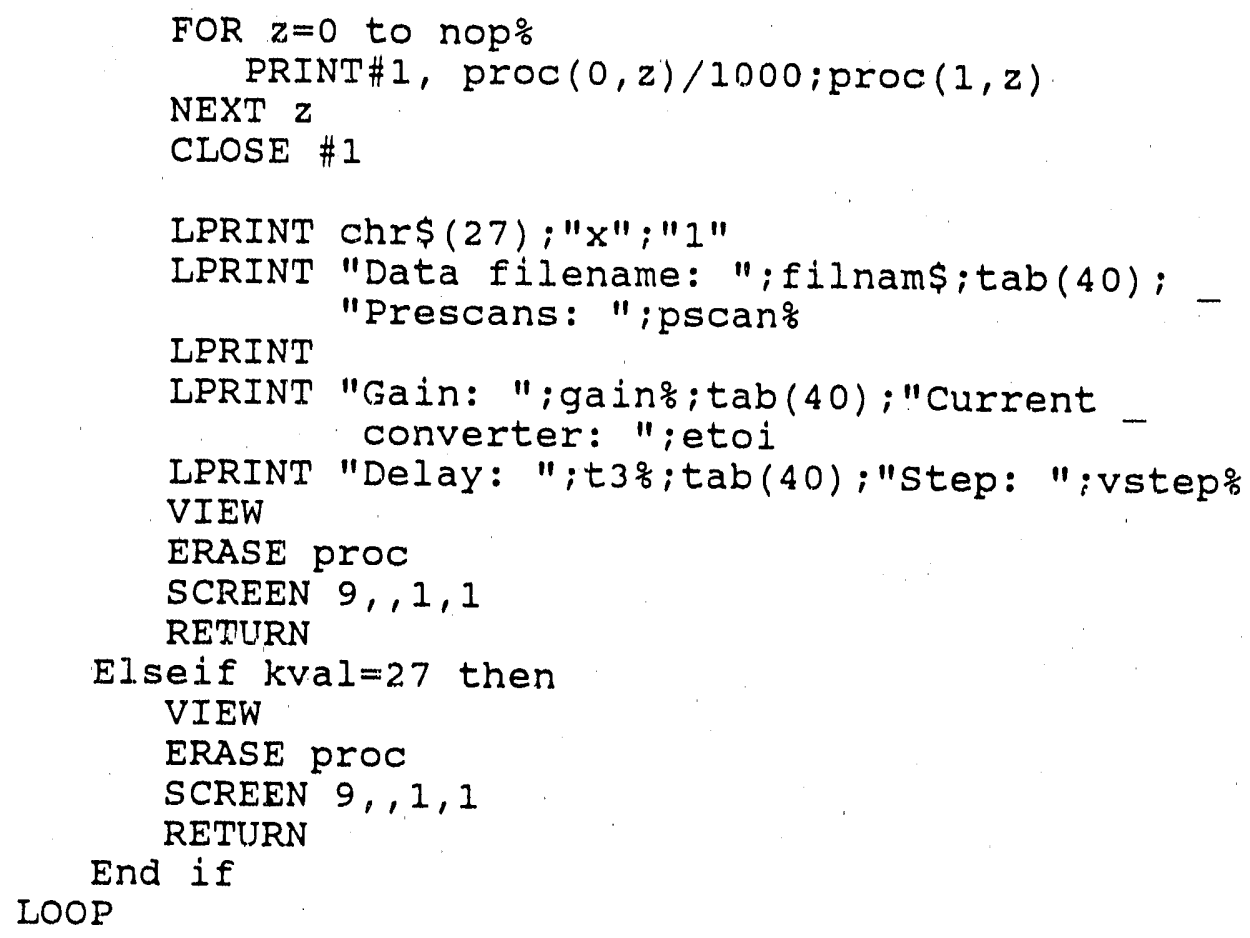




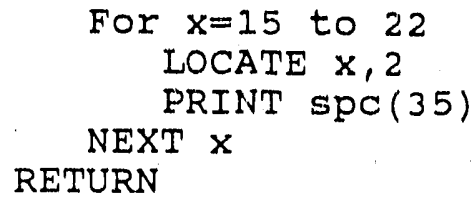

'subroutine for changing

'parameters...

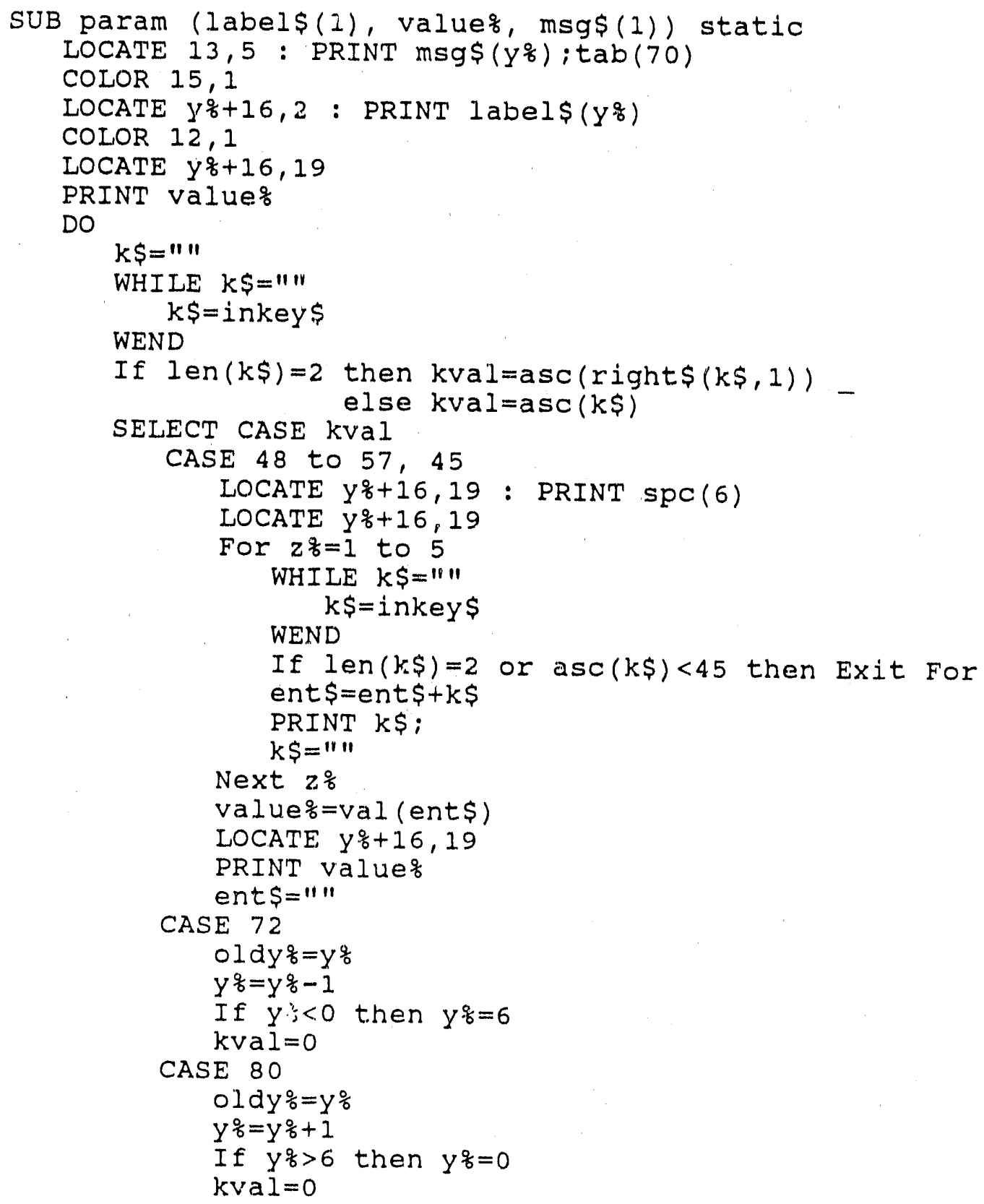




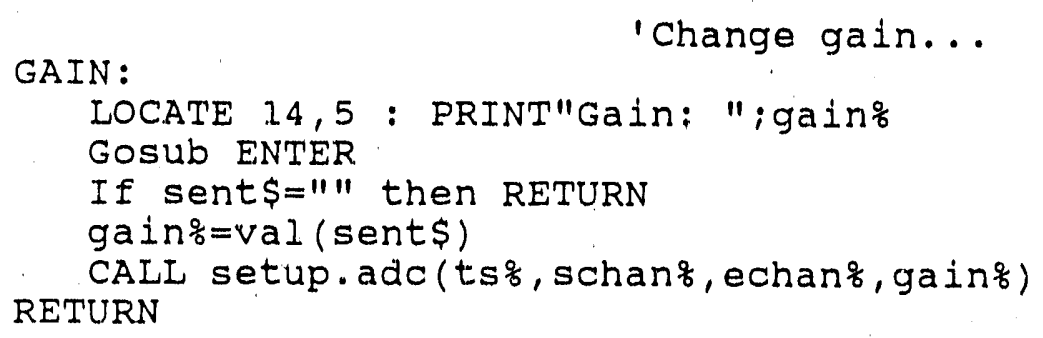

CALL setup.adc(tsq, schang, echanf, gainz)

ADCHAN :

'Change analog to digital

'channel...

LOCATE 14,5 : PRINT"Starting channel: ";schan\%

GOSUb ENTER

If sent $\$=1 "$ "then

LOCATE 14,5 : PRINT"Ending channel: ";echano GOSUb ENTER

If sent $\$="$ " then RETURN

echanf=val (sent $\$$ )

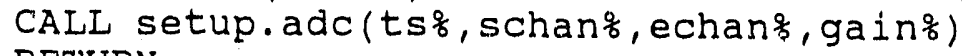

Else RETURN

End if

schan $\%=\operatorname{val}(\operatorname{sent} \$)$

LOCATE 1.4,5: PRINT"Ending channel: ";echano

GOSUb ENTER

If sent $\$<>"$ then echan\%=val (sent $\$$ )

RETURN

CALL setup. adc ( $t 5 \%$, schan\%, echan\%, gain\%)

ENTER:

'Subroutine for inputing data...

ent $\$=" \prime$ : $\operatorname{sent} \$=" \|$

DO

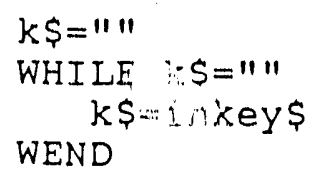




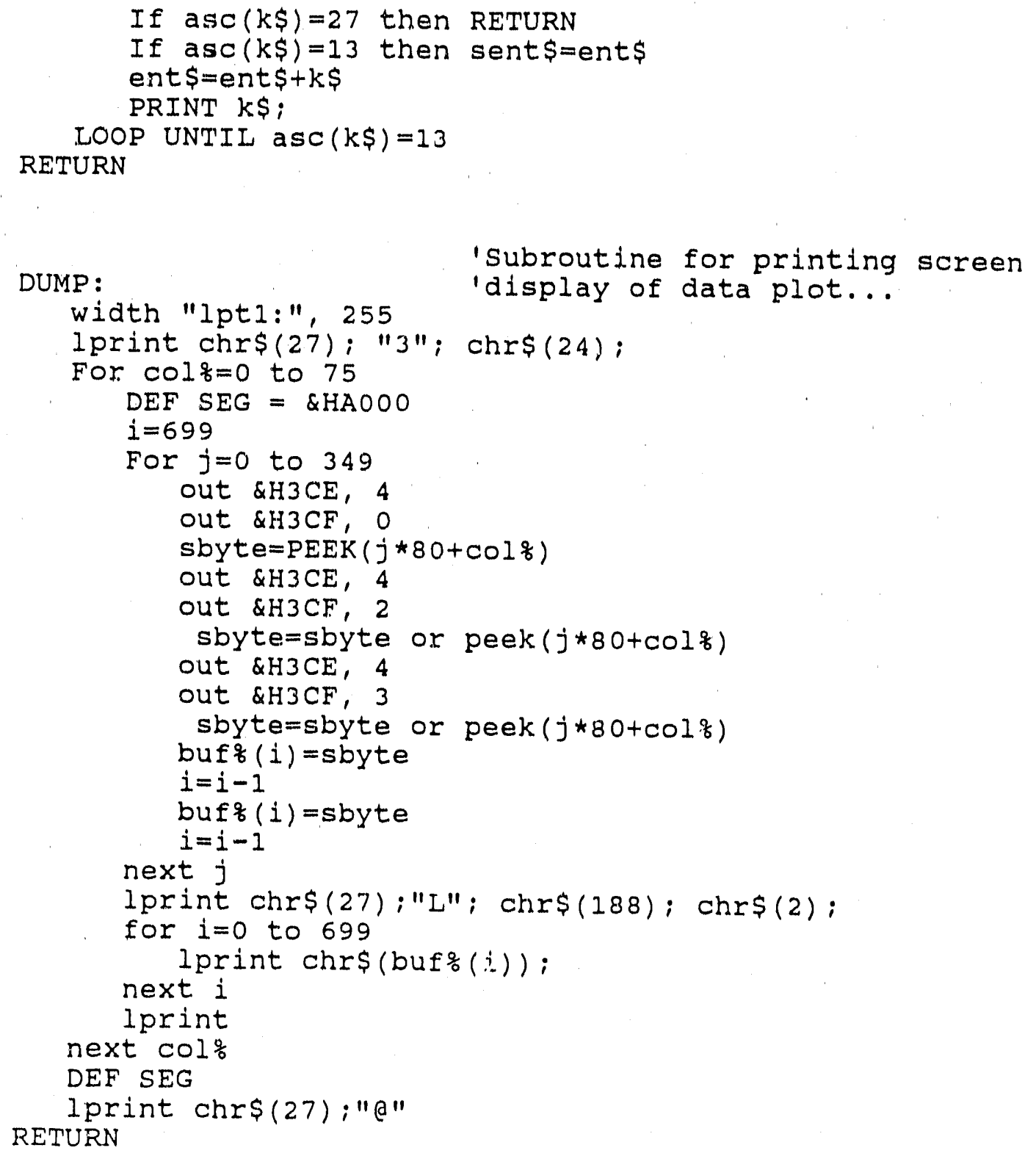

\section{Glossary}

alim\% - anodic scan limit (mV). bufo() - screen display inage bits for printer output. climor - cathodic scan limit (mV). col() - x-coordinate for menu selections. d\$ - today's date. daco\% - D/A channel number 0 . dacl\% - D/A channel number 1. drys - directory name for storage retrieval of data files. 
ea - anodic potential. Iimit for displayed plot of data. ec - cathodic potential limit for displayed plot of data. echang - ending channel number for $A / D$ converter. ent\$ - sum of keyboard input.

etol - current converter setting on potentiostat (mA/V). filnam - name of file to hold data. freq! - Erequency (Hz) at which $A / D$ conversions are made. gaing - gain of A/D converter. hif - ADV corresponding to anodic limit. $i$ - marker for menu subprogram. ia - anodic current limit for displayed plot of data. ic - cathodic current limit for displayed plot of data. incr: - ADV corresponding to potential step. k\$ - keyboard input characters. kval - ASCII cole of keyboard input. label\$() - used in menu subprogram for menu selections. low - ADV corresponding to cathodic limit. mess\$() - used in menu subprogram for selection messages. msg\%() - selection messages in parameter subprogram. names - name of file holding list of experimental parameters. nop\% - number. 'sf points in voltammogram.

nov: - number of values of current measured per potential step.

oldi - markes: for menu subprogram.

oldyo - marker for parameter subprogran.

pot - voltage analog of measured current.

proc() - processed ADV's from rawt().

pscan: - number of prescans executed before data is processed.

raw () - ADV's for voltammetric data.

rot: - ADV corresponding to rotation speed.

row() - y-coordinate for menu selections.

rpmo - rotation speed (rev $\mathrm{min}^{-1}$ ).

slmsg\$() - messages for "Configure system" menu selections.

sbyte - screen image bit for printer output.

schan\% - starting channel number for $A / D$ converter.

sent\$ - sum of keyboard input.

sml\$() - "Configure system" menu selections.

sr\% - scan rate $(\mathrm{mV} / \mathrm{s})$.

start: - initial potential (mV) of voltammogram.

ts - time of day.

t3\% - time delay (ms) following potential step and before current is measured.

titles - title for plot of data.

ts\% - timing source.

value - parameter values in parameter subprogram.

vlmsg\$() - messages for main menu selections.

$v 2 m s g \$()$ - messages for "Change parameters" menu selections.

$\operatorname{vml\$ ()~-~main~menu~selections.~}$

$v m 2 \$()$ - parameters menu selections. 
vstep: - size of potential step (my). $y \%$ - marker for parameter subprogram

zerof - ADV corresponding to 0.0V output. 

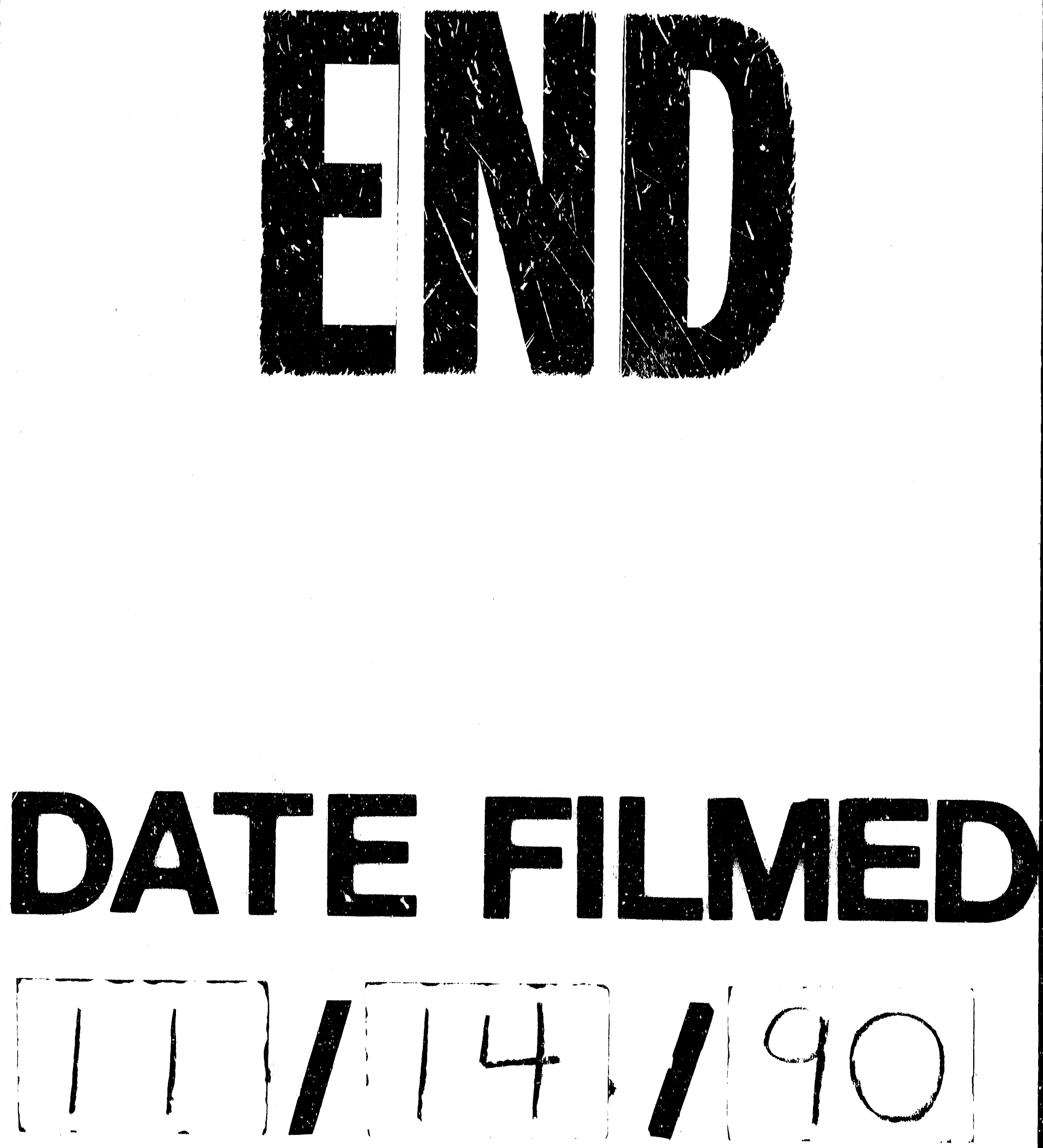
